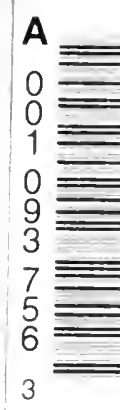

ae Particles of Relation of the

\title{
Isinai Language
}

BY

\section{OTTO SCHEERER}

of the College of Liberal Arts, University

of the Philippines.

Manila, P. I.

PUBLISHED BY THE, ,KONINKLIJK INSTITUUT VOOR DE

TAAL-, LAND- EN VOLKENKUNDE VAN NED.-INDIE".

The Hague.

MARTINUS NIJHOFF.

1918. 


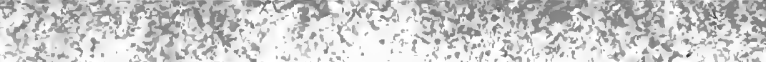

$x+3, \quad x+5 x$

an?

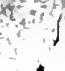

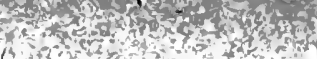

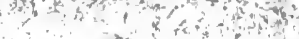

40

, 


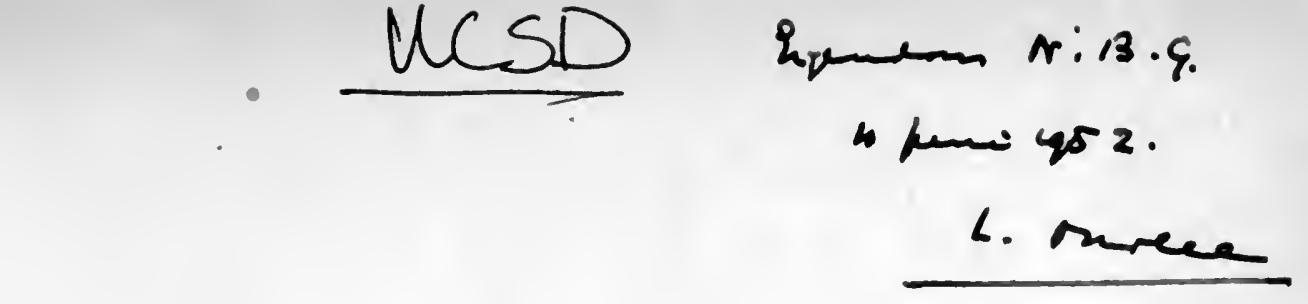

\title{
The Particles of Relation
}

\author{
of the
}

- Isinai Language

BY

\section{OT TO SCHEERER}

of the College of Liberal Arts, University

of the Philippines.

Manila, P. I.

UITGEGEVEN DOOR HET KONINKLIJK INSTITUUT YOOR DE TAAL-, LAND- FN VOLKENKUNDE VAN NED.-INDIE.

'S-GRAVENHACE.

MARTINUS NIJHOFF.

1918. 
Digitized by the Internet Archive in 2007 with funding from Microsoft Corporation 


\section{INTRODUCTION.}

Relegating, for once, to a rôle of secondary importance those constituents of speech which express the substance of thought, I offer the present paper as a-contribution to our knowledge of those elements in the Indonesian - especially Philippine - languages that indicate relation, or connection, between words assembled into a sentence. The discussion is particularly aimed at the elucidation of certain sounds, and groups of sounds, which in the grammars of Philippine languages are playing a somewhat obscure rôle under the name of "ligazones.»

The general subject here indicated cannot fail to engage our interest if we consider how largely our own languages depend, for syntactical coherence, on inflection, and if we ask ourselves how these others, which we are told are noninflectional, manage to do without that means.

As for ligazones (i. e. ligatures), we may well be at a loss, upon first hearing that term, how to associate it with anything known to us from European grammar, in whose classic nomenclature it does not occur. Should these ligazones in some way make up for the missing inflection?

What the old Spanish authors on Philippine languages, who first used that term, understood by it, is best shown in the following passages from Padre Totanes. On page 5 of his "Arte de la Lengua Tagala» ') he says (in translation):

aLigazon is some letter, or letters, added to the vocables which admit and require them - for not all vocables do this and the trouble is to know which do and which do not, in order to unite or bind them together with those that follow, thus making them as one.»

He returns to the subject on page 116, where he states:

«It has been said what ligazones are in this language and also how troublesome this matter is even for the natives them-

1) Manila, 1850 . 
selves, who have imbibed it with their mother's milk. The truth is, however, that they are indispensably necessary, not alone for speaking with elegance, but also for a proper intelligence, for, if the ligazon is omitted, where it is necessary, or added where not required, the language not only becomes insipid, harsh, coarse, and uncouth to the ear, but it remains without substance for the intelligence, and often the meaning is perverted.»

Other authors express themselves similarly or attribute to these connective letters, which are a common property of Philippine languages, a purely euphonic character.

A practical illustration of a ligazon from the Tagalog language is as follows: The island Talim in Laguna de Bay (SE. of Manila), is formed by a small mountain, which, from its outline as seen at a distance, is called by the natives Susung dalaga. Susu is "breast», and dalaga. "maiden»; the whole meaning "maiden breast». The velar nasal $(n g)$, which in compounding the two nouns is added at the end of the first, is a ligazon.

This is but one instance of the varied use of this connective in Tagalog, but just one which, if we look around for something similar in other languages more familiar to us, offers a ready comparison to a German Bindesilbe.

In German compound nouns the syntactical relation in which the two members of the composition stand to each other, is often indicated by an inflectional ending of the first. For instance, in Gottesgabe the syllable $e s$ is the genitival ending of the (strong) noun Gott, the whole meaning "God's gift» or "gift of God», a syntactical combination. On the other hand, in words like Liebeslied, love song, Regierungsrat, government councillor, a like explanation of the connective $s$, which they contain, is not possible, since no such genitives as ${ }^{*}$ Liebes and ${ }^{*}$ Regierungs exist. In these, and in other compound-nouns having a feminine as first component, or for which a genitival relation is quite out of the question (compare: Rittersmann), the presence of the connective $s$ (es) is to be explained by the influence of analogy, or of euphony. As an element alien to the organism of the word to which it is added for the purpose of connecting it with that which follows, it receives the name Bindesilbe, and may, in such general function, be compared to a ligazon.

In the light, now, of this comparison we may view the Philippine ligazones'as a class. Making due allowance for the possibility of 
their having been called into service, in some case or other, through analogy or for the, sake of euphony, we are safe in attributing to these more or less loose particles the same general functional character as has the syllable es in Gottesgabe, namely, that of indicating a syntactical relation.

In the case of one of the Tagalog ligazones this character is very evident. In this language " $\mathbf{I}$ 》 is $a k o$, and the sentence $A k o-i$ Tagalog means "I am Tagalog». Who will doubt that the ligazon $i$ added to $a k o$ is the element that establishes the relation between the words ako and Tagalog which English expresses by the proper form of the auxiliary verb "to be"?

Not in all cases of employment of a ligazon in a Philippine language is the presence of a syntactical relation equally clear, and it will be the more occult the more we lend, through specious translation, the syntactical coherence of an inflectional language to the peculiar word-forms which these languages have created for themselves. But even where the ligazon appears to be a mere formative of a compound noun, as in the case of susung dalaga, we are safe to start with the presumption of a syntactical relation, as it is axiomatic that all word-formation has primarily arisen in connected speech, that is in syntactical combination.

The same, then, as we could not understand the true nature of the German Bindesilbe, above exemplified, without a knowledge of the inflectional modification (declension) of the nouns of that language in general, so also _can we not gain a clear insight into the nature of Philippine ligazones except by investigating their whole system of connecting words by particles of relation.

An investigation of this kind had, undoubtedly, best proceed through comparison. Closely related as these languages are, they help to explain each other. Unfortunately, the syntax of no Philippine language has ever been presented in such a way as to facilitate a ready comparison, nor can I bring myself to believe that the whole grammatical plan upon which these languages are, as a rule, presented is the best adapted to give an insight into their genuine nature. It is for this reason that I have limited myself to the contemplation of a single language, attempting to set forth the fundamental traits of its syntax in such a way as to show the particles of relation as natural organic parts of its system of word-connecting. In so doing I have 
not had the advantage of founding myself on any prior work following the plan just outlined, but have found it necessary to come to a decision on several fundamental points for myself. I am not all certain that I have hit upon the right solution in every instance, and hope the present paper will be judged for what it is: an attempt, any pertinent criticism of which will be welcomed by nobody more than by myself.

The language which I have selected for this study is of special interest for two reasons: First, because it has not yet been made known to philologists through any grammar or vocabulary, and thus affords entirely new material; and, second, because its highly developed system of particles of relation makes a study of it specially apt to throw light upon that of other languages of the same group. In fact, this language, which outer difficulties kept me from scrutinizing as closely as I could have wished, is worth more minute study, and access to it should be made easy through an ample collection of texts, a necessity which has been repeatedly rightly emphasized with regard to Philippine languages in general.

The language in question is that spoken by a tribe of northern Luzon, who - originally or by adopting a name given them 'by others - call themselves Isinai. The same designation is also generally applied to their speech, similarly as such tribal names as Taga$\log$ and Iloko are given to the languages spoken by these peoples.

The Isinai who probably number at present between four and five thousand souls, are, according to old mission reports and local traditions, the descendants of Igorrotes, taking that term in its old etymological sense of "hill-men». Their conversion by Spanish friars commenced as early as the beginning of the eighteenth century. To-day they form the bulk of the population of the three Christian towns Aritau, Dupax and Bambang in the province of Nueva Vizcaya. ${ }^{1}$ )

1) Cf. Angel Perez, Relaciones Agustinianas, Pub. P. I. Bur. Sei., Div. Ethnol. (1904), 3, 370, Span. ed.: "With the immense majority (of the Isinai) that embraced Christianity, the Augustinian fathers founded the towns of Nueva Vizoaya, which they afterwards ceded to the Dominicans. We do not know whether or not the Christian descendants of the Isinai, who peopled the towns of Aritau, Dupax, Bambang and others, conserve their. idiom like those who still remain pagan. They were also called Inmeas, Malaat, and Ituis, and to them belong the Ipituis, Ibabilones, and other tribes."

Certainty about the present extent of the Isinai language can only 
Although, as said above, neither a vocabulary nor a grammar of Isinai has yet been published, there exists a very neatly printed catechism in this language ${ }^{1}$ ), and Pardo de Tavera in his "Biblioteca Filipina gives the title of a grammar of the Spanish language written in Isinai ${ }^{2}$ ), a publication $I$ have been unable to obtain. The catechism is based on an old manuscript and may be supposed to contain, besides solecisms natural to the first foreign users of this difficult language, some antique forms of speech. I have studied this catechism and shall occasionally: refer to it.

The information on Isinai given by me is based on direct and independent research into the facts of the living language. Unable, to visit the people in their own country, I engaged as teacher a young Isinai, whom I was fortunate enough to find in Manila. After some patient training, he was able to give very intelligent explanations on the usage of his language. I mention this source of my information in order also to make it clear that $\mathrm{my}$ representation of Isinai sounds rests on intercourse with a single member of the tribe whose individual pronunciation I had no means of comparing with that of others, except what he himself told me concerning certain local differences.

In order to enable the reader to verify my results for himself as far as possible, I give, in an appendix, the Isinai version (as related to me by my teacher) of the Philippine tale "The Tortoise

be gained through research on the spot, as also about its relation to that spoken by the unconverted Isinai now living on the eastern slopes of the mountains which separate southern Nueva Vizcaya from Benguet and along the Padre Juan Villaverde trail. (Worcester, The non-Christian tribes of northern Luzon, Phil. Journ. Sci. (1906, 1, 860). As to the tribal names Inmeas and Ibabilones, the first is, according to my information, a designation now bestowed on people living in the center of the town of Bambang who consider themselves the purest Isinai in this town because they descend from those first converted to Catholicism; the second is probably to be connected with Balivon, which is the name the Isinai give to the town of Bayombong, Lvalivon being that of the inhabitants of that town who are said to be mostly eivilized Gaddang.

1) "Catecismo de la doctrina cristiana en la lengua de isinay ó inmeas, corregido, añadido y redactado en mejor forma del antiguo manuserito", por N. M. R. P. Exprovincial Fr. Francisco Rocanıora, siendo Vicario de Dupax... Manila, Imprenta de Sto. Tomas (1876).

2) Joaquin Lizaro, Introducción al estrdio de la lengua castellana en isinay. Manila, Imprenta del Colegio de Santo Tomas (1889). 
and the Monkey", which was published by Rizal in English ${ }^{1}$ ) and has been commented upon by Kern ${ }^{2}$ ). The Isinai have a continuation of this story, not given by Rizal, which I have added as Part II. Upon comparison it will be found that this continuation describes the death of the monkey in very much the same manner as it is related in the Tou-n Sea' version reproduced by Kern in his commentary just mentioned.

\section{CLASSES OF WORDS.}

- Nouns and Particles.

$\S 1$. The discussion of the fundamental traits of Isinai syntax may fittingly begin with an examination of the material of which this language builds up its sentences.

Leaving a detailed classification to the future writer of an Isinai grammar, I fix my attention mainly upon the general import, the significant value, which the words of this language have in connected speech, and distinguish, in this respect, two chief classes, namely, those that name the substance of 'thoughts, naming words, and those that convey no independent thought content, particles. Between both stand pronominal words.

The outward form in which these words appear shows the well-known characteristics of Philippine languages in general: radical form, composition, reduplication, affixation. With these the reader is presumed to be familiar and only such of these features will be dwelt upon as are essential to the matter in hand, or are peculiar to Isinai.

§ 2. Naming words name independent objects of thought; for example: tahu, person; dahóm, wind; sa-it, pain; tanóm, idea of planting; puráu, whiteness. Due, perhaps, to the abstract nature of their predicament, many words of this class are used by the language mostly or only in union with an affixecl particle, with the result that the general sense they convey is referred by this particle to something concrete or special; for example: puráu, whiteness, mapuráu, what is white; tanom, idea of planting, itanóm, what is planted, cultivated plant.

1) José Rizal, Two Eastern Fables, Truebner's Record, July, 1889.

2) Actes du VIIIe Congrès International des Orientalistes (1889) Ve Section, III, 17. 
In the following pages I frequently substitute for the term "naming words» the handier "noun» or "nomen" (adj. "nominal»). I thus use "noun" in its primitive sense of "name», somewhat as «örous and "nomen" were used by the earliest grammarians. I do not distinguish between "noun substantive" and "noun adjective» (n. substantivum and n. adjectivum), but speak, where an object of thought is designated by two or more nouns in attributive apposition, of "adnouns» or "attributives». My reason for doing this is that words of the "substantive" class display in Isinai, as will later be shown, a certain weakness for representing substance. On the other hand, names for properties are either what in English grammar are called "abstract nouns" (for example: puráu, whiteness; ngô-ngót, blackness; túx-oi, height; atung, heat, sickness ${ }^{1}$ ), or they are. -- and this is their common use in designating objects - combined with particles (affixes) which, by referring their sense to something special, concrete that sense. Thus puráu, giving the idea of whiteness in abstracto, is used in concreto, for designation of objects, only in. the form mapuráu which does not mean "white", but "what is white," or "something white." The consequence is that the function of both classes of words is incongruent to that of our "substantives". and "adjectives». In the English sentence "That is a white house» the word "house» represents the nomen regens of the family of languages to which English belongs, and to this is added "white, as a subordinate determinant. In the equivalent Isinai sentence Sário ot mapuráu an beoi, the immediate designation of the object in question is mapurau, white thing, to which $b c o i$ is added as a second noun determinating the first and linked to it by the explanatory particle an.

I shall substantiate this view in the course of the present discussion and wish to remind the reader here only of the fact that the categories of "substantive" and "adjective» have been established upon characteristics of sence, function, and form which the words comprised under them show in our (Indogermanic) languages, and which one may not a priori assume to be present in the same concurrence in an Indonesian language.

I shall, in proper cases, speak of "verbal nouns", as also by way. of comparison with English, of "participial forms», but shall not

1) Example: Uar ngô-ngótnar ot amung uling, The blackness-his is like charcoal. 
speak of a "verb" in general, since in the languages in which this category is at home, it is essentially characterized by the vorbum finitum, exclusively verbal forms which I have not found developed in Isinai. On the contrary, while the syntax of the languages possessing a verbum finitum receives thereby a distinctly. predicative character, that of Isinai is, by the absence of the finite verb, and by the substantival value which to words expressing verbal ideas is given through affixation, left with an equally distinct attributive character. This, too, will become evident in the course of the present discussion.

$\S 3$. Particles have no independent thought content, but presuppose the presence of substantial ideas to which they refer, or which they connect. I discuss them, respectively, as affixes and as loose (or enclitic) particles.

(a) As affixes their general function of referring the meaning of the stem to some special idea, has already found an illustration under "naming words». In exercising this function they give to the reference they make a spécial direction, whereby the sense of the stem becomes, in the resultant derivative, variously modified. In the example itanom, previously used, the sence of the stem tanom (idea of planting) is referred, by the affixed particle $\mathbf{i}$, to some object at, or with which, the action of planting is executed. By another affix, the suffix an, the sense of the stem is referred to a place, as in tamnán ( $<$ tanóm + an), place of planting, a meaning for which also the form pantamnán, place used for planting, is employed. Compare further:

$\begin{array}{ll}\text { mantanóm } & \text { person occupied in planting } \\ \text { pantanóm } & \text { mode of planting } \\ \text { mitanóm } & \text { person who plants for pay } \\ \text { mangitanóm } & \text { person going to plant sometime } \\ \text { intanóm } & \text { what has been planted }\end{array}$

Special attention merits the fact that by certain affixes a relation to time is expressed, regardless of whether the stem denote an objective, verbal, quantitative, or qualitative idea. Compare in this respect:
Stem.
Affix.
Derivative.
batu, stone
- in - binatiu, what has been made of stone
tavó, fat
- um - tumavá, what is gradually getting fat
$l a-a r$, walk
- in - lin $a$-ar, time or distance walked
man-óx, what is small - um -
uman-óx, what is getting small
dua, two
- nan- nandua, what has become two 
(b) Lnose (or enclitic) particles bring the words among which they are found into relation to each other. Examples:

$\begin{array}{lll}\text { bû si éau } & \text { feather of } & \text { kalau (horn-bill) } \\ \text { mevvés ri óhomar } & \text { good } & \text { man (is) governor }+ \text { ar }\end{array}$

In their phonetic structure such particles manifest a peculiar weakness. They have an inclination to become enclitics, that is, to lean for support on the preceding word whenever this is open to receive them. In the liaison into which they thus enter, they lose part of their complex of sounds. One particle is, in this respect, especially noteworthy as it changes, as enclitic, even the only sound left over. This particle is si which, for reasons that remain to be cleared up, adopts the enclitic form of t. Examples: «Broken-thing-my is the pot» may be Gimpá-u ri caserolar; or, with ri as enclitic, Gimpá-ur caserolar; "Alive is Mariano" may be Matahu si Mariano, but Matahut Mariano is for the Isinai a readier form of the same sentence.

A special class is formed by certain emphatic and demonstrative particles of an interjectional nature. For instance, in the sentence Atdanà ai si osán vasot daním! Give me, please, a glass of water! the particle $a i$ is an interjection serving, like English "please», to give more emphasis to the request. In : Si na! Just there, where you are now! na is half demonstrative, half interjectional, indicating the point just reached.

The fact that such particles (including inverfed forms) coincide in sound, and to a certain degree also in sense, with particles that are to be found, in Isinai as well as in other Philippine languages, in pronominal, prepositional, affixal, and other use, should make their closer study a very interesting one, since it may show the former as having given origin to the latter. ${ }^{1}$ )

\section{The abstract noun.}

$\S 4$. Judging from the standpoint of our grammar, a characte-

1) Writing a century ago, Crawfurd, in his "History of the Indian Archipelago", found the most remarkable evidence for an original (Indonesian) stock language in that class of words which is "connected with the metaphysical structure of langnage", and in support of his view he quotes, in the second volume of the work just named the following notable passage from Diversions of Purley (Vol. I, p. 147): "The particles of every language shall teach them whither to direct and where to stop their inquiries, for wherever the evident meaning and origin of the particles of any language can be found, there is the certain source of the whole". 
ristic trait of Isinai, as of its sister languages, is the more general use made of radical (unformed) nouns unaccompanied by an article. I shall call these "abstract nouns".

When in sight of a distant object in the shape of a house, an Isinai may answer the question "What is that yonder?" with the single word «Beoi». In so doing he uses the isolated unformed noun bcoi to give an information equivalent to that conveyed by the English answer "House», although English would not give that information without extending it at the same time to the fact of the singleness (or individuality) of the object in view by adding the indefinite article, thus: "A house».

Also to a narrower question, such as "What is that, a dog or a cat?», an Isinai may answer with the noun in the same form: "Boon an asu, kuting», literally "Not-particle of relation-dog, cat ", emphasizing the last word.

Again, if an Isinai picks up some feather or feathers, remarking that he has found something, he will, upon the question "What is it?", give a description of his find with a mere "Bîu», literally "Feather", where we would name and count, saying "A feather», or "Feathers».

A similar absence of the article, as pointed out here for Isinai, we have, as is well known, in English in the case of names of abstract objects of thought (for example «We praise virtue»), and of designations of substance (for example "This is gold»), where the articleless, noun has seemingly the same value as in Isinai. Compare: "This is gold» with "Sátie ot balitû. There exists, however, the essential difference that English may use, in that form, nouns of the categories named both as predicate and as subject of predication; for example: "Gold is a metal", while Isinai employs its radical nouns (regardless of categories) without the article only in the predicate (or attributively), but - with one certain exception - never as subject. Isinai says "Sário ot beoi», literally "That is house», but it cannot possibly advance the articleless beoi to the place of the subject and say "Beoi ot .... (some predicate)». The proper form to be used in this case is what in the next section will be treated of as "the definite noun». The exception just mentioned occurs in another class of sentences, attributive in character (cf. the si and ri constructions), which allows the sense of the single abstract noun to be referred to as something "that is there», but as nothing more. For the 
present I wish only to point out the fact that the radical noun in Isinai, unaccompanied by an article, is more generally used than in English, but that this use is restricted to being descriptive of preexisting ideas. The radical noun cannot introduce new matter of thought if more than mere existence is predicated.

$\S 5$. The "substantive» of the "Malayan» languages, alone and without nearer determination, has been defined by Fr. Müller as designating the sum of all those individuals or things which fall under its concept, that is, as an indifinite plural. ${ }^{1}$ ) From the facts just given, and from other observations to be mentioned later in this paper, I incline to the belief that the Isinai abstract noun taken by itself represents the object in whose designation it is used, not so much as a substantial and individual whole, but as an appearance. It is rather an attribute standing on a line with radical names of properties than a "substantive». Whereas English "gold", as exemplified above, represents substance without shape, its Isinai equivalent balitî might represent appearance without substance. Thus it becomes clear that this radical noun, alone and without any nearer determination, cannot concern itself with number, be it even in the sense of an indefinite aggregate of individuals; it cannot be a class-name. I find that Byrne ${ }^{2}$ ) holds a somewhat similar view of the noun in Tagalog, when he says: "There is great use made of demonstratives, as if the noun needed their help to be thought as an object», and "There is a deficient sense of individuality, as if there was a weakness in the element of substance in the substantive ideas».

\section{The definite noun.}

$\S 6$. In $\$ .4$ I stated that if some one house were pointed out to an Isinai with the question: "What is yonder object?» he might answer the question by merely uttering the word describing the nature of that object: "Beoi», House. The vague sense of this word was brought by me into connection with its radical form.

If, now, we point to the sun and ask the same man to give the name of that peerless heavenly body in his language, he will answer: "Eháwar", The Sun. This word is composed of

1) Fr. Müller, Reise der österreichischen Fregatte Novara. Linguistischer Teil. Wien (1867).

8) General principles of the structire of language, London (1885). 
the radcal noun ćlau, sun, and an appended particle -ar, having the force of "the in the English translation given.

I illustrate that particle by another example:
Neir ánd̀-u,
Neir ri ánd̀-ular
I have no children
My child is not here.

Here we have two Isinai sentences which, ignoring for the present the merely syntactical particle $r i$ in the second, are differentiated by the same particle -ar appended to the last and

Ncir, or in purer but less usual form nair, is a sentence-word composed of the two particular elements $n a$ (weakened to $n c$ by following $i$ ), which predicates present existence, and $i r$, which has the meaning of "absence» or "void», and expresses generally negation. Neir means, then, "There is absence», or "There is not». Anà is "child, children, offspring, issue», and $u(<k u)$ the possessive suffix of the first person singular.

The sense, now, of the two sentences quoted is quite different. The first means (freely translated): "I have no children», and the second: My child is not here». How is this wide divergence in meaning brought about? It is effected by the syllable -ar, which, added at the end of the second andi-u, so modifies the sense of the preceding noun ánà, that this, after standing in the first sentence for the mere conception of "issue», is referred, in the second sentence, to a person representing that conception in corpore. Ánd̀- $-\iota$ is "issue of mine», ánà-ılar, "my child». Ncir and $x-\iota$ has — to force out the distinction - the meaning of "There is no such idea as issue of mine», while Neir ri ánà-uar means "That person, my child, is not here".

$\S 7$. The following dialogue will illustrate the force of -ar still further:

Servant (informing his master of the arrival of a visitor): Dioi si dimmatóng si tahu ni-bus Kayap-pa. There is (follows particle of relation $s i$, not to be translated) one-arrived (p.o.r.si) man from (literally sallied) Kayapa.

Master: Siran die? Who is it?

Servant: Sin-ili. Igorot (Understood: $\mathrm{He}$ is).

Master: Ibaham isia ta umalit-tu beoiyar. Object-of-speaking-thy respecting-him that (he, understood) coming- $(+\mathrm{t}<\mathrm{si})$ here house-the.

Servant (ushering visitor in): Etoi ri táhuar siri Kayap-pa. Thishere-is (p.o.r. ri) man-the there (i.e.from) Kayapa. 
In this dialogue a stranger is introduced and first described by a combination of the two nouns dimmatong (one-arrived) and tahu (person, man); further on by the single noun sintili (Igorot). Dimmatóng is a derivative (radical datóng +infixes in and $u m$ ); talu $u$, a radical noun. Spoken of again, he is designated as tahuar, the man, or: that man. The particle ar is here again seen to refer the sence of a radical noun (namely, tahu, man) to a particular individual: tahuar, that man (of whom I told you). The particles $s i$ and $r i$, preceding that noun, play a syntactical role and must be left for later treatment.

$\S 8$. We distinguish, then, a certain form of the Isinai noun which is characterized by an appended ar, and is used to designate definite objects. This form is, as will be seen, not peculiar to 1 adical nouns, but may be adopted by any noun in general. It will be designated in this paper as the definite noun.

\$9. The following table gives a view of the value which the abstract and definite Isinai nouns have in speech in comparison with that of an English common name in different modes of employment:

\section{ENGLISH}

ISINAI

The noun «fish» used:

1. As a descriptive term:

His food is fish;

Typical value of the abstract noun: Daláx si anóna;

2. As a denomination of class:
a) That is a fish;
b) Fishes live in the water;

a) Abstract noun (descriptive): Sário ot daláx;

b) Abstract noun cannot be subject of predication; it becomes definite:

Uar daláhar ot mit-tut danimar ');

3. In designation of definite Typical value of the definite objects :

The fish (fishes) you caught is (are) dead. noun:

Uar dinaláx-muar ot natói (for plural: natóira) ${ }^{2}$ ).

J) Or: Uar beoi ri dalnhar of danimar, The house (dwelling place) of the fish is the water.

3) Dinalax, Fished thing, product of fishing; dalahon, object of fishing. The Isinai have no class-name corresponding to "fish". Dalux is the most common kind of fish with them. Ilk. ikan occurs in Isinai as $i$-an for a special kind of fish. Kank. nigai is contained in Isinai mannihai = fisher (obsolescent?). 
This table shows that each of the two English categories numbered 1 and 3 finds its correspondency in Isinai. Category 2 , on the other hand, is partly comprehended in the sphere of the Isinai abstract, and partly in that of the Isinai definite noun. The table also shows that where a designation of class is required, Isinai makes use of the definite noun, just as for "Fishes live in the water», English also might say "The fishes etc." Note in this connection the definite danimar in the same sentençe. As no definite fishes and no definite water are referred to here, it may be concluded that Isinai uses -ar in these cases to give that substantiality to the respective nouns which, as said before, I suspect them to lack in their abstract form.

$\S 10$. As to the original nature of the particle (suffix) -ar I cannot speak with certainty. It evidently strengthens the significance of the word to which it is appended. Such strenghtening by a postpositive is more or less systematically in use in the generality of languages belonging to the Philippine group. Compare, for instance, the use of the noun in Tirurai and, farther south, in Sangir ${ }^{1}$ ). The particles used for this purpose appear to be either emphatic or demonstrative, a distinction which, however, cannot always be drawn very clearly. The possible nature of -ar as an emphatic particle is discussed in $\$ 35$. For its demonstrative character might speak the existence in the Ifugau dialect of Magulang of a demonstrative particle $a d$, as also the occurrence in Bisayan dialects of a demonstrative pronoun adto, the first element of which may be identical with the Isinai particle in question, which is locally also pronounced ad. As we shall see further on, ar in Isinai seems to have been formerly in use both as a postpositive and as a prepositive particle.

\$ 11. The appendix -ar tends to form a phonetic whole with the word to which it is attached, but leaves, upon encountering a possessive suffix, the precedence to this.

A demonstration of this proposition touches a difficult part of Isinai phonology, namely, the rôle played in this language by the glottal stop. For greater clearness, therefore, of exposition, I have prepared the following table which allows the eye to follow readily the different phonetic changes occurring in this connection. I preface it with some explanatory remarks.

1) N.Adriani, Sangireesche Spraakkunst, Leiden (1893). 
In Isinai the disappearance of $k$ in many words which in other Philippine languages show this as a final sound, gives to the preceding vowel a peculiar abrupt pronunciation which I represent by a grave accent on that vowel; for example, Phil. anak, child, becomes in Isinai ánà; Phil. $a k$, personal suffix of the first person singular, Isn. $\grave{a}$. Also initial $k$ of other dialects disappears in Isinai, though without leaving anything audible behind, even in whispered voice. Still, a vowel following such disappeared initial $k$ is never joined to a preceding vowel or consonant, but remains detached from it by a break in the voice which I mark by a hyphen; for example, Phil. $k a$, personal suffix of the second person singular, Isn. a (Mángan-a! Eat thou!, but Mang'ánà, I eat); Phil. ko, possessive suffix of the first person singular, Isn. $u$ (beoi-u, house-my). This latter suffix experiences in Isinai change which will be seen in the table.

In the majority of Isinai radical words which I have heard, the voice seemed to mark the penult. This accent appearing to be the common one, I give it as understood and do not, as a rule, indicate it by any sign. Only in the following table, as also occasionally in the text, when desirable for the sake of greater clearness, I have distinguished the greater quantity of the penult by the same sign (acutus) with which I mark, thruout the paper, the accented ultima. ${ }^{1}$ )

When a stressed ultima is followed by the glottal stop, representing a disappeared $k$, the sudden stoppage of the strong expiration required for the stressed vowel - or, as my teacher expressed it, the sudden drawing back of the breath - causes a remarkable increase in the abrupt pronunciation which, as said above, vowels preceding such disappeared $k$ always have. The coincidence of the signs used for the two phenomena involved leads, for a graphic distinction of such abrupt vowels, naturally to the employment of a circumflex; for example, Phil. balitók, gold, Isn. balit $\hat{u}^{2}$ ).

In Isinai long consonants are frequent and care must be taken to give them their proper quantity. To avoid the use of too

1) The stress on the ultima varies greatly in different words. It is very light, for example, in iná, matí, batí, and very marked in atayín, orawón, and other derivatives.

2) A similar abrupt pronunciation is noticeable in the case of a stressed o after which a $t$ has dropped out; for example, mangô-ngót, black; dô-lót, greed. 
many special signs, I mark the length of consonants by doubling the letter. In the case of stops, the first letter stands for the closure and the second for the release. Examples: mevvés, good; manpassial, one promenading (Span. pasear). Occasionnally long consonants become (through the quantity of the preceding of following vowel?) over-long, in which case I separate the two letters representing them by a hyphen; for example: urit-ti, few, scant; át-tai, excrement.

I. - Radical words with closed ultima.

A. Penult accented.

$\begin{array}{ll}\text { vóop sky } & \text { + ar viópar } \\ \text { lábban hawk } & + \text { ar labbáanar } \\ \text { ćom enemy } & + \text { ar ćomar } \\ \text { bátang body } & \text { + ar bátangar } \\ \text { tá-ut fear } & \text { + ar tá-utar } \\ \text { (inà child } & \text { + ar ána-ar }{ }^{\mathrm{a}} \text { ) }\end{array}$

B. Ultima accented.

cás forest

+ ar éasar

tumbixx key

+ ar tumbihliar

tandif edge

+ ar tandihar

taróm camote + ar tarómar

balitî̀ gold

$b \hat{a}-b \hat{a}$ word

+ ar balití-ar

$b \hat{\imath}$ feather
+ ar bâbú-ar

+ ar bit-ar
Same stem with addition: of poss. suffix | and further

1. P. S. addition of ar

vióp-u vióp-uar

labbin-u

śom-u

labbcin-nar

som-uar

bitang-u

tei-ut-ut

cinc̀-u

bitang-uar

tá-ut-uar

cinc̀-uar

éas-u

tumbit $x-u$

tandif $-u$

taróm-u

balitîn-u

$b \hat{a}-b \hat{a}-u$

$b \hat{\imath}-\imath$ éas-uar

tumbiux-liar

tandic-uar

taróm-uar

balit $\hat{u}$-uar

$b \hat{a}-b \hat{a}-\imath$ ar

$b \hat{\imath}-u$ ar

II. - Radical words with vocalic or diphthongal final.

A. Penult accented.

-

tända sign

ísu dog

ininti sugar

sóxso temptation

isai shield

béoi house
Same stem with addition: of poss. suffix and further

\begin{tabular}{l|l} 
1. P. S. & addition of ar \\
\hline tíndì & tandá-ar \\
ásì & cisu-ar \\
inintî & ininti-ar \\
sóxsò & soxsó-ar \\
ésai-u & ésai-uar \\
b́́oi-u & héoi-uar \\
éhau-u & éhau-uar
\end{tabular}

a) Absence of glot!al check in ina-ar distinetly perceived! 
B. Ultima accented.

Same stem with addition: of poss. suffix and further

\begin{tabular}{|c|c|c|c|}
\hline & & 1. P. S. & addition of ar \\
\hline other & + ar inār $\mathbf{r}$ & $i n \hat{a}$ & inci-ar \\
\hline ive & + ar matăr & matồ & matú-ar \\
\hline boxtói group & + ar boxtói(y)-ar & boxtói-u $\left.{ }^{a}\right)$ & boxtói-uar \\
\hline young d & + ar kelizuar & kelúu-u & Kelíut-uar \\
\hline & + ar batuar & batî & batúl-ar \\
\hline
\end{tabular}

III. - Derivatives in on and an, with forms mutilated through attachment of the possessive suffix 1.P.S.: u (Phil. ku, ko).

A. Penult accented.

Same stem with addition:

+ ar

sulátan paper to be written sulitanar

adálan person to be taught adílanar alian arrival

appion work to be done adálon lessen to be learned

B. Ultima accented

atayain death

ahaíhayán liking

anón food

orawón obj. o. begging

\section{alíanar}

appionar

adúlonar of poss.suffix and further

1. P. S. addition of ar

sulcíta | sulíta-ar

adúlà adcila-ar

alici

appiò

adúlò

alía-ar

appio-ar

adílo-ar

Note formation of above stems with poss. suffix 2. P.S.:

\begin{tabular}{|c|c|c|c|}
\hline \multicolumn{2}{|c|}{+ ar } & \multicolumn{2}{|c|}{+ ar } \\
\hline sulátam & sulátamar & atayám & atayámar \\
\hline adálam & adálamar & ahaíhayim & ahaíhayámar \\
\hline alíam & alíamar & anóm & anómar \\
\hline & appiomar & orazoóm & orawómar \\
\hline adálom & adálomar & & \\
\hline
\end{tabular}

Note also equivocal forms in the 3. P.S., as, for instance: sulatan $+n a($ his $)=$ sulútana $+\mathbf{a r}=$ sulátanar "the paper» or "his paper».

appion $+n a$ (his) $=$ appiona + ar $=$ appionar "the work» or "his work".

a) "my share". 
$\$ 12$. The preceding table shows, in regard to the tendency of ar to form a phonetic whole with the word to which it is attached:

First. That ar merges its initial with a final $a$ of the word to which it is appended: tandar, incir, matír;

Second: That it joins itself to a preceding $i$ or $a i$, oi, au, by a more or less distinct glide: ininti(y)ar, ésai(y)ar, béoi(y)ar, chicu(w)ar, kcliu(w)ar. In the case of preceding au, especially, the junction is so close that one may write: chizuar, kcluzwar.

Third. 'That in words ending in a palatal or velar fricative (two sounds which I have tentatively represented by the symbols $f$ and $x$ of the Association Phonétique Internationale) the access of -ar frustrates the proper formation of the closure and converts those sounds into slightly scraping h-sounds: tandif: tandihar; tumbíx: tumbithar. Other examples are: buinif, ghost, : bainihar; beandix, pest, : beandihar.

Fourth. That the rhythm of the word is influenced by -ar:

(a) in so far as this appendix may draw the quantity from the original penult to the one newly created by the access of ar: viop: viopar; líbban: labbinar; ininti: inintiar; sóxso: soxsóar; chau: ehicwar. This is, however, not always the case: ́om: comar; tú-ut: tú-utar; cinà: ána-ar; (b) by a considerable lengthening of certain syllables. This occurs in the case where ar merges with a preceding syllable ending in $a$ and having the accent: inär, matär $\mathbf{r}$ also, in the case where ar is attached to a derivative of the $a n$ - or on-class accented on the suffix: atayan: ataj'ànar; ahaihay'in: ahaihayánar; anón: anónar; orawón: orawōnar.

The merging of the initial of ar with a preceding $a$ as mentioned under 1, occurs consistently also in the case of words carrying the possessive suffix of the third person singular: $n a$. As the initial of $n a$, in its turn, merges with a preceding $n$, as in all on- and an-derivatives, the individual form of $n a$ is completely absorbed, whereby the equivocal forms arise that have been noted at the end of the table.

$\S 13$. The suffix ar is, according to my informant, pronounced ad by the Isinai of the town of Bambang.

$\S 14$. Of two definite nouns standing to each other in genitival relation, only the qualify'ing noun takes the suffix ar:

Uar beoi ri ohomar ot ammi-i, The house of the governor is large. 
Uar pió-ar ot pinalsan di dios di cristiunoar, The earth is created-thing of the God of the Christians.

$\S 15$. Mention may be made here of a prepositive particle ar, which is frequently found in Rocamora's catechism, but which, since the time that book was written, seems to have gone out of use, either generally or locally. My teacher, a native of Dupax, regularly took exception to it when used by me tentatively, alleging that it was heard only occasionally in the mouth of old people, especially in the town of Bambang, and at this place as ad. To judge from the use given it in the catechism, where it occurs regularly with postpositive -ar in what appears to be a combination of two articles, it serves, or served, to give to the noun, thus enclasped by two ar, a special prominence amounting occasionally to a predication. The following are examples of its use, taken from the catechism, and given the spelling used by me:

Ar mariardarin mangihalang si papuidreardari, apurardari on dara-liaiardari. Those who do not honor the Padres, their grandfathers (or superiors) and the elders. (P. 74.) ${ }^{1}$ )

Tangan dic aruanar Sacramento? Ar confirmacionar. What is the second Sacrament? The confirmation. (P. 96.)

Tangat mibawal sitien tongtong? Ar panpardahar si isuar tahut $b \hat{a} \hat{\imath}-b \hat{a}$. What is forbidden by this commandment? The causing of evil to fellow-men by words. (P. 80.)

Uar aruanar: Confirmación, ar panpasdéar si panit-tuar The second: Confirmation, the corroboration of the faith. (P. 9.) In these examples, prepositive ar reaches an expressiveness approaching predication in so far as we might also translate: It is the confirmation; It is the causing of evil; Confirmation, that is the corroboration. This potential predicative force of prepositive ar is, however, no obstacle to the use, together with this particle, of the Isinai predicative particle "par excellence», which is ot;

Uar lugarar ayanda ot ar limboar, The-place-of-their-going is the limbo. (P. 96.)

Uar impamalsanar si mundóar ot ar panaráumnar mariós, Themode-of-his-creating the world is (by) his-power divine. (P.43.)

The catechism shows the same prepositive also in prepositional phrases:

I) Da-iai, elder person. 
Si ar tandan di Santa Cruzar, In the sign of the holy cross. (P.3.) Christiano-a.' O, ama, christianoà si ar gồ-gos di Diosar isaon. Art thou a christian? Yes, Father, a Christian am I by the love of God toward me. (P. 22.)

The employment here of prepositive ar produces a greater pointedness of diction, but that its presence was already at the time when the catechism was written, in no way a grammatical necessity, is proved by its absence in an equally great, or perhaps greater number of exactly similar cases: for example, si ngaron di Amar, in the name of the Father; si graciamar masantos, by Thy holy grace, etc.

The indefinite noun.

$\$ 16$. According to their value in connected speech, there have so far been distinguished two classes of Isinai nouns; the abstract and the definite. In form, the first was characterized by its radicality, and the second by its suffix ar. That value, which an English noun receives by being used with the indefinite article (e.g. "a fish"), or by the pluralizing of the articleless noun (e.g. "fishes»), was shown in a comparative table to be comprised in Isinai partly within the functional sphere of the abstract, and partly in that of the definite noun.

Are there, then, to be found among Isirai nouns no forms which, while individualizing the sense expressed by the abstract noun, do not fix that sense on definite individuals (as is done by the suffix -ar), but leave the object, or objects designated indefinite? The answer is that, as far as such indefinite individualization is obtained in English by "numerus" (as in "a fish" and "fishes», from the abstract "fish»), no such forms exist in Isinai.

There exists, of course, in this language, the same as in English, that class of words which from their very nature take stock of individuality, viz. numerical words, and these, used in combination with abstract nouns, serve to indicate one, two, three, any number of indefinite individuals. Their value is, however, quite unlike that of English numerals. In English phrases like «a fish» or aten fishes", the noun is conceived as a designation of a class of objects from which a certain number is singled out by the numeral. In Isinai it is different. Here the idea of objectivity is not to be looked for in the noun, but goes evidently with the 
numerical word (meaning not «one», «two», «three», but «one thing», «two things», «three things», etc.) and is then determined by the following abstract noun as to its specific nature. The Isinai numerical word is not an article (like English «i»), nor an adjective of number (like «ten in «ten fishes»), but a word embodying as independent a thought content as the following noun. This relation between the numeral and the noun in Isinai is to be deduced from their syntactical use as set forth and illustrated in the following section (cf. Numerical nouns), in which the question of anumerus" will be given further consideration.

On looking again around among Isinai word-forms for such that express individual objects indefinitely, a large and varied body of words is found that comes under this description. It is constituted by all those nouns which refer the vague sense expressed in their stem to something concrete or special by means of a particle forming part of the noun as an affix. These nouns, which are, then, derivatives, and which often show considerable change of signification in comparison to the stem, are true class-names. From examples previously used I cite here a number of such words:

dinatóng (stem datóng, reaching, + infix in) what is found dimmatong (same stem + infixes in and $u m$ ) what has arrived dinalax (stem daláx + infix in) what has been fished, product of fishing

natói (stem*tói of extinct sense + prefix $n a$ ) what is dead mannihai (stem nihai of extinct sense + prefix man) one going to fish (or plural).

In the derivatives here considered are, of course, not to be included such affixed word-forms as those showing the specializing ar, or those built with personal suffixes. In a class with them are, on the other hand, possessive forms like:

án $a-u$ child of mine, children of mine

beoina house of his, houses of his.

Any of these indefinite nouns may be given a definite sense by the attaching of -ar: dinatongar, the object found; dimmatóngar, the person arrived; andi-nar, that child of mine.

It has been said at the beginning of this paper that all wordformation is axiomatically .conceived as having arisen primarily in syntactical combination.

I can readily conceive derivatives like those first cited above to owe their origin to a radical noun, used in connection with 
a particle of originally emphatic or demonstrative nature, which refers the sense of that noun to some other idea, so that, even with this second idea remaining unexpressed, a communication of thought, virtually a sentence, is produced. The word natói, for instance, evidently a combination of a radical*to $i$, embodying the idea of «death», with a particle $n a$, referring that idea to some object, is a naming word for that object: nató $i$ what is dead, natoiar the dead one. But it has also a predicative force which makes it apt to stand alone as an equivalent for the English sentence «He (she or it) is dead», and this partly by virtue of the emphatic force of na (compare na mentioned at the end of $\S 3$ ), partly by virtue of the Isinai usage of not indicating the third person singular by any personal suffix. Compare in this respect the use of the word $\sin$-iii in the dialogue given in $\S 7$.

It is not the object of this paper to go so far back as to elucidate the origin of derivatives. I only wish to fix more clearly the value which I conceive them to have in connected speech, by pointing out their probable origin, which may be this: the using of an abstract noun in connection with a particle which relates the sense of that noun to something concrete. By such use the particle comes to form part and parcel of the noun with which it thenceforward forms a new word susceptible of adopting a signification of its own.

The following table gives a synoptical view of the development which the general significant value of the abstract noun may experience:

Abstract noun:'ánd issue, beoi house

Indefinite noun, that is, an abstract noun specialized by an affix : andi-u issue of mine, nambeoi house-owner

Definite noun, that is, an abstract or an indefinite noun rendered definite by -ar:

ana-ar the child; beoiar the house,

andi-uar that child of mine, nambcoiar the house-owner.

Numerical nouns.

$\S 17$. Under this heading some remarks on "numerus» shall first find a place.

With an exception, presently to be mentioned, in the case of the definite noun, an indication of number in names of objects does not exist in Isinai. Such names remain unchanged whether they are used in singular or plural sense. Examples: 
Annu: Sia et tahut-tu.: What ? He (or she) only $(+\mathbf{t})$ person $(+\mathbf{t})$ here? = Is he the only human being here? ${ }^{2}$ )

Deét tahut -tu? Many $(+\mathbf{t})$ person $(+\mathbf{t})$ here? = Are there many persons here?

Nambuti di rtar. The Negrito has run away.

Uari star ot marin mit-tut beoi. The Negritos are not ones $(+\mathbf{n})$ dwelling $(+\mathbf{t})$ house $=$ The Negritos do not live in houses.

In these examples the noun talu, person, and itar (*ta+ar) the Negrito, are seen to remain immutable whether used for singularity or plurality. Either the context or the general circumstances of the discourse must make clear what is meant. Occasionally this indefiniteness as to number may serve a question very well :

Dioi si init-mu. Extant (si) issue-thy? = Have you any children?, ${ }^{2}$ ) in which example the phrase and $a-m u$, unconcerned as it is with number, has an advantage over the prejudicative English "child" or "children".

$\S 18$. Reduplication in any form is in Isinai not systematically used as a means of expressing plurality in the noun. Where used, it denotes chiefly a dispersion (variety, scarcity) of the meaning of the word affected:

Dioirat tahu-tahu Dupax an maamtára si $b \hat{a}$-bâ si ivilau There are some persons in Dupax who know the speech of the Ilongot;

Neir cuárta-cuartána rien tahu Not even a copper has that man. itán-tanóm various kinds of cultivated plants

buen-buen month by month

seu, fault, sesseu, joke

Some designations of persons are, however, at times used with reduplication of the first sound, or syllable, where an intention to represent thereby multitude might be taken into consideration:

Uar mamaritardari ot immoiran niloov The young women (stem mariit not yet married young woman) have gone to church.

Uar iiunardari ot maninumdat alax The old men (stem iuna old man, from uluna.) are drinking wine.

1) "Only" is expressed in the emphatic postpositive monosyllable $e$.

2) Alternative: Uarat ána $\cdot m u$ ? but note that uara, is there?, is used only in questions, dioi also in answers and in statements in general. 
$\S 19$. The examples given in the preceding paragraph have introduced a postpositive particle dari. It occurs only in connection with the definite noun. This noun is generally supposed, (as previously illustrated) to be rightly apprehended by the hearer as representing a singular or a plural according to the general circumstances and the purport of the speech. Only where ambiguity is to be avoided, or where more impressiveness or the necessity of indicating collectivity makes it desirable, the particle dari is added to ar as a sign of plurality. In sentences like the following, a plural sign is not required:

Uar star ot marin mit-tut beoi The Negritos do not live in houses;

$B \hat{a}-b \hat{a}$ di sin-iliar tie A word of the Igorot (is) this;

$P \hat{a}$-nam di nasiringanar Feed the hungry.

In the first two, the addition of dari is ad libitum, in the $l_{\text {ast }}$ this particle would impart to nasiringanar, the hungry ones, a comprehensiveness so drastic as to make that commandment rather difficult of execution. On the other hand, if an Isinai wished, for instance, to ask his neighbor the whereabouts of the latter's children, whose number is, of course, known to him, he would necessarily have to say: Neirat di ana muardari? Where are your children? as and̀-muar would, not expressly, but through the omission of dari, refer only to one child.

A man, surrounded by children, might be asked by a stranger: (with indefinite noun) And-mu raratic? Offspring-thy these? (with definite noun) Saratur ánà-muar? These the-offspring-thy? The difference in the form of the noun springs from the fact that the first question starts, in the mind of the speaker, from the group of human beings pointed out by raratie (these), and then connects these tentatively with the idea of issue of the man addressed; while the second question favors him at the outset tacitly with the assumption of his having children, and only inquires if that offspring is the one there present. The second is, then, a more genial way of questioning and may be further colored by marking with dari the multitude of children as a collective body, thus :

Saratur andi-muardari? Is this the body of your descendants?

The collective force of dari is most clearly seen from the following comparison of Isinai with English. "Open your hand" is Bilahom di limamar. "Open your hands" (addressing one 
person) is not Bilahom di limamardari. This would sound in Isinai somewhat as "Open all your hands" would sound in English. The correct expression is Bilahom di duardarin limam. Dari is, of course, not added to dua stwo to indicate that this numeral indicates more than one, which would be absurd, but in order to express "two together " that is, "both": "Open both your hands». In this sentence the objects in question are expressed, in the first line, by the word dua, two things, and this, their chief representative, receives the suffix ar rendering the sense definite: "the two things". After dari has been added for the purpose already explained, the objects are further described - through a syntactical act whose symbol is $\mathbf{n}$ and which will be discussed in detail later on - as lima, an abstract noun standing in attributive apposition to the preceding phrase and condensed in significance by the attachment of the possessive suffix, second person singular, $m(<m u)$.

The preceding examples make it clear that dari is far from being a sign of the plural responding in use to any grammatical necessity. I have not found it otherwise than in continuation of suffix ar. It is written by Rocamora regularly as attached to the latter. In their writings the Isinai follow this use, or they separate the particle, according to personal inclination. Dari has a slight accent on the penult.

$\$ 20$. The expression of number, in connection with names of objects is made with the help of independent numerical words, as, tiu, three; simpiu, ten; dé, many. Their use has already been illustrated by the example "Bilahom di duardarin limam" used in the last paragraph. In such employment, their very nature of expressing distinct individuality makes these words preferentially apt to supply or to strengthen, in the complex of words, the element of substance, in the expression of which the abstract noun has been said to be deficient. Two features in the use of numerical words may be commented upon here: the different form of their connection with another name, and the different meaning which the numeral osí, one, has according to that form.

$\$ 21$. In paragraph 19 , the addition of limam to the preceding numerical word duardari was achieved by means of what was called a syntactical act, formally characterized by an enclitic $\mathbf{n}$. In treating of this, and of a second form of connection, we are, 
indeed, entering upon Isinai syntax, and what is said here, incidentally, of numerical words will be found later to belong to the main topic of the present paper.

The connection of the numerical word with the following noun may be made in two ways:

I. a) By the enclitic connective $\mathbf{n}$, or, in case of consonantal ending of the numerical word, by simple juxtaposition; b) by an.

II. $\mathrm{By}$ the enclitic connective $\mathbf{t}$, or, in case of consonantal ending of the numerical word, by the particle si.

$\S 22$. To illustrate the first mode of apposition, take the numeral osá one. ${ }^{1}$ )

In the sentence: Sário ot beoi That is house, the word beoi plays merely a descriptive rôle according to the view set forth in $\S 4$. In the sentence: Sário ot osian beoi the two words osá and beoi, joined by $\mathbf{n}$, represent the same object of thought, individualized by the presence of osá one (thing), but the word-complex osán beoi goes in force of expression beyond what we would be inclined to attribute to it, that is, an equivalency of English "a house». Osá has here not the sense of "anyone of a class», but of "a particular» or "a certain». I draw this as a conclusion, aside from the common employment of osán presently to be illustrated, from the fact that, if an Isinai were to utter the words "Sário ot osán beoi» and then stop, his hearer would (according to my informant, trough disappointment in a certain feeling of expectancy raised by osá) be led to suggest a further explanation by an idiomatic inquisitive "An?". To this the speaker would respond by adding, for instance, : "an n $n \hat{a}$-gon " or he would repeat the whole and say: "Sário ot osán beoi an $n \hat{a}$-gou», That is a house (which is) burned, wherein an may be taken, for the present and pending further explanation, as a by-form of the connective $-\mathbf{n}$.

We thus find osá $+\mathbf{n}$ most often employed in allusion to, or definition of, certain individual objects which are not only named but described in particular. Examples:

Sirat Dios? Who is God? Osán apun mevvés lan panunan mahô-gos, maamtá, etc. A (certain) $(+\mathbf{n})$ supreme being $(+\mathbf{n})$ good very $(+\mathbf{n})$ exceedingly $(+\mathbf{n})$ kind, wise, etc. Ngat ato-dahan si infiernos." What is the meaning of "infiernos?"

1) The sharp voiceless $s$ of osa is represented by Rocamora thus: ossa. 
Osín liang ammái-i napnut apui A (certain) ( $+\mathbf{n}$ ) hole large full $(+\mathbf{t})$ fire. $\left.{ }^{1}\right)$

Inilarat osán simpun mahalila an mi-anu-anur etc. Seen-thingtheir $(+\mathbf{t})$ a (certain) $(+\mathbf{n})$ stalk banana ( + an) floating etc.

Sinisipenat osán anón ó bungan si kahél (freely:) Her fancy. was for a (particular) aliment, that is, for a fruit of the orange-tree.

Nanindatóngda si osán lugar They met in a (certain) place. The same mode of apposition used for other numerical words than os'a is shown in the following examples:

(a) Vocalic ending of the numerical word:

Saratien duan tahu ot ma-áa These two men are thieves.

Saratien tiun bava-i ot ivâ. These three women are sisters of mine.

Deén uunga si natoi siri Manila A great many children have died in Manila.

(b) Consonantal ending of the numerical word:

Sararion opat kabayu ot pannór The e four horses are for racing.

Sarárion onom pi-pî ot tonan di iváar Those six chicks are property of my sister.

Urit-ti an tahut mit-tut tu Few people are living here.

Note: Instead of opat kabay'u and onom ph-pî also opat an $k a b a y u$ and onoun an pi-pi may be said.

$\S 23$. The other of the two modes of apposition above specified may be illustrated by answers to the question:

Diơi si án'̀-mu.' Have you any children? A simple affirmative answer would be: $O$, dioi si anda-u; with addition of a numeral it would take this form: Dioi si osát ánà-u; Diói si duat-tiutueut-simpiut ánà-u, freely: I have one child; I have two-three. eight- ten children; in which answers the numerals dua, tiu, $u e u^{2}$ ) and simpiu, all ending in vowels, are seen to be connected with the following word by an enclitic $\mathbf{t}$. This $\mathbf{t}$, now, changes to si in case of consonantal ending of the numeral: Diói si opat-onom-siam si ánà u I have four- six- nine children. This connection by $\mathbf{t}$, or by si, indicates, as will be explained more fully; a less close association of the sense of the words to which

1) This and the preceding example are from Rocamora and are idiomatic. Also Inibaloi would say: Sefa's Chius? Saxei dya marunung apo. Apu (apo) is progenitor, grandtather, chief.

2) Sometimes $u e(y) u$ is heard. 
it applies than the connection by $\mathbf{n}$ or by an, or by simple juxtaposition, as first illustrated. It preserves, accordingly, for os $a$ the numerical force more clearly than is done in the connection of $o s a+\mathbf{n}$. An example of the difference in sense which the use of either osát or osán brings about is this: Diói si osát ánà-ut mevvés means, "I have one child (and no more) and that a good one», while Diói si osan ánà-ut mevvés means I have a (certain) child (among others) which is good. ${ }^{1}$ )

A special meaning is also to be recorded for the definite form of osá which is osár. For instance, the question is put: Diói -at beuar an beoi? Do you live in the new house? to which comes the answer: Neir, dióià si osár an beoi an damdamá No, I live in the other one, the old one. Another question: sá tie ${ }^{2}$ ) Shall I take this? Answer: Boón, sário, osár No, that, the other. From these examples the specialization of the meaning of osár "the one» to "the other» is very apparent.

\section{II. - The syntactical use of the noun in general.}

$\S 24$. The syntactical use of the Isinai noun begins with the combination of a radical noun with a particle, in so far as the resultant expression may have in itself an assertive force and find use as a sentence word without further addition. This phenomenon has been mentioned already, in $\S 16$. I illustrate it here more in detail.

The noun expressing the idea of clame, lameness», is in Isinai pi-dai. Through anteposition of the particle (prefix) na, the derivative napi-dai arises. This has a concrete sense, similar to the equivalent English participle klamed" (or to "something lamed»), but possesses, beyond this, a predicative force, that is, it declares, through the prefixed $n a$, the existence, in the object alluded to, of the phenomenon of "lameness» as a state reached or attained. This double import of napi-dai, viz, allusion to something concrete, and predication, cannot very well find simultaneous expression in English word-forms; "Is lamed" is a predicative fragment of speech, "one lamed" is a denominative

1) My occasionally careless pronunciation of si, that is, with something of voice in the sibilant, was instantly corrected by my teacher. Note ueu<ualo and piu<pulu. The change from al (ag, ar, ay) to $e$, and from $u l(u g, u r, u y)$ to $i$ are characteristic of Isinai.

2) ${ }^{\prime}$ à $<$ Phil. álan-ko, object-of-fetching-my. 
phrase. Isinai profits by this double import of its expression in using it, now as sentence word, now merely as a name.

To show the predicative force of napi-dai, we can draw the following approximate parallel:

$\begin{array}{ll}\text { napi-dai(y)d } & \text { am lamed I } \\ \text { napi-dai-a } & \text { art lamed thou } \\ \text { napi-dai } & \text { is lamed (he, she, it) } \\ \text { napi-dai ami } & \text { are lamed we (excl.) } \\ \text { napi-dai ta-u } & \text { are lamed we (incl.) } \\ \text { napi-dai ta } & \text { are lamed thou and 1 } \\ \text { napi-dai ayu } & \text { are lamed you } \\ \left.\text { napi-dai } r a^{1}\right) & \text { are lamed a plurality (they). }\end{array}$

In this paradigm I have put the prefix na of napi-dai in contrast with the English copula "to be», a contrast which is justified by the assertive force which must be recognized for na not only in Isinai, but in Philippine languages in general, whenever it is used to proclaim a state or condition (a finding one's self.) Note, then, the rigidness of the particle na of napi-dai against the inflected English forms am, art, is, are. This paradigm shows that the nominal form napi-dai by itself alone is sufficient to indicate that "third person» which in English, if not named, is alluded to by he, she, or it; napi-dai, then, is the equivalent of English "he is lamed» and thus has what I wished to show in the first place: the value of a complete statement.

On the other hand, that the same word is also made use of by the language merely as a nomen is seen in the sentence: Sia ot napi-dai, $\mathrm{He}$ is one lamed, wherein it is the predicate noun following the particle ot which in Isinai plays very much the same rôle as the English copula. The nominal character of the word taken here for example is still more clearly recognized if that word is encountered in the form of a definite noun: Uar napi-daiar ot si Mariano, The lame one is Mariano. This is a possibility of employment not existing, of course, for English finite verbal forms, but only for participles: "The lamed.»

1) The particle $r a$ does not seem to have acquired a pronominal character as exclusive as that generally atiributed to other pronominal root particles. Besides a rarely encountered pluralizing element for desiguations of persons, it is in Isinai a common pluralizer for demonstrative pronouns, as for instance, in sarátie (or even; sararatie) these, from sátie this. Prefixed with di, as dira, it is, however, distinctly a pronoun for the third person plural, although this form is of limited use for other than human beings. 
We find, then, that a single Isinai word-form, composed of a radical noun and an attached particle, may, through that particle, have a distinctly: assertive force, enabling it to stand alone as a sentence word, and that it can be also used as a simple naming word.

$\S 25$. The elements, now, which constitute the word napi-dai, viz. a noun and a particle, are representative of the two classes of words that form - with the addition of pronouns - the building material of Isinai syntax in general. In fact, the placing of two nouns against each other, and the connecting of them by a particle may be said to represent - beyond the sentence word - the ground work of Isinai sentence formation. The following example may serve to illustrate this.

Where English says: "The child sleeps», Isinai may use either one of two constructions, the rudiments of which can be approximately represented thus: "Asleep: child" and "Child: sleeping. ${ }^{1}$ ) The use of such a primitive construction as represented by this skeleton, that is, the bare juxtaposition of two nominal forms in a certain order, would be, however, repugnant to most Philippine languages as a lifeless stammering, acceptable as it may be to other tongues. Accordingly, Isinai clothes these rudiments with certain particles that serve to establish an intelligent connection between them. These particles, which will be named further on, clearly reveal, through their originally emphatic or demonstrative nature, the primary motive of their employment: the desire of the speakers to make themselves more clearly understood.

$\S 26$. With this notion of the elementary character of Isinai sentence construction, it is profitable to cast a glance of comparison at the general syntactical development of English, the language serving here as the means of interpreting and appraising the peculiar Isinai forms. Such a view is obtained by a reference to the synopsis of the means for expressing connection of ideas in speech that is found in Paul's "Prinzipien der Sprachgeschichte», page 123. The means there indicated are (in translation):

1. Juxtaposition of the words, by themselves, which correspond to the ideas.

1) Neô(di) ungar or (Uar) -ungar (ot) neô. 
2. Order of these words.

3. Graduation between them in regard to the energy of their production, their stronger or slighter accentuation (cf. "Charles is not coming "Charles is not coming").

4. Modulation "of voice-pitch (cf. "Charles is coming", as a statement, and "Charles is coming? as a question).

5. Tempo, usually in close connection with energy and pitch of voice (also pauses may be included here, as marking the closer or less close connection between the several words.)

6. Connectives, such as prepositions, conjunctions, auxiliaryverbs.

7. Inflectional modification of the words, with the object

(a) to determine, by the inflected forms themselves, the nature of the connection (patri librum dat)

(b) to indicate, by agreement in form (concord) their association (anima candida).

To this is added the following comment: «It goes without saying that the two last-mentioned means could be evolved only gradually during a long period of historical development; while the five first are, from a beginning, at the disposal of the speaker. But also 2 to 5 are not always only determined directly by the natural course of the ideas, but are susceptible of being traditionally developed.»

The historical dividing line, if I may so express it, which Paul draws here, theoretically, between section 5 and 6 , falls, for Isinai, one section farther ahead, viz, between 6 and 7 , provided that under 6 , the class of connectives represented by auxiliary verbs is stricken out. Isinai syntax operates with connectives, ${ }^{1}$ ) or, as I have called them, particles of relation, but, whatever be the rudiments of inflection one may find in its word-forms, a systematic inflection comparable to the classical examples above given has not yet been developod in this language. Thus, at the historical moment where in Isinai sentence-construction the need is felt of a formal expression of pure predication, it

1) Cf. Paul's definition (p. 294): "Verbindungswort nenne ich ein Wort, welches die Funktion hat das Verhältnis zwischen zwei Begriffen anzugeben, welches daher auch nur neben zwei solchen Begriffen funktionieren kann, so dass es weder für sich noch auch bloss mit einem Begriff verbunden etwas Selbständiges darstellen kann." 
is a particle that takes the place of the English copula «to be», and it is particles, more or less loosely attached and more or less intact in sound-form, that meet the requirements which are pointed out in the above synopsis under $7 \mathrm{a}$ and $7 \mathrm{~b}$ as the principal aims of inflection. If, in spite of this absence of inflection, Isinai word-forms and sentences have a distinctly assertive energy, they derive this in great part from the vigor of the particles employed, which, as indicated above, show themselves clearly as of emphatic or demonstrative origin.

\section{III. - Three fundamental types of construction.}

$\S 27$. Upon first taking up the study of Isinai syntax in quest of light on its particles of relation, I propounded to myself, as guides for my work, these two questions: "By what simplest means is the declarative sentence formed?» and «How is the simple declarative sentence enlarged?» In other words, I directed my inquiry, first, toward the relation of subject and predicate, and, second, toward all other relations arising upon a nearer determination of either of these two chief parts of the sentence.

I soon found that such a division, profitable as it proved for obtaining the specific information desired, fits the Isinai system of sentence-construction organically only in part, that is, for but one class of sentences. For others, that is, for certain classes of sentences of more primitive construction, it could be maintained only at the expense of organic cohesion. In these sentences the relation of subject and predicate exists as a result of logical consideration, not as a matter of distinct grammatical expression. Grammatically considered, the sentence partakes more of the character of an attribution than of that of a predication. This will be understood, if it is realized that the general absence of finite verbal forms, which are the main spring of the predicative character of our sentences, is supplied in Isinai by particles. Inasmuch as these particles serve to produce - as some do - a subject-predicate relation as well as attributive combinations of words within the sentence, they obliterate the line of demarcation between these categories and indicate also for the former an attributive character. This is the reason why in the following discussion of Isinai syntax, certain particles, which at first appear as elements answering the inquiry into the rela- 
tion of subject and predicate, appear again later where the combination of words forming a secondary part of the sentence is looked into.

$\S 28$. Among the various relations into which the Isinai language brings its nouns, three fundamental groups of construction can be distinguished, according to the following characteristics:

The first is characterized by the particle n. As this sound can, however, be made use of only after nouns with vocalic ending, it shares its office, in the absence of such ending, with simple juxtaposition as an alternative means, of bringing two nouns into the same relation as by $\mathbf{n} .{ }^{1}$ ) This has been already mentioned and illustrated in $\$ 21$. Either of these two alternative means is replaced, in certain cases which will become apparent later, by the particle an, which, in consonance with its fuller form, has also a greater expressiveness than $\mathbf{n}$, so that, while embodying the $\mathbf{n}$ relation, it possesses a distinct value of its own.

The second group is characterized by the particle si (enclitic form t), with the particle ri or di (enclitic form r) as a collateral.

The third is distinguished by the particle ot, occasionally replaced by ya.

Of these three fundamental groups of construction, the third is that which in the preceding paragraph was alluded to as forming the only class of sentences lending itself openly to that distinction which to us generally appears so clearly drawn in grammar, namely, the relation between subject and predicate as different from other possible relations. It is the one that outwardly most nearly approaches our sentence formation, in so far as its characteristic particle ot plays, more or less, the part of our copula "to be."

The two other forms just specified lead, with limitations, likewise to the formation of sentences, though of sentences having a much more primitive character. Characterizing them both together, they cover, as indicated above, predicative, as well as attributive, relation in a way tending to obliterate a distinction between these categories. Between them, they put a common stamp on all such varieties of syntactical combinations known to our grammar as appositional, adjectival,

1) Note here that, when, in the following pages, the $\mathbf{n}$ relation is spoken of in general, this alternative is always understood. 
adverbial relations, prepositional and participial phrases, relative clauses, etc. Comparing these groups with one another, it is found that the one, characterized principally by $\mathbf{n}$, indicates, at the bottom, a near, that characterized mainly by si, a more remote relation. Only the genitival relation finds a distinct expression by a combination of both particles or of their allies.

\section{IV. - Inquiry into the formation of the simple declarative sentence.}

The an (n) construction. ${ }^{1}$ )

$\$ 29$. The particie an used as a connective in a sentence consisting of only two nouns does not indicate a relation between these equal to that of subject and predicate.

In $\$ 6$, the sentence neir ánd̀- $\iota$ was used as an example, and was explained as meaning "There is absence: offspring my;" This same sentence may, without any essential difference in meaning, and simply as a slower and, consequently, clearer mode of expression, take this form: neir an ánd̀- $\iota$. In this form an discharges the office of expressly proclaiming or declaring the relation between the two apperent members of the sentence neir and anda- $u$, which in the first form found no other expression than trough their mere juxtaposition. It would, however, be an error to compare this relation with that expressed by the copula in English "Non extant is offspring-my", much as such a rendering would be favored by the sense. The main predicative force of the sentence lies in neir (<naír) as a sentenceword (compare napi-dai, § 24), meaning "There is absence» (or "void», "nothingness»), and the following 'and $\bar{c}-u$ is but a determinant of that antecedent, that is, of the idea of absence expressed by the component part ir of neir. In neir and $\dot{a}^{-} u$ this determination is latent, in neir an ánà- $\iota$ it is expressed. The first may be represented, as done above, by: There is absence: offspring-my; the second by: There is absence, viz. (or: that is) offspring-my. The essential characteristic shown by an in this example - and not only here, but wherever we shall find it later - is that it

1) In connection with this section, the reader is, for collateral information, referred to Kern's "Bijdragen tot de Spraakkunst van het Oudjavaansch: Over 't gebruik van $n$ en an als bestanddeelen van een volzin" (B. T. L. V. Ned. Ind., 7e Volgr. V). 
helps to determine (explain, describe), wath a predicative force of a secondary degree, an antecedent word.

A further illustration of this character of an is found in another kind of combination of two nouns, viz. in the junction of what European grammar calls a "predicative attribute» to a sentenceword implying an agent. English "He has returned alive» is in Isinai Immuli an matalu (immuli one returned, supply "He is"; matahu one alive). Here immuli is again a sentence word in the sense explained in $\$ 24$, and the third person implied by it is described, with the words an matahu, thus: "as one alive». Similarly : immuli an nangasawa he has returned as one married. ${ }^{1}$ )

$\S 30$. The two Isinai sentences quoted at the end of the last paragraph receive through an the same character of slow clear speech that was mentioned above in connection with neir an $a n d-u$. Like the latter they may be pronounced also in a readier way, though not, as in the above case, with mere juxtaposition of the two nouns, but with the substitution of enclitic $\mathbf{n}$ for an, a difference which, upon comparison, is seen to coincide with a difference in the final sound of the antecedent:

\section{Consonantal final}

neír an ánà-u

neír ánà-u (mere juxtaposition.)
Vocalic final

immuli an matahu

immulin matahu (enclitic $\mathbf{n}$ ).

The fact, then, that the sole difference between immuli an matahu and immulin matahu is what may be called a rhetorical one, and that the same difference is found to characterize the alternative employment of an and $\mathbf{n}$ in general, wherever they may be exchanged at all, makes enclitic $\mathbf{n}$ appear as a representative of an shorn of its measure of predicative force (embodied in a?) and with only its associative energy left. I shall have occasion to return to this point later on.

$\S 31$. By not restricting our sphere of observation to the case where only two nouns are joined by an, its function as a connective in descriptive combinations of words can be amply illustrated. I take the case in which, upon the question *What kind of person was it ?», the appearance of an individual is to be described. In English this might be done, for example, by

1) Note here that Isinai often prefers a construction the reverse of English. This seems to be the case when a very striking feature is to be described: nanaxtax an immuli, running he came back; nangkabayun immuli riding he returned. 
the following words: A boy, lame, dirty, with red hair,... which is in good Isinai:

Unga an napi-dai, an maavihan, an mandiritò di bî-nar ${ }^{1}$ ) and which is a cumulative description of inherent and adherent qualities, susceptible, as far as grammatical construction is concerned, of being prolonged ad libitum. The several members are in Isinai, the same as in English, separated by more or less marked pauses, according to the greater or lesser celerity with which the different ideas present themselves before the mind of the speaker. Only the first two are more immediately joined, and as in English, instead of "A boy, lame», we might begin "A lame boy", so also in Isinai we may substitute Unga an napi-dai by Ungan napi-dai. Another similarity with English consists in the fact that in both languages the string of descriptive words often receives a final rounding off by a remark having, through its concluding position and more comprehensive sense, greater rhetorical weight than the preceding single members. In the case taken for example such an addition would be made in English with the help of a relative clause, thus: "A lame boy,... whom I do not know," while Isinai uses again an: Ungan napi-dai .... an uria an $a m t a{ }^{2}$ ). Here the predicative force of an before uria becomes especially vivid through the final position of the phrase and the fuller sense. Taking the whole sentence thus modified:

Ungan napi-dai 1, an maavihan 2, an mandiritò di bî-nar 3 , an urià an amta 4 ,

we have a series of words which are, but for one pair, all connected by an or $\mathbf{n}$, in a rather monotonous manner, but which group themselves, by their order and by the sense they convey, into four sections (distinguished in the above sentence by the numbers 1 to 4 ) thus:

1. Antecedent: ungan napi-dai, two coördinate nouns determining each other, and giving through their union a more concrete sense than each by itself;

1) Unga young one, maavihan dirty, mandiritò red, bû.nar hair-his + ar: the last three words form a nucleus by itself, belonging to the di construction of which I shall speak later.

2) Uria (<*urian-ko) my object of negation; "negation" determined by "an amta" (amta know) = not knowing, ignorance; thus urià an amta object of my iynorance. The radical of urian is very probably the same $r i$ occurring in mari (Ilk. madi) "to be not", and also, in metatletical form, in neir. 
2. and 3. Determinants of the antecedent;

4. Concluding determinant with greatest measure of predicative force.

In this arrangement, the functional difference between $\mathbf{n}$ and an, which was said above to be a rhetorical one whenever they may be used alternatively, appears more marked. Enclitic $\mathbf{n}$ in section 1, used als a formative element of the compound antecedent, might be replaced by an in case the first word ended in a consonant or diphthong (napi-dai an unga), or, less usual, by mere juxtaposition (napi-dai unga). On the other hand, an, introducing section 4 has, as pointed out above, an especially marked predicative force and must under all circumstances be. retained.

§32. An assemblage of words as in the example used in the last paragraph may, or may not be called a "sentence" in English. That depends upon the definition given to that term and is a question that may be set aside here. It is a fact that the same outward construction is used in Isinai where the subject of the discourse is not, as in the above mentioned example, understood from a previous question, but introduced within the construction; that is, in cases where English formulates what is ordinarily conceived as a sentence.

For instance, a native, showing a traveller over a locality, remarks, by way of information, and without any previous question: Deén tahu an neir nangamta, an natói si gerar, an niluvì sitú ${ }^{1}$ ) meaning;

Many people, there are not any who know them, who died in the war, are buried here.

That this utterance may be in Isinai a complete statement does not depend upon any grammatical requisite. It depends, from the viewpoint of the speaker, on whether or not a piece of intelligence has been satisfactorily conveyed by him, so that, having uttered all he desired to say, he allows his voice to drop; and, from the viewpoint of the listener, on whether his expectancy of hearing something new is, or is not, satisfied to a reasonable degree. If it is not satisfied, the listener would demand a con-

1) dee idea of many, much (the alternative forms dadaé and dadé for "parents» point toward a sort of vowel harmony in deé; ef. Ilk. dakél, Bat. rakix) tahu, person; nangamta, one who has come to know; natoi, dead; gerar (Sp. guerra, + ar), the war; niluvi, what is buried; siti, here. 
tinuation by an inquisitive: $A n$ ? (English: Yes?), inducing the speaker thereby to continue his explanation. Already the words: Deén tahu an neir nangamta an natói si gerar are under circumstances sufficient to constitute a complete piece of news to the effect that "Many unknown people have died in the war». In this latter sentence the attribute: an natói si gerar, which in the first sentence was (in the English translation) a relative clause ("who have died in the war»), is now, (in like translation) the predicate ( haye died in the war»). Giving priority to the second shorter sentence, I may express this also thus: What in one sentence is the predicate becomes, through addition of a further determinant, degraded to an attribute in the other.

$\S 33$. To show how occasionally an is relieved by a particle on (etymologically related to an?) which corresponds to English "and», I give a number of alternative forms of the example used above for the description of an individual:

1. Ungan napi-dai, an maavihan, an mandiritò di bî-nar

2. Napi-dai an unga, an maavihan, an mandiritò di bî-nar

3. Maavihan an unga, an napi-dai, an mandiritò di bî-nar

4. Ungan napi-dai, an mandiritò di bû-nar on maavihan.

5. Ungan mandiritò di bû̀-nar, an napi-dai on maavihan.

In form 4 on is used between bî-nar and maavihan because the use of an would connect here the idea of dirty (maavihan) with "hair-his», while the intention is to refer it to "boy» in general. In form 5 the sence of napi-dai (lame) prevents any misunderstanding in this connection and on, connecting without comma (pause) the last two attributes, reflects here a readier manner of describing

$\$ 34$. As a result I have, therefore, that the particle an is, in sense, explanatory. When connecting two single nouns it does not constitute such combination into a simple declarative sentence, but only comments upon the antecedent noun by introducing a descriptive or otherwise explanatory attribute. When encountered in repeated use in a longer series of words, it shows a tendency to develop its force in two different directions. Near the beginning it becomes (preferentially in the enclitic form of n) a mere associative element (Bindesilbe), helping in the composition of the antecedent; nearer the end it turns to account its predicative force and acts as a relative pronoun acts in English, or even finds itself lifted into something like the position 
of a predicative particle, not so much by its own force as by virtue of the sense of the whole utterance.

Grammatically an (n) produces an attributive apposition. The combination established by it is a relation in the sense of connection, not in that of reference.

Owing to the method adopted for the present investigation, as characterized in $\S 27$, the particle here described will be found treated again in the section devoted to the enlarged sentence. Here a few remarks may find place on the probable e.tymology of an.

$\S 35$. I believe an to be but another form of the particle na.

Of different observations that have led me to this belief I mention the fact that the identical place occupied in Isinai by an may be found in Tagalog occupied by na. The attribution, for instance, of the idea "good" to that of "man" is expressed:

In Isinai by tahun mevvés, or by tahu an mevvés

In Tagalog by ta-ong mabuti or by ta-o na mabuti.

These groups of forms differ in meaning only in the greater explicitness of phraseology in the case where the attribution is made by Isn. an, Tag. na. Compare English "good man» and "man that is good.»

Another illustration of the fact that this particle occurs in different dialects in the same place, now in one form, now in another, and which at the same time shows such mutability to be common to other particles is the following:

"There is not, is in Pangasinan andi, in Isinai nair, usually pronounced neir. Both expressions seem to me to be built with the same root particles though these appear in each case in inverted form:

\begin{tabular}{c|c}
$a n$ & $d i$ \\
\hline$n a$ & $i r$
\end{tabular}

In both expressions the first element furnishes mainly the assertive force, so that the second must be taken as embodying the idea of negation, which also in a number of other dialects is thus expressed. This negative meaning of $d i$ (三ir) seems to have arisen, however, only secondarily. Its primary meaning is suggested by the inverted forms $\breve{e} d$ in Pangasinan, $r i(d i)$ in Isinai, which are both demonstrative particles, so that both andi and nair, ignoring their current sense and considering them 
etymologically, would seem to denote the same as the corresponding Tagalog particles mai «there is", and roón (doón) «there» denote in the form mairoón; viz. "there is." Whether or not the contradiction in sense of combinations of etymologically synonymous elements as Isinai nair, Pangasinan andi, on one side; and Tagalog mairoón, on the other, might be explained by considering that the expression "is there» implies, with an emphasis on "there the sense "is not here", I must leave undecided. ${ }^{1}$ )

\section{The si and ri constructions}

$\S 36$. While the general object of association of ideas is achieved in the an ( $\mathbf{n})$ construction by the establishment of a connection between the words expressing them, which connection takes a more mechanical form by enclitic $\mathbf{n}$ and a more explanatory form by an, the particles si and ri achieve that association by establishing a relation in the sense of a reference. They do this by virtue of their demonstrative nature, which may be set forth in the first place.

$\S 37$. Si is found in Isinai before definite nouns as a preposition denoting any possible relation of place. The following examples are from Rocamora's catechism:

nipasax si cruzar was nailed to the cross

limmasun si infiernosardari descended into hell

Amamin uarat viopar Father our who art in heaven

manmeong si uawanón di Diosar sitting at the right of God.

1) Uses similar to those of the particles treated in the foregoing passage occur in the case of a particle appearing in Isinai as.uará, in Pangasinan oala, in Iloko as oadá or addá, in Inibaloi as guará, in Bontok as uoda, and in Ibanag as uuad. This particle has, in all these dialects, the meaning of athere is notn. The word here in question is composed of the two root partieles $u a$ (with variants) and $l a(d a, r a)$. In Pangasinan oa alone means where isn and asomething". On the other hand, $l a$ is generally used in that language to throw a strong and somewhat impatient emphasis on the preceding word. In Isinai, $u a$ plays an important rôle, which will be discussed later, and la is employed as an emphatic particle similarly as in Pangasinan. The interrogatory use of "is there?", is, curiously enougb, reserved for the compound particle uari in Isinai, while "there is" may be expressed by either uara, or, more usually, by dioi. Inverted forms of the two root particles $u a$ and $l a$ are found, for $u a$, as $a u$, in Iloko auan "there is not" (compare also ayau in Tagalog, meaning "I do not like), and, for $l a$, as ad, in Ibanag uuad "there is". Also the Isinai postpositive for definite nouns ar, (ad), may have to be explained thus. 
The explanation of this capacity of si to do service as a universal preposition where English distinguishes different relations of place by special particles, lies in its vagueness. $\mathbf{S i}$ is a verbal indigitation and as such does nothing but point into space. As English lacks, to my knowledge, an equally vague demonstrative, I find no better means of graphically representing its significant value than by substituting for it a pointing finger. For instance, "mountain» is in Isinai ba-iuer (or ba-iyur); si baiurar is 0 the mountain. To express in Isinai con the mountain», one would either have to content one's self with si ba-iurar, vague as it is," or would have to indicate one of the upper parts of the mountain thus: si tahep di ba-iurar 5 ridge of the mountain, or si uddin di ba-iurar wi top of the mountain. Si uddu is the expression which has found most generalization.

The vague pointing of si is often given an aim by the addition of another particle indicating, pronominally, the spot to which the demonstration is directed. Thus siri is "there», sitú "here». Example :

Mî-bus siri. umalit tiı "Sallying there coming here» or, as the

Creed has it: "From there he will come». ${ }^{1}$ )

In this example sitic is seen to adopt, as explained in $\S 3$ (Particles b) the form -t tí. Siri is subject to the same and even to a more extended change. "We went there" is either Immoi ami siri, or, more usually Immoi amit $d i$, in which latter form first si is seen to change (as before in sitú) to an enclitic $\mathbf{t}$, whereupon also ri, following now a consonant, adopts the form $d i$. Adding to this sentence a place-name, we get, for instance, Immoi amit di Manila, "We went to Manila», where the placename appears as an explanatory apposition to $d i$ ( $r i)$.

$\S 38$. The two particles si and ri, with which we have become acquainted, in the examples just given, as two demonstrative elements, si being characterized by vagueness, ri by a determinative force, are made use of for the formation of simple declarative sentences in the following manner:

The speaker delivers himself, in the first place, of the salient point of his communication, the thought uppermost in his mind,

1) Mi-bus has really taken in Isinai, the specialized sence of "from" (cf. French: ’̀ partir de). 
such as that created in him, for instance, by the perception of some phenomenon. With the help of one of the two demonstratives in question, he then refers that dominant idea to another of more general nature, serving, so to say, as a base for the first. In such a case, this second idea would be the material object in, or through which that phenomenon makes itself perceptible. For example:

ná-gou ri beoi-uar; nambutî di y kabayumar burnt p.o.r. house-my tar; run-away p.o.r. horse-thy + ar If in the two events here exemplified, the chief interest of the communication centered, not in the phenomena, but in the objects which they concern, the order of words would be reversed; the objects would be mentioned in the first place and the indication of the accidents would follow, thus:

\section{beoi-uar si ná-gou; kabayumar si nambutî.}

The communication would take this form if the speaker knew that the general fact of a fire, or of a stampede, was a matter of note to his hearer, and because of this, desired to impart the information that the house of the one and the horse of the other were concerned in it. If, however, the house and the horse thus concerned had already been mentioned, and only the identity of these were the interesting point, the communication would be made in this form:

\section{beoi-uar ri na-gózuar; kabayumar ri nambutî-ar.}

Comparing the preceding three groups of examples with each other, and also with the forms in which equivalent utterances would be made in English, three points have to be noted.

First. In the place of the finite verbal forms which English would employ to render any of the Isinai sentences given - as for instance in, "My house is burnt down", "It is your horse that has run away", - we have in Isinai rigid nominal forms (nouns) representing the verbal ideas of "burn» and "run away", objectivated, indefinitely, into "what is burnt" and "what has run away», and, definitely, into "the burnt thing», and "the run away animal».

Second. The noun expressing the dominant idea is always uttered first. If that idea has been called up in the speaker's mind by a question put to him and establishing the topic of the discourse, that noun remains alone. Thus the questions 
"Where is your house?» and "Where is my horse?», are answered in Isinai, under the circumstances suggested in above examples, by the single words "Ná-gou» and "Nambutî». If the objects alluded to in these statements are not understood, they are pointed out to the mental eye of the hearer, so to say, with help of the demonstrative particles si or ri (di), a reference resulting in an attribution of the sense of the first noun to that of the second.

I would compare simple sentences of this construction to such emphatic expressions of ours as «Blessed this day !», «Lucky that man!» and other similar ones. ') These they resemble not only in the disposition of their component parts, but I believe them also, in view of their impulsive character, to share the same origin, namely, emotion, be the latter born from the perception through the senses of some phenomenon, or be it the movement of the mind consequent upon reflection. May I be permitted to translate in this connection a singularly pertinent passage from Wundt's Völkerpsychologie ${ }^{2}$ ): «It is an inveterate habit of grammarians, in cases where, in a declarative sentence of attributive character, the copula happens to be absent, to set this down as an omission constituting, in comparison with the normal complete sentence, a solecism, permissible though it be, under circumstances, for rhetorical reasons. Also here the figure of the "ellipse is resorted to, however far removed from the mind of the speaker may have been the idea of an omission. But the reversed view probably comes nearer the truth: attributive declarative sentences, approaching our emotional sentences through the direct union of the attribute with the subject, occupy, by their nature, a place nearer the primitive form. We shall thus, undoubtedly, be justified in the general assumption of two fundamental forms of the declarative sentence, which even to-day exist side by side in numerous languages in this their primitive form: the attributive sentence, in which an attribute, and the predicative sentence, in which a predicating verb is joined with the subject.

For the development of thought it was an event of the utmost importance that in our culture languages the predicative form of sentence bore the victory over the attributive one. ${ }^{3}$ )

1) Compare, for instance, with "Blessed this day" its Isinai equivalent Mapear di ehawar tie, or, less emphatic, Mapear di satien ehau. In the latter form the suffix ar to ehau is superseded by the combination of this noun with the demonstrative pronoun satie.

2) II. Band: Die Sprache, p. 277.

s) Italics are mine. 
Third. The reference from the first object of thought to the second, if the latter is definite, is made by ri (di), if it is indefinite by si $(\mathbf{t})$. This distinctive employment of the two particles of relation is quite in harmony with their individual character as set forth in $\$ 37$. The phonetic change to be observed in the form of each particle will be dealt with in one of the following paragraphs.

§39. The examples so far given contain the words «ná-gou» and "nambuti" in this their indefinite, and also in definite form with suffix $a r$. The presence of words which, like these, are, through their composition with particles of an assertive force, specially apt to form by themselves a sentence, is, however, not at all a requisite for this type of construction. Compare, in this respect, the sentence: Ayu ri lamesá-ar (or Ayur lamesá-ar) Wood + p.o.r. + table + my + ar, My table is of wood, a statement which, in answer to a previous question "Of what material is your table?», would take the simple form of "Ayu».

$\S 40$. In fuller illustration of the present construction, I give in the following a series of examples, grouped into various combinations of expressions for objective, verbal, and qualitative ideas; in definite and indefinite (or abstract) form, and with transposition of the two members to show the change in sense. I comment these examples, and, in so doing, introduce, for a better understanding of the sense, questions real answers to which would usually consist simply of the first member of the combination.

I.

Sin-iliar ri presidentéar The-Igorot p.o.r. the-president. Sin-ili ri presidentéar Igorot p.o.r. the-president.

The first of these sentences may be conceived as an answer to the question «Who is the president, the Igorot or the Iloko?»; the second, as an answer to "Of what tribe is the president?» ( Presidente» is the Spanish form of the modern official title of the chief executive of a town administration).

II.

Manaxtax di lámanar Running (or: one running) p.o.r. the-deer Lámanar si manaxtáx Láman di manaxtáhar Deer p.o.r. the running-one. 
The first sentence simply states, «The deer runs». The second distinguishes the deer, as something already spoken cf, from some other animate being also likely to run, as if in answer to the question «Which (of two or more) is running?» The third declares a certain being, which has been noted running, to be a deer, as if answering the question \&What is it that is running there ? As previously explained $(\$ 4)$ the abstract noun láman has merely a descriptive value, the oneness of the individual, indicated in English by the indefinite article, is not considered and, consequently, not expressed.

Other examples of this group are:
Cuarta si in-atór-u
Money p.o.r. gift-my
Cuarta ri in-atór-uar
Money p.o.r. the-gift-my
In-atór-u ri cuartar
Gift-my p.o.r. the-money.

The first statement is in English, aI have given money» with some accent on «money», as in answer to the question:. «How did you settle the matter?

The second makes the same statement, but shows, by the definite in-ator-uar, that the fact of something having been given is already a matter of note, as in reply to the question: «What was it you gave?» The third emphasizes the fact that the speaker has handed over money, but does not distinguish whether it is a certain sum of money ( $\alpha$ the money») or «some money», since Isinai, as will be explained, can have here in the place of «money », only the definite noun.

\section{III.}

Mevvés di óhomar

Óhomar si mevvés

Óhomar ri mevvésar
What-is-good p.o.r. the-governor

The-governor p.o.r. what-is-good

The-governor p.o.r. the-good-one.

While the first sentence simply gives an opinion on the character of the person in question, ( What man is your governor $? \times)$, the two following ones show, through the emphasis carried by «óhomar», that they make a comparison with another person (or persons), answering thus questions which, to bring out the difference in sense, may be formulated thus: "Who is good, the governor or $\mathrm{X}$ ?» and «Who is the better one, the governor or $\mathrm{X}$ ?» Similarly to be explained are the following. sentences:

Atáx-oi di béoimuar Freely "Your house is high"

Béoimuar si atáx-oi Freely "Your (emph.) house is high" (in comparison to another) 
Béoimuar ri atax-óyar Freely "Your (emph.) house is the higher (or highest)».

In the "last two sentences my teacher compared atáx-oi to a comparative, and atax-oyar to a superlative, adding that the difference in meaning was only slight.

Mevvés di inappiámar

Inappiam di mevvésar

Inappiam si mevvés

Mevvésar si inappiam

Mevvésar ri inappiámar
Good-thing p.o.r. the-work-thy ${ }^{1}$ )

Work-thy p.o.r. the-good-one

Work-thy p.o.r. what-is-good

The-good-thing p.o.r. work-thy

The-good-thing p.o.r. the-work-thy.

The first sentence gives to a certain piece of work done by the person addressed the attribute «good»: "Your work is good». The second says of a certain thing, characterized as athe good one in comparison to others, that it is a work of the person addressed «The best was made by you». The third attributes some work of the person addressed to the category of "what is good» (to the ideal of what is good, so to say): "You have done (it) well.» A construction: * «Mevvés si inappiam» was declared impossible. The two last 'sentences identify a certain good thing with the indefinite or definite work of the person addressed; freely: "You have taken the good thing (perhaps a material, as timber, cloth or the like) for your work», or efor that work of yours.»

$\S 41$. The series of examples given in the preceding paragraph show clearly that, by whatever word-form the antecedent expression for the dominant idea may be represented, the complement is regularly referred to, if definite, by ri (or di), and, if indefinite, by si. One might be inclined to look upon these words as articles, but one should not overlook the fact that they are distinctly syntactical elements. Excepting si in its quality of a personal acticle - cf. Si Mariano ri presidentéar, Mariano is the president - they never head the dominant word at the beginning of the sentence.

$\S 42$. A noteworthy feature of the construction here discussed is the fact that a single abstract noun cannot, except after dioi "there is", take the place of the word to which the sense of the antecedent is attributed by si. Isinai says:

Cuarta si in-atór-u Money p.o.r. gift-my

1) Inappia, completed work; appion, present or future object of work; appia, habit, manner, style. 
Beoi si it-túd

Láman si anô
House p.o.r. dwelling-place-my

Venison p.o.r. food-my,

but it never expresses itself, whether for the same meaning or for any other, in the reversed order: In-ator-u si cuarta, etc. Sentences in this form may be heard, as my teacher informed me, from sin-ili (i.e. Igorot) of the rancherias of Amugen and Pintian when they "hack» Isinai, but the normal language repudiates them altogether. Much less would it be possible to render an English sentence like: "A horse is an animal» according to this construction; *Ayop si kabayu (or Kabayu si ayop) are words conveying, in such combination, absolutely no intelligence to the mind of the Isinai because they lack any substantiality. ') The single abstract noun is, as said above, allowed only after dioi, as for instance in:

$\begin{array}{ll}\text { Diói si tahu } & \text { There is somebody } \\ \text { Diói si apui } & \text { There is fire } \\ \text { Diói si beoi } & \text { There is (a) house }\end{array}$

when these sentences answer questions such as Uarat tahu? Is there somebody?, etc. The opposite of these statements, viz. the declaration of nonexistence would be given, as already explained in $\S 6$, by neir, with or without following an: Neir tahu, Neir an apui, etc.

According to the foregoing, the English sentences "I live in a house», "I live in a forest" can in Isinai take this form: Beoi si it-tía (quoted above), Eas si it-tía ${ }^{2}$ ), that is, with the abstract noun as antecedent, although it would be better to use, in this particular instance, the more substantial definite form and to say: Beoiar si it-túà, Easar si it-tíà. Similarly, in English we may substitute, at least in the latter of these two examples, for the sentence "I live in a forest», the sentence "I live in the forest» without meaning precisely any definite forest. These same two English sentences may also be rendered in Isinai thus: Mit-túà si beoiar and Mit-túà si easar, in which sentences si beoiar and si easar are prepositional phrases added as third members to the binary expression mit-túa (mit-tú, dweller; $\grave{a}$ I; supply "am»), meaning literally "Dweller (am) I in house $+a r »$ and Dweller (am) I in forest $+a r$. But an inversion

1) "The horse is an animal" is in Isinai: Uar kabayuar ot ayop.

2) it-tiù *it-tian ko, my dwelling place; eas, forest. 
of the forms first given, Beoi si it-túà, or Eas si it-túà, into *It-túa si beoi or *It-túa si eas is impossible.

With the restricted use here shown for the single abstract Isinai noun, I compare the use of the English substantive, unaccompanied by an article and not determined as to number or otherwise, as subject of a declarative sentence. As it is impossible in English to say: "House is being built by him», so neither in Isinai is it permissible to use the expression: "*Appiona si beoi "Work-his p.o.r. house». English may say: "Gold is being found by him», but not Isinai. The latter never says: Dinatóngna si balitû, Found-object-his p.o.r. gold, but only Balitû si dinatóngna Gold p. o. r. found-object-his. It is this exclusively attributive use of the Isinai equivalent for the bare English substantive that has contributed to the view I hold of its unsubstantiality as explained in the definition given of the abstract noun in $\S 5$.

$\S 43$. The particles ri and si, in the employment here shown for them, as well as in any other in which they may be found, are subject to the following changes:

(a) After vozuels ri remains unaltered or takes the form of an enclitic $\mathbf{r},{ }^{\mathbf{l}}$ ) according to whether speech is slow (accentuated) or rapid:

Gimpâ-u ri caserolar or Gimphâur caserolar Broken-object-my p. o. r. the pot $=$ I have broken the pot.

Beuóna ri beoinar or Beuónar beoinar Object-of-repairing-his p.o.r. the-house-his $=\mathrm{He}$ is repairing (or going to repair) his house.

Matáhutar apu-ar (matáhutar $<$ matahu $+t a+$ ri) Alive-still p.o.r. the grandfather-my $=$ My grandfather is still alive.

For si after vowels there is generally found an enclitic t, although the language is not very strict in this respect, making use, especially in slow speech, also of si, very much in the same way as in the case of $\mathbf{r i}$ or $\mathbf{r}$ just illustrated; examples:

Tinto si inumô or Tintot inumô Claret (Spanish tinto) p.o.r. drink-my $=$ I drink claret.

Deé si neutu or Deét neutu Many p.o.r. ripe-ones $=$ There were many ripe fruits.

1) not to be confounded with $r$ ar. 
I incline to the belief that this enclitic $t$ is but a changed pronunciation of the first snund of si after the vowel has dropped off. The change from $\mathbf{s}$ to $\mathbf{t}$ is frequently found upon comparing the local pronunciation of the different Isinai towns; for example, «hard is, according to locality, masulit or matniit; ato jump», tepau or sepau; «strongs, matdé or masdé $(<m a+$ soré $)$. This change is also found upon comparing Isinai with outside dialects; for example, Isn., toha, vinegar; Tag., suka; Isn., Unit, tax; Tag. buis; etc. For the transformation of the particle si into an enclitic $\mathbf{t}$, at pleasure of the speaker, a parallel is found in Inibaloi, where the demonstrative element chi takes, in rapid spealing. the enclitic form d. for cxample, guara chiman, it is there, may be heard, alsn, as guarad man. Compare also. in the same dialect, the change illustrated by Sefa si chins? Who is God? and Sefas chins? In other dialects similar charges may be found.

(b) After consonants, including the glottal check, the definite particle of relation always appears as di, the indefinite always as si. Examples:

Luatam di pantawar Object-of-opening-th! p.o.r. the-door = Open the door

Naptor di ayuar Broken-thing p.o.r. the-timber $=$ The timber is broken

Biney'u di beoi-uar Renovated-thing-my p.o.r. the-house-my = I have renovated my house.

Dióilohom si osat beoi-u There-is only p.o.r. one p.o.r. house $\mathrm{my}=\mathrm{I}$ have only one house

Binum-as si $\hat{a}$-a-án What-has-begur: p.o.r. feasting $=$ The feasting has begun

Ahai-hayầ si Maria Object-of-affection-my p.o.r. Maria = I like Maria.

(c) After diphthongs the definite particle of relation shows itself unstable, appearing now as $\mathbf{r i}$, now as $\mathbf{d i}$; si remains unaltered:

Mangá-au ri sin-iliar or Mangá- an ai sin-iliar One-whosteals p. o. r. the-Igorot $=$ The Igorot is a thief.

Natói ri amigonar, or Natói di amigonar Dead p.o.r. the-friendhis $=$ His friend is dead.

$\$ 44$. No particle of relation is employed, nor indeed recpuired, if the object to which reference is made is expressed by a pronoun in itself of demonstrative nature: 
Tahun iaritan tie Man from Aritau this $=$ This is a man from Aritau.

Burui rie Lie that $=$ That is a lie (reference is made to something said).

$\S 45$. If the reference is made to persons who are to be indicated pronominally. particles are made use of which, according to their sound-form, attach themselves more or less closely to the antecedent as personal suffixes:

Isinay'i

Ilollo-a

Makasalanan-ami

Mangkantá-ay'u
Isinai (am) I = I am Isinai

Iloko (art) thou $==$ Thou art Iloko

Sinner (are) we $=$ IVe are sinners

Singer (are) you $=$ You are singing

Mahchéara (Mahelica-ra) Active (are) they = They are active.

$\$ 46$. The construction discussed in the preceding paragraphs and typified by the particles ri and si, serves not only for the declarative, but likewise for interrogative and imperative sentences. The two latter classes are each distinguished of course, by a special modulation of the voice, which, not being markedly different from that used by us, requires no special description. Examples :

Láman si anò is, in current English «I eat venison».

Láman si anóm:" is "You eat venison?", and

Láman si anóm! is "Eat venison!"

Beyirona di bcoinar is "He is renovating (or: He will renovate) his house.

Beyllom di bcoimuar? is "Are you renovating (or: going to renovate) your house?" and

Bcyitom di beoimuar! is "Renovate your house!»

$\$ 47$. Before leaving the discussion of si and ri as elements constituting a subject-predicate relation between two single nouns, I record here an interesting transformation which the sentence thus formed by si may, under certain circumstances, experience, and in which si seems to appear in a new character.

Whenever the reference made by si is directed to an objectivated verbal idea, as for instance, in the sentence Cuarta si dinatóng-u Money p.o.r. found-object-my, the language may broaden this form of speech (which I believe, as stated above, to be emotional in origin) and give to it a quieter, more narrative turn by opening the communication with dió $i$ there is»; thus: Diói si dinatóng-u si cuarta "There-is p.o.r. found-object- 
my p.o.r. money». The material sense of the sentence "I have found money", remains exactly the same, only the affect of the language is toned down by opening the sentence with the commonplace dioi.

Diói has the meaning both of English "to be» and ato have.» The following examples may help to illustrate its use:

Dioiai (dióiyia) si beoiar $1 \mathrm{am}$ in the (nr «a») house

Diói si beoi-uar $\mathrm{X}$ (third person singular) is in my house

Diói si beoi-u I have a house

Diói si asì I have a dug

Diói ri asu-ar These is my dog.

For the value of dió $i$ in Isinai story-telling, compare the comment made on the beginning of the tale "The tortoise and the monkey" given in the appondix.

As regards the grammatical change, which takes place upon the transformation of

\section{Cutarta si dinatóng-u}

into

\section{Diói si dinatóng-u si cuarta}

it consists in that the abstract noun "cuarta" (which in the first form is the attributive predicate to "dinatong-u») cedes its place to the new predicate dioi, and takes, in exchange, that of an attributive apposition to its former "subject».

This apposition is symbolized, nevertheless, by exactly the same particle si which in the first form served to express the predicate-subject relation between cuarta and dinatóng-u and which continues'to express that relation also for the new predicate diói. Note here, then, two interesting facts: first, that the abstract noun cuarta does not, as might be expected, take, like an English substantive, necessarily the place of a nomen regens ("There is money found by me»), but contents itself with the secondary place of a determinant behind dinatóng- $u$, an indefinite noun of the character of a past participle; and second, that the particle si serves to express two kinds of relations which we are accustomed to keep sharply apart: the relation between subject and predicate, and the attributive relation; discriminating as we are in this respect, it appears that here the "attributive» si must have a lesser force than "predicative» si, since, in the first case there is an active and energetic refe- 
rence, while in the second, a mere connection or association is indicated.

It is true that, if, according to the phonetic rule established for si in $\$ 43$, we say: Diói si dinatóng-ut cuarta, the grammatical composition of the sentence becomes clearer inasmuch as the predicative combination diói si dinatóng-u is both formally. and rhetorically differentiated from the attributive combination dinatong-ut cuarta. This, however, is not a safe guide for the grammatical distinction to be made, since we have seen before that also the predicate si may take the enclitic form after vowels:

Tintot inumô I drink claret

Dećt ncutu There were many ripe ones.

In the sentence above taken for an example, it is, then, only the position of the words, together with the significant value of the latter (whether abstract or indefinite) which allows us to judge of the grammatical composition, while, as far as the particle of relation is concerned, the language does nothing to help us make a distinction between predication and attribution. Indeed, what satisfaction we may feel on meeting such a clearly and tersely formed sentence as, for instance,

Tinto si inumo Claret $\$$ what-I-drink,

it is decidedly impaired upon discovering that, after all, that brisk reference made by si becomes, by too frequently repeated use, a counterpart of that wearisome an construction first discussed. I must, in fact, confess to a certain bewilderment upon first discovering that the same sentence, for instance, which was used in $\S 32$ to illustrate the capacity of the particle of relation an for bringing about, in union with 'a number of nominal forms, a complete declarative sentence, can be constructed, with only a secondary change in meaning, by the help of si instead of an. To facilitate a comparison, I arrange the two constructions thus possible side by side:

$\begin{array}{llc}\begin{array}{l}\text { Dén tahu } \\ \text { an neir nangamta }\end{array} & \begin{array}{l}\text { Dét tahu (t) } \\ \text {-t neir nangamta }\end{array} & \begin{array}{c}\text { Many people, } \\ \text { there are not who } \\ \text { know them, }\end{array} \\ \text { an natói si gerar } & \text { si natói si gerar. } & \begin{array}{c}\text { who have died in } \\ \text { the war, }\end{array} \\ \text { an niluvì sitú } & \text { si niluvì situ } & \text { are buried here. }\end{array}$

The only difference which my teacher could point out to me between these two constructions consists in the value of the 
antecedents: doin talu means, according to him, "so many people that they cannot be counted", while deét tahu has just the literal sense of "many people». It may be concluded from this that the closer association of ideas effected by $\mathbf{n}$ produces an expression lending itself to a specialization of significance (here perhaps, to be rendered by an expression like "a human crowd"), while the connective $\mathbf{t}$, born from the demonstrative si, keeps the two ideas involved clearly apart and thus prevents a similar change. This conclusion is in keeping with the distinction found for os ín and osít in $\$ 23$. For the rest, it may not be inferred from the above two constructions that the form of the antecedent, whether characterized by connective $\mathbf{n}$ or by $\mathbf{t}$, sets the type, so to say, for the connection to be observed in the rest of the sentence. This connection may be as illustrated in the above paradigm, but it may also consist in a mixture of the two modes of connection, thus the first sentence may adopt either of the following forms:

Dcén tahut ncir nangamta si natói si gerar an niluvie sitú or:

Deén tahut neir nangamta an natói si gerar si niluoì sitú.

These constructions were declared by my teacher to be entirely equivalent in sense to the one first given, and he was unable to assign any reason for using the one and not the other. Their occurrence is thus an example of the indiscriminate use of an and si of which mention will be made again later.

$\S 48$. To go back again for a moment to the sentence Dioi si dinatóng-u si cuarta, the construction of which was analysed at the beginning of the last paragraph. I was interested in finding cut how the particle si is felt by the language in its different modes of employment, that is, whether it always preserves that original demonstrative force which it has been shown to possess, or whether this is lost, in certain cases, in the change of grammatical function, or in the phonetic change from si to $t$. Giving that particle, as occurring in above sentence, its apparent primitive value, I arrive at the following interpretation:

There is 5 found thing $\mathrm{my}$ money, that is, after the word diói — which takes here the place of the word expressing the dominant idea - there is a repeated pointing out of other ideas without other connection than succession, all going back to the first as a common starting point.

This may very well have been the origin of this construction, 
yet my teacher was unable to recognize - at least at the beginning of our sessions - any special value for the particle si as here employed. The force of the same particle in a phrase like: si ba-iurar he interpreted readily enough by pointing to a mountain; but of the value of $\mathbf{t}$ in dinatóng ut cuarta, dećt tahu, etc. all he could say was that these phrases without the enclitic $t$ "would sound very badly." Considering, on the one hand, the energy of the particle si as represented above, and, on the other, the considerable mutilation which this particle undergoes upon being converted into the voiceless mute $\mathbf{t}$ attached to words with vocalic ending, it is evident that, insignificant as it may outwardly appear in this latter form, its omission would cause the language to become - in the words of Totanes "not only insipid, harsh, and uncouth to the ear but to remain without substance for the intellect."

\section{The ot construction.}

$\S 49$. The ot construction, the third of the three fuudamental types in the syntactical arrangement of Isinai nouns, is that which at first glance appears most familiar to us inasmuch as it closely corresponds, in many cases, with those simple declarative sentences which we form with the help of the copula "to be", such as The rose is red, The earth is a globe.

Of these latter Wundt ") holds that they are really thought attributively and only given a predicative form, with the help of the copula, after the pattern of purcly predicative sentences formed with finite verbs. Respecting the copula, «which in the majority of the languages does not exist at all, he says ") that in view of the abstract sense which, in our languages, the verb ato be» has taken as copula, there must, in the course of development of these, also have been a time when a copula was not in existence. *How, then, at that time, was its place in the predicative sentence filled? Looking at the languages which to-day still lack the copula. that question is with great probability to be answered thus: Where with us the copula has made its way into sentences in which a narrative character predominates, there in all probability a finite verb of more concrete thought content generally took its place. On the other hand, where to-day we connect with the subject a purely attributive

1) Op. cit., 325 .

2) Op. cit., p. 276 . 
predicate. there the old language must have formed altributive sentences without verb, cxactly as even to-day we form our emotional sentences in many cases This could be done so much more easily as here a direct attributive connection is entirely sufficient to give expression to the thought-content of the sentence. The copula, indeed, does not add in the least to the real content of the sentence; its function is quite exclusively a formal one. which is none other than to transform the originally attributive expression inlo a predicative one. In so doing, it is, however, only the outward form of the sentence which becomes predicative; in value the batter remains altributive».

I have reproduced this passage in literal translation in order to allow the reader the better to judge of my conception of the ot construction here to be treated as involving that class of Isinai sentences which most nearly approaches the predicative form.

$\$ 50$. The first example used in illustration of the si and ri constructions was

Ná-gou ri beoi-uar Burnt p.o.r. house-my $+a r$.

Of sentences of this class, it was said that, born of emotion, they were emphatic in character. Now, the same sentence, and any other formed like it with the particle ri (di), can be given an essentially different form, which - while preserving exactlythe same sense - connotes, according to the circumstances of the case, a slower, more deliberate, more doctrinal, or a more courteous mode of expression. For the present example, this form is

\section{Uar beoi-uar ot ní-gout.}

Is this form the outward arrangement of the words, the previous mention of the subject of speech, and the introduction both of this subject and of the following. predicate by special particles indicate in themselves a greater composure of language. An appropriate rendering would be: That house of mine, it is burnt; or, shorter, My house is burnt.

$\$ 51$. Other examples of this construction, grouped so as to show the rôle which different classes of words play in it, and freely rendered in English, are the following:

I. Expressions for objectival ideas.

Uar presidentear ot iloho The president in an Iloko.

Uar óhomar ot aputa-uar The governor is our chief. 
Uar beoiynar ot tinabla

Uar panescuelínar ot pader
Your house is of boards (Span. tabla).

The schoolhouse is of masonry. (pader < Span. pared wall).

II. Expressions for objectival and objectivated verbal ideas.

Uar huesar ot umali

Uar ivei-ar ot mangappiat beoi

The judge (Span. juez) is coming.

$\mathrm{My}$ brother is building a house.

(literally: is builder-respecting house).

Uar appionar ot beoi

Uar asuar ot pinatóinar

Uar áyandar ot payázuar

Uar sinaliz-uar ot gurabis My purchase is matches.

III. Expressions for objectival and objectivated verbal ideas.

Uar céngardari ot nammahún

Uar mandiritio-ar ot savung.

The clothes are dry:

The red thing is a flower.

Uar irupaliar ot naununa

Uar natóyar ot tagalur

Uar bî-uar ot mandirítò

The man from Dupax is the first.

The dead man is a Tagalog.

$\mathrm{My}$ hair is red.

\$52. An examination of the preceding examples shows the subject to be in every case a definite noun. In the predicate, however, there may appear definite, as well as indefinite and abstract word-forms. This is characteristic of the construction here under discussion. As will be seen, the place of the subject may also be taken by personal names or by pronouns, but never by an indefinite or abstract noun. Sentences like: "Rice is a plant", "Good water is the best beverage», can be rendered in Isinai only by giving the subject the definite form, thus: Uar pahoyar ot itanom, literally, The rice is object of planting, and Uar malitingar danum ot mevvés inumón, literally, The clear(thing) water is good(thing) object-of-drinking.

Apart from this distinction between subject and predicate it is mainly by the use of the two particles uar and ot that this construction is given its peculiar stamp, and an elucidation of these particles will be likely to show how the language arrived at building up this class of sentences.

$\S 53$. Respecting uar, it must before all be stated that in its 
place there is often found what appears a fuller form of the same particle, viz, uari. This latter seems to be used, at times, merely as an altemative of uar; at others, it carries with it a somewhat greater particularization respecting the noun following. For instance: Uar danimar ot maliting is: The water is clear, but may, according to the usage of the definite noun repeatedly. pointed out, also mean: Vater is clear. Uaridanimar ot maliting, on the other hand, could not be understood in this latter sense on account of a sharper specialization produced by the fuller form uari '.)

The existence now, side by side, of these two forms with no more important difference in meaning than is commensurate to their difference in sound, suggests in itself their close relationship. Comparing their composition, we are at once reminded of the particle ri which after vowels changes to $r$. If it could be shown that a syllable ua exists as an independent particle in Isinai, the formula uar $<$ uari $=$ ua + ri might be taken to have been demonstrated. It is, now, easy enough to produce such sentences as:

Uat ama ot natoi Father is dead.

Uatie ungar ot mahaté poldi This child is mischievous in the extreme.

Ua $i$ Fuan ot malastos Juan is a spendthrift, (Span. gasto, expense)

Ua $i$ Vicente ot immoi Manila on ua $i$ Maria ot immoi Pangasinan Vicente has gone to Manila and Maria to Pangasinan.

Ua irâ-mi ot ilián on ua irâ-yu ot mayman lVe are common people and you are rich people.

'These sentences show the element ua clearly as an independent particle. In the first example, it has experienced an accretion of sound, not by $\mathbf{r}$ as in uar, but by enclitic $\mathbf{t}<\mathbf{s i}$, which is here the personal article for ama, father. In the second, it is joined to the demonstrative pronoun tie, this, which otherwise occurs also independently. Lastly, in the third, fourth and fifth, we have it in its bare form ua, followed in the third and fourth by a particle $i$ which, being written in the fifth as a proclitic, is a demonstrative element forming, with personal names and pronouns, what might be called an "oblique case». In all these examples, ua occupies the same characteristic position in which

\footnotetext{
1) For generalization of meaning concument with rotrenchment in form, compare Ge man am Tage, with an dem Tage.
} 
it was found in the beginning; viz, at the head of the subject from which, as we now clearly see, it is separated by such demonstrative elements as $r, r i, t(s i), t i e, i$. Only before place names is such an element absent; for example, in Ua Aritau ot bebeoi, Aritau is a town, a peculiarity which such names show also in other combination as in immoi Manila, one gone to Manila.

As to the primary significance of ua, the language gives me no indication. In $\$ 35$, a reference was made to oa in Pangasinan, probably the same particle and which may be surmised to mean something like "thing». From the employment of ua in Isinai, as set forth above, the conclusion may be drawn that, together with the demonstrative following, it exercises an isolating force and gives to the subject a position comparable to that which English gives to the same part of the sentence by such expressions as: regarding, respecting, as for, as to, etc.

In making this comparison, allowance will, however, have to be made for a considerable loss in the primitive isolating force of the Isinai construction through the constant use made of it. Where uari is used, the isolation may be felt somewhat more distinctly. In adversative sentences, such as the fourth and fifth example above given, uari obtains fullest force. But uar, as commonly used, introducing the subject of simple declarative sentences bearing no particular emphasis, was declared by my teacher to mean no more than the ordinary subject-indicating English "the». If, then, we look upon ri (which, by the way, never alone introduces the subject) as by itself a fair ety-mological equivalent of English "the», it is interesting to observe what additional syntactical energy (represented by ua) is required in Isinai to lift the definite noun into the place of a grammatical subject. ${ }^{3}$ )

$\S 54$. In the place of the subject we find, instead of a common name, often a proper name or a pronoun. These present themselves in such position invariably preceded by an article or an article-like prepositive.

(a) Proper names. The case of personal and place-names preceded by ua has been already illustrated in the last paragraph by :

1) Readers having a knowledge of the Japanese language will be struck with the identity of function which the postpositive wa has in that language. 
Ua $i$ Fuan ot mahastos

Ua Aritau ot bcbcoi

Place-names were said to be exceptional and to require no demonstrative. Regarding personal names, I observe, as so often in Isinai, a vacillation in the language. Instead of the first of the two sentences just quoted, either Si Fuan or Uat Fuan of mahastos may also be said. The former was declared by my' teacher to be the least recommendable. Between Uat Fuan and Ua $\mathbf{i}$ Fuan a difference exists in that the latter throws a stronger emphasis on the personal name so that, under certain circumstances, it might come to acquire a particular meaning such as, for instance: Juan himself is a spenclthrift.

(b) Personal pronouns. The form taken by personal pronouns as subjects opening a sentence is illustrated in the following examples:

Saon ot isináyà I am an Isinai (saon probably $<s i+a(k)+o n$ )

Si-a ot masugal-a Thou art a gambler

Sia (siya) ot umali $\mathrm{He}$ is coming

$D a$-ami (or Dî-mi) ot malinawa ami We (exclusive).are happy

Dita-u ot and Eva IVe (inclusive) are children of Eve

Dita ot masa-it-ta Thou and I are poor

Da-ayu (or Dô-yu) ot tagalur ayu You are Tagalog

Dira ot immoira Manila They are gone to Manila

If in any of the preceding, or in similar sentences, it were desired to lay special emphasis on the pronoun, as for instance in adversative use, in such a case ua with following $\mathbf{i}$ would be resorted to: Ua i saon (Ua isaon) ot isinayà, Ua i si-a (ua isi-a) ot masugal-a, etc. Note that all examples show the personal pronoun twice; once, in the stem-form at the end of the predicate noun, and once, opening the sentence as subject in a form enlarged by the anteposition of $s i$ in the singular, and $d i$ or $d a$ in the plural.

Only the third person singular is never thus doubly expressed. As a matter of fact, also in the remaining cases the repetition is not absolutely necessary. As they stand, these sentences are somewhat heavy and throw a decided emphasis on the subject. In ordinary unaffected speech such statements would be heard in the form given in $\$ 45$ under the si construction.

Regarding the prepositive particles, si and $d i$, I believe theymay be safely set down as being originally demonstrative in character. 
(c) Demonstrative pronouns. These, too, take, when opening the sentence as subjects, an enlarged (emphatic) form. The following examples are designed to contrast this enlarged form with the radical one:

Andie tie:' What is this? (pointing)

Sátie ot awali This is a frying pan

Andio rió: What is that? (pointing)

Sario ot taliumbau That is a castor-oil plant

Andie ric.- What is that? (reference is made to something said)

Sárie of lámanar binarilmi It is about the deer we have shot If, however, the opening demonstrative pronoun is not used in answering a question like those here formulated, but is at the commencement of a sentence introducing new matter of thought, or if it is used adversatively, then a combination of the stemform of the pronoun is made, not with sa, but with ua. A distinction, however, between the forms with sa and those with ua is not always very clearly to be drawn. I attempt to bring it out in the following examples:

Sátie ri otc̀-uar; uatie ot inappian si sin-ili This is my woodknife; this other is made by the Igorot

Sário ot Pis-ungar; úario ot libbu That is the (montain) Pisungar; that there is a cloud

Sárie ot sesséuna That is a joke of his

Uárie ot bumi As for that, it is a lie.

$\S 55$. The examples given in the preceding paragraphs show plainly that the subject is alway's introduced by an expression which may be in the nature of a single demonstrative, but more often and preferentially is in the form of a combination of particles which emphasizes the subject by isolation and whose characteristic element is ua.

Turning now our attention to the other particle which characterizes these sentences and after which I denominate the construction under discussion; viz, ot, we find this has, so far, occupied the position of an intermediary between the subject and the predicate noun. Since the former is introduced in a manner calculated to arouse in the hearer a certain expectancy, and since this expectancy finds its gratification in the predicate noun, there would seem to fall upon the intervening ot the role of an element of assertion similar in function to our copula. Before attributing to it this character definitely, however, it is 
necessary to consider still other modes of employment which it finds.

In the first place, it not only occurs in such clearcut simple declarative sentences as have been produced hitherto, but also in combinations where we would not render it at all, but would, instead, make a short pause in speaking. E. g.

Uar ivá-ar ot appionar beoiar As-for my-brother: work-his p.o.r. a (or the) house

Uar nambeoiar ot pinátoina ri asuar As-for the-house-owner: killed-object-his p.o.r. the-dog (or: a dog)

Ua isia $i$ aran ot pinilinar pungtunar As for-him, the monkey: chosen-object-his p.o.r. top-part-its (See Appendix).

In these and similar sentences ot does not create the relation of subject-predicate in the-same strict grammatical sense observed in previous examples. From the introductory ua up to ot, the whole first part of the sentence is here destined to establish the topic of the discourse. Ot marks a kind of caesura (the colon of my translation) and what follows is an independent construction of the ri type. Ot, then, appears to help here ua in the isolation, that is, the accentuation of the anteponed parts of the sentence. That ot may, under certain circumstances, affect this accentuation also without the concurrence of uar, is shown by the following example. The sentence: "I have bought rice with the money he gave me" is, if pronouced with some stress on the word rice, in Isinai:

Bohás si sinaliu-u si sárie cuartar inatórna Rice p. o.r. objectbought-my p.o.r. that money $+a r$ object-given-his.

But if the same statement were made in English with an intonation responding to the question: "With what funds did you buy rice?», it would have to be rendered in Isinai in this form:

Si cuartar inatórna ot insalinl-ut bohás p. o. r. money + ar object-given-his (ot) has-been-instrument-of-purchase-my-p.o.r. rice.

In this construction the accentuation of the means of buying is obtained by the anteposition of the corresponding part of the sentence and by the following ot: "With the money given me by him it is that I have been able to buy rice". .

In quite a different but probably more original character ot is found in the following examples:

Immoi ami Bayombong ot inila-mir tahuardari Goers we (have been to) Bayombong and seen-object-our p.o.r. the-people (We went to Bayombong and saw the people there). 
Inean amar ungar ot immosnat danumar freely: The father fetched the child and bathed it in the water.

The mere additory role which ot plays here is still more evident in its employment as a connective between numbers.

"Eleven» is expressed in Isinai by simpiu ot os $\ddot{a}=$ ten and one; twelve is simpiu of dua; twenty-three, duampiu ot tiu, ets.

Similarly, "Thirty pesos and forty cents" is tiumpiun pesos ot duan peseta (Span. peseta, twenty centavos).

$\S 56$. The equivalency to English "and》 found for ot in the examples last given naturally suggests a comparison with that other Isinai equivalent of "and» which was introduced in $\$ 33$, viz, on. In order not to digress too far, I will point out here only the probability that ot will be found to have its first sound $\mathbf{0}$ in common with on not accidentally but by an etymological relationship '); and that its second $\mathbf{t}$ bears to the second sound of on the same relation that exists between the two enclitic elements $\mathbf{t}$ and $\mathbf{n}$ which form such an important part of the present investigation. If this view were to find confirmation, the connection made by the particle ot necessarily would be a less intimate one than that by on. Such a distinction is indeed borne out by the examples given for the typical use of on in $\S 33$ and for ot, as a mere conjunction, in the last paragraph.

For a comparative study of the composition and characier of ot, the following reference will be of interest:

As will already have been noted, the piperet, which in Pangasinan remains unchanged, or approaches an $\ddot{o}$ sound, is represented in Isinai by $o$. We may thus compare Isinai of with Pangasinan $\breve{t}$. According to Pellicer, ${ }^{2}$ ) $\breve{t}$ is in Pangasinan a conjunction often used as leading up to, or introducing an adverse criticism which remains, however, unuttered, so that $\breve{e} t$ becomes a kincl of suspension mark followed by a self-imposed displeased silence: for example, Tatazvagen taka, ět...., I am calling you, but (you do not come). In other cases $\breve{e} t$ is used in making an intimation; for example: Alam, ĕt mabli, Take it, but consider it is an expensive (or precious) thing. In others, again. it expresses the displeased astonishment first mentioned in this form: Sika ĕt? You too? A certain similarity in the furce of this $\breve{e} t$ with that of ot in Isinai (where, by the way, ot is

1) The indications are that $o$ has the meaning of "thing".

)A Arte de la lengua Pangasinan, Manila (190i), 206. 
never empluyed as just illustrated) was discovered in an answer of my teacher to the question of how ot was felt by the Isinai. He declared it to be somewhat like an expletive destined to fill up a halting point in the speech so that the following words could be better considered. This explanation is indeed fully in accord with the situation in which a speaker necessarily finds himself after opening his discourse with the particle $u a$, as this has been characterized above.

$\S 57$. From the examples first given in illustration of the ot construction ( $\$ 51$ ), we have come to know ot as a particle, intermediary between subject and predicate, that helps to declare of the former, facts of a character more or less natural, general or current, but which, at all events, are allowed to speak entirely for themselves, ot not adding any perceptible meaning or color of its own. In cases now, where the intelligence to be conveyed contrasts with a previous knowledge, belief, or expectancy of the hearer, a particle stronger than ot, and possessing apparently a certain emotive character, is used. This particle is ya. The following examples, contrasting ot and ya, and freely. rendered in English, will illustrate the employment of this latter particle:

Satun tahu ot makasalanan This man is sinful.

Satun tahu ya makasalanan This man is the guilty party.

Si Fosé ot iloho José is an Iloko.

Si Fosé ya mamaestro José, don't you know, is going to become a teacher.

Sia ot mavutaviutong (or: mavutovittong) He is a (habitual) drinker.

Sia ya mavutavutong He easily gets tipsy.

Uar inánar ot natói His mother has died (recently, after having been known for some time to be sick).

Uar inánar ya natói His mother, why, she died long ago.

Sárion tahu attox ${ }^{1}$ ) ya si Fuan! That man there, why, it is Juan!

If I were to continue these examples; two things would become more apparent: First, the interjectional character of ya, and second, that its use is in a large measure idiomatic and imparts to the sentence a meaning not easily to be deduced from the

1) Attox, like 'Tagalog pali, is an interjectional paricle expressing surprise. 
original (emotive) value of ya set forth above. Like ot, ya does not limit itself to the clischarge of a certain particular gramimatical function, but lends itself freely to the language within its natural sphere of activity, whose raclins may be further determined from the following aclditional examples:

Immoi amit di ya neir dinuirngan mit tahu' '), We went there but encountered no people (lit. : but there-was-not encounter-our-respecting people)

Datóng mi lat di ya nangan ami, IVe had hardly arrived there, when already we fell to eating

Mu mangan-at ma.som ya manátung-a If you eat sour (unripe) fruits, without fail you will become sick

Mevvés si fosé! Boon, mardix ya! José is good! No, he is bad, I tell you $!^{2}$ )

Mevvésà mos ya, I am well already, as you see.

A number of similar examples of the use of ya will be found occuring in the tale given in the appendix. I have no doubt that it is the same particle ya here treated which is found, in identical or inverted form, doing service in a number of other Philippine languages in more or less the same capacity.

\$ 58. Before concluding the present chapter, brief mention may be made of another typical form which the subject-predicate relation takes in Isinai.

This form is not characterized by any special particle, but partakes of the characteristics partly of the ot, partly of the si and ri construction; of the former, inasmuch as it stipulates from the beginning a definite object as topic of speech; and of the latter, inasmuch as it introduces the second member of the sentence by a reference made with the help of ri, if that member is represented by a definite noun, or with the help of si, if it is represented by an indefinite noun. Since also the first member is regularly pointed out either by a demonstrative pronoun or, at least, by a particle of demonstrative character, the particularity of this form of sentence consists in that the sentence points first in the direction of the subject, and then in the direction of the predicate noun, obtaining thereby in significance,

\footnotetext{
1) dináxngan probably corrupted from dinátngan, (stem datong).

2) In mardix ya, ya might be taken to be-the pronoun of the third person singular, but it lias been said before that no pronoun is used in a case like this. "He is bad" is either Sia ot mardax, or, simply, Mardix.
} 
a comparison or identification of the two objects thus brought into view similar to that expressed in English by sentences beginning with "This is the...", "That is the one which...", "He is the one who...", etc.

The confrontation, made with the help of ri, of two definite objects results naturally in a more definite identification than that made by si of a definite and a indefinite object, which latter is only a comparison of an individual with a class. This much as to the mechanism and general purport of this class of sentences.

The idiomatic usage of this construction will be gathered from the following series of examples:

Sário ri beoi-uar That one there is $\mathrm{my}$ house (establishing the identity of the speaker's house; compare: Sário ot beoi-uar declaring the house in view to be the speaker's property.)

Sátie ri panyuar This (and not that other) is my handkerchief (Span. paño)

Si Fosé ri mata-itanar José (emph.) is the one who inspires fear

Si Fosé si mata-utan José is one the people are afraid of

Saon di sestigoar I am the witness (answering to: "Are you the accused or the witness?» Span. testigo)

Saon si sestigo I am a witness (answering to: "Are there any witnesses?») Compare: Sestigoò, I am witness (answering to: "What are you?")

Dirat mirongongnge They are people who go around listening to what others are saying.

Sirion beoi ri tawir-uar freely: That house there represents (all) $\mathrm{my}$ inheritance; compare: Sárion beoi ot tawir-u That house there is an heirloom of mine.

Satun elaau lohóm (or, more emphatic: Satu lohóm an ehau) ri inalia-ar sitú This time only (or: This only the time) p.o.r. advent-my $+a r$ here $=$ This is the first time I have come here.

\section{V. - Inquiry into the formation of the enlarged declarative sentence.}

\$ 59. In the first part of this paper the Isinai language was shown to contain three fundamental types of syntactical construction, characterized by the particles an, si with ri, and ot. 
All these particles were demonstrated to be capable of combining nouns into declarative sentences, although in varying degree: an only in a sort of polysynthetic construction; si and ri readily and with the simplest elements; and ot, assisted by ua, in a manner most nearly approaching simple predicative constructions of ours. Only these two last constructions, therefore, have proved to contain an answer to the question: "By what simplest means is the declarative sentence formed?», and it is, consequently, in them that we shall have to find also the answer to the second question, which now comes up for discussion, viz.: "How is the simple declarative sentence enlarged?: ${ }^{1}$ ) As may already have been observed in the examples previously given, the si and ri constructions as well as the ot construction are capable of being elarged. The means of enlargement being in both cases the same, the clearness and brevity of exposition make it advisable to limit the discussion to one of them and I select the ot construction for the reason that, in view of its clear distinction between subject and predicate, it is the construction likely to preserve, upon the accession of attributes, most faithfully the image of the ground-plan.

The attributes, as we already know, will attach themselves to the existing elementary parts of the sentence in very many cases with the help of connecting particles (particles of relation). These latter are principally an and si, with their corresponding enclitic forms $\mathbf{n}$ and $\mathbf{t}$. Besides these a third type of relation will appear, characterized by a combination of enclitic $\mathbf{n}$ just mentioned with si or with di, the particle already known to us as a variant of ri. As the language itself characterizes the relations here to be examined by these particles, I adopt them as natural guides for the division of my work.

\section{The an (n) construction.}

$\$ 60$. The sentence "The child sings», which I take at random for a paradigm, finds its equivalent in good current Isinai, under the ot construction, in this form: Uar ungar ot mangkanta.

1) I use the term "enlarged sentence", as current in English grammar, for that form which arises upon the attributive determination (qualification) of the elementary parts of a simple declarative sentence, that is, of the subject, predicate and object, it being understood that Isinai, not possessing a pure verb, cannot have an object in the sense of our grammar. 
Unga (definite: ungar) is infant; mangkanta is a derivative formed with the prefix mang (which creates nomina agentis) from the Spanish word cantar, to sing, so that mangkanta means properly "singer", "one who sings", or "one singing». Enlarging this sentence with attributives both to the subject and the predicate, I find for English "The big child sings loudly , two expressions: in Isinai, corresponding to the two different shades of meaning which that sentence has also in English; viz.

1. The big child is (by nature or habitually) a loud singer

Isinai: Uar amma-iar unga ot matdén mangkanta ')

2. The big child is singing in a loud voice

Isinai: Uar amma-iar unga ot mangkantat matdé.

The difference in meaning between these two sentences consists, of course, in that the first predicates an immanent ability of the child, and the second an accidental performance by it. In the former, Isinai declares the child to be, in the first place, matdé, that is a "strong one», and explains this further by the attributive apposition of the word mangkanta, singer. The intimate relation between these two ideas, the immanence of the one in the other, is symbolized by the particle $\mathbf{n}$ connecting both expressions: "The child is a strong one as a singer."

Quite different is the Isinai construction for the second meaning: Here the child is in the first place declared to be one singing,mangkanta; and only this quality of a performer (Täterschaft), not directly the subject "child " by itself, is thereupon determined as to an accidental quality of its own by the attributive matdé, which denotes thus an attribute of an attribute. In this case; the relation of matdé to mangkanta, and still more to the subject amma-iar unga, is very properly felt by the Isinai to be a remoter one than in the first case, and in order to establish the necessary association of ideas the particle si (or $\mathbf{t}$ ) is employed.

We see, then, that $\mathbf{n}$ stands for an intimate connection, si $(\mathbf{t})$ for a looser or more remote relation; the former compounds two ideas, the latter keeps them apart and only compares them.

$\S 61$. The divergence of the renderings which in Isinai may be given to the sentence "The big child sings loudly" has afforded an opportunity to establish a fundamental difference between the two modes of apposition characterized by $\mathbf{n}$ and

1) Amma-i, big (amma-iar nearly ammaiyar) matdè or masdé, strong, solid, able, efficient, powerful good. 
by $\mathbf{t}$. This done, the second of these renderings may now be discarded from present examination and only the first be given further consideration.

The Isinai sentence given above under number 1 may, without any material alteration of the sense, undergo certain variations, affecting the composition of the enlarged subject and predicate, which I present in the following table in synoptical arrangement:

1. Uar amma-iar unga

2. Uar amma-iar an unga

3. Uar ungar amma-i

4. Uar ungar an amma-i

(1-4) matdén mangkanta or

A short examination of this table shows that there are two cardinal points which characterize the variability here exposed, viz:

First, the use of the particle an instead of enclitic $\mathbf{n}$, or instead of simple juxtaposition of noun and adnoun; and, second, the transposition of the two nouns representing the subject.

$\S 62$. Regarding the first of these points, the speakers of this language themselves distinctly feel a special force introduced into the expression by the use of an. Upon examining my informant, I found that, through this particle, the adjunction of the attribute is made with a measure of predicative force, which renders the expression more distinct, giving the attribute something of the character of an explanation, and serving thus to emphasize it.

I show this first in the case of an as opposed to simple juxtaposition. To the question: What have you bought? an Isinai might simply and promptly answer: Uar sinalin-uar (the-objectbought-my) ot mangồngót (black-thing) balanggut (hat), freely: I have bought a black hat.

He might, however, also give to his answer this form:

Uar sinalíu-uar ot balanggut an mangô-ngót. The use here of an may indicate one of two things: either that he wished for some reason, to accentuate his having bought just a black hat, and not one of a different color; or, simply, that the addition to the name of the object bought, of a term describing its color had occured to him somewhat tardily; leading him, as if in anticipation of a further question regarding the color of the hat, to tag the descriptive term to the appellative with the help of the particle an, which in this case probably would be preceded by a momentary pause. An is thus explanatory and 
possesses a predicative force of a secondary degree. Compare English: I have bought a hat, a black one, or: a hat, that is, a black one; German: cinen Hut und zwar cincn schwarzen. The same character of supplementing a previous statement is found for an in the case where the attribute has the weight of an English relative clause: I have lost the new hat which I bought yesterday, Isinai Tinilita- $\iota \mathbf{r}$ (Object-lost-my + ri in enclitic form) béuar balanggut (new + ar hat) an sinalúu-u (which is object-bought-my) uhawan (yesterday). ${ }^{1}$ )

These examples show clearly that an, used instead of simple juxtaposition, connects the adnoun with the noun in a distinctly declaratory manner.

Availing ourselves of this result in judging the composition of the subject in the two alternative sentences marked 3 and 4 in the above table, we find, then, that the phrase Uar ungar an amma-i gives the attribute amma-i with more emphasis or simply greater clearness than: Uar ungar amma-i. In the latter, amna- $i$ is a mere epithet, in the former it may serve to distinguish the big child from other smaller children, or be only a more distinct mode of speaking.

What - to consider this next - is now the relation which an holds with respect to the enclitic $\mathbf{n}$ in the two alternatives for the predicate given in the above table: matdé ang mangkanta and matdén mangkanta? Has an here, as contrasted with $\mathbf{n}$, the same force which it was shown just now to possess as compared with simple juxtaposition? Beside - and this is a question put from the point of view generally taken in grammars on Philippine languages — how is it that an should be found here between a preceding "adjective» (matde) and its following "substantive" (mangkanta)? After the explanation given above of the nature of an, this order of words would seem to make a substantive a complement of its subordinate adjective! -

Readers inclined to ask this latter question I must ask to have patience while I take time to answer the first. The diffculty will be considered when the second of the two cardinal points stipulated above, viz. the relative position of the noun

1) Comparing English "The hat which I bought yesterday" with "The hat I bought yesterdayn, we have a very apt illustration of the greater clearness which Isinai an, corresponding here to English "which", introduces into the expression. 
and adnoun is discussed. To remove, however, for the moment the objectionable point, the paradigm may be here temporarily amended to read: Uar ungar amma-i ot sin-ilin (Igorot $+n$ ) maliksí (smart), or .... ot sin-ili an maliksí, meaning: The big boy is a smart Igorot. Since here the adjective» follows the "substantive", the former can, if connected with the latter by an, readily be resolved into the relative clause: (an Igorot) who is smart.

The answer, now, to the first of the above questions, respecting the force of an if compared with enclitic $\mathbf{n}$, is that the relation of an to that enclitic is, in significance, exactly the same as that which was shown before to exist between an and simple juxtaposition. The language shows $m e$, in fact, that just as mere juxtaposition is a sign of association between the two ideas expressed in ungar amma-i, so is $\mathbf{n}$ a sign of the same association in the case of sin-ilin maliksi (or in the case of the discarded matdén mangkanta). Both juxtaposition and $\mathbf{n}$ are equivalent in this respect. The reason for the occurrence of one or the other is - as I shall presently illustrate by examples - merely an external one, one of phonetics: A final vowel in the first noun calls for enclitic $\mathbf{n}$, a final dipthong or consonant, for simple juxtaposition. An occupies, thus, a position equidistant from both, as I attempt to represent graphically in the following sketch,

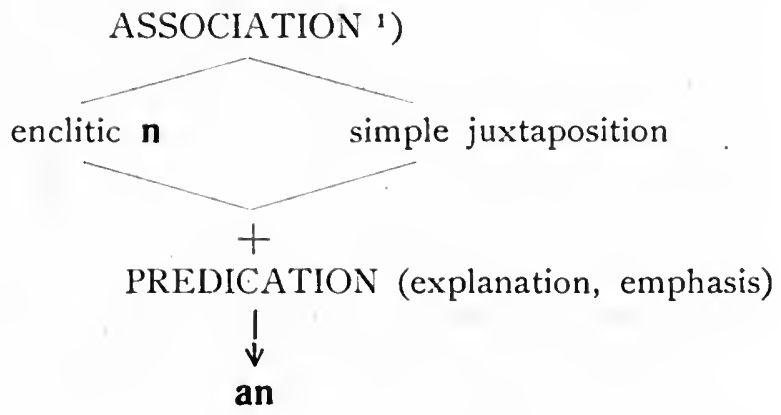

Having shown before, by a special example, the force of an in comparison with simple juxtaposition, I will do the same in comparison with $\mathbf{n}$.

Let the idea to be expressed in Isinai be *The two little American girls are dead." "Two» is dua, "little girl» would find its equivalent

1) German: Zusammengehörigkeit. 
in bara-in unga, literally, woman-infant; "dead" is natói. Now, if the speaker, at the beginning of his statement, had present in his mind all of the four nouns which name, number, and describe the subject of his speech, he would, since all end in a vowel, string them together by the necessary number of connecting n's, thus: Uar bava-iardarin duan unngan americana ot natoira. If, on the other hand, utterance of thought proceeded with him only with that - greater or lesser - promptitude with wich ideas flowed to his mind, that sentence might take the following form: Uar bava-iardarin duan unnga, an americana, ot natoira, wherein a momentary halt after unnga, and the following particle an before americana, (against enclitic $\mathbf{n}$ in the first case) would characterize this last attribute americana as an epithet not originally intended to be used, but, just at that stage, felt to be necessary as an explanatory addition.

The two forms, then, Uar ungar amma-i ot sin-ilin maliksi and Uar ungar amma-i ot sin-ili an maliksi are differentiated only in that the latter lays, through an, greater weight on the attribute maliksi than the former, or that it denotes a slower and therefore clearer mode of expression. ${ }^{1}$ )

$\S 63$. I insert here a number of examples illustrating the decisive influence which the final sound of the-first word of the combination has on the special form of the connection. The first word is the substantive; the second, the adjective of the English translation:

(a) final vowel with appended $\mathbf{n}$ :

matan mataróm sharp eyes

aazwan marita poisonous spider

leén mandiritò red colocasia

ilohon mahehéa industrious Iloko

c-ín aptioi short rice pestle

(b) final diphthong, consonant, or glottal check determine simple juxtaposition:

beoi beu new house

bantai ivangbang Bambang guard

1) The predicative force of an is felt especially elearly in a sentence like the one quoted in $\$ 58$. Satu lohom an ehau (instead of Satun ehau lohom) ri inalia-ar siti, where an comes to measure its force with ri and seems to relegate this to the position of an attributive particle: This only is the time of my adrent here. 
payau natai(inan') abandoned rice field tayab mapurau white feather sax-on maddahet bad neighbor

$b \hat{o}-b \hat{o}$ damdamá old stone mortar (for betel nut)

$\S 64$. I now come to the second of the two cardinal points which, as pointed out before, characterize the variability of the paradigm given in $\S 61$; viz, the transposition of the two nouns representing the subject.

The paradigm shows that the words for "the big child" may" in Isinai assume the position of amma-iar unga or of ungar amma-i. Connected therewith is the circumstance that whichever the order of the two nouns, the one occupying the first place is distinguished by the appended syllable $a r$, making it a definite noun, while the other is left abstract or indefinite. It is further to be noted that, in case of the second noun being added with the help of $a n$, the language has no objection to letting the word for "child» appear as a determinant of that for «the big one», thus: amma-iar an unga.

As regards, in the first place, the simple fact of the possibility of transposing the two nouns, I observe in this respect a great liberty in Isinai, which, generally speaking, permits the speaker to put into the first place just that one of several nouns which is foremost in his mind. In ungar amma-i, the latter word is but an ordinary epithet to the general appellative of the object in question, and this appears to be the common arrangement. In amma-iar unga, the anteposition of amma-i indicates that the size of the child has, for some reason, particularly struck the mind of the speaker. This was the explanation given by $\mathrm{my}$ teacher, and I find it corroborated by a number of characteristic examples.

An Isinai, out on the trail, wishes to draw the attention of a companion to a distant tree covered with red flowers and exclaims: Ilam di mandirito-a), ijón ayu! See that red thing there, that tree! Or, if the notable object were four white birds, he would call out: Ilam dio opatar, ijón mantatayab an mapuráu, See those four there, those birds (literally flyers), all white! In both cases he uses for an immediate designation of the objects he is pointing out not their common names, but, in the first

1) No glide between natai and ánan. 
instance, the striking color (mandivito, what is red), in the second, the number (opat, four) with the color (mapuriu, what is white) in an emphatic final addition (an mapuráu). The indication of the essence of the objects: ay $u$, tree, and mantatayab, bird (this, nota bene, a nomen agentis), recedes before the stronger impression made by outward look or appearance.

The sertences here used as examples are, in a degree, formed under emotion. But also in quiet, well considered speech, the use is found of the word for a prominent characteristic of an object as its chief designation, to the detriment, so to say, of its common name. This is best exemplified by the occasionally preferential use made of the name of the material of which an object is made :

Azvitom di katátar libru (or: katátar an libru) Bring me the leather book (katát, leather)

Diói si sinaliu-ut lutan $b a k-k a$ (or: luta an $b a k-k a$ ) I have bought an earthenware pot (luta, clay; $b a k-k a$, a deep pot)

Sário ot ayun pasax (or: ayu an pasa.x) That is a wooden nail (ayu, wood; pasax, nail)

Gimpá-ıır utongnar caserola I have broken his iron cooking pot (utong, iron; note the addition to this name of $n a$, his, before ar; caserola, Spanish for cooking pot)

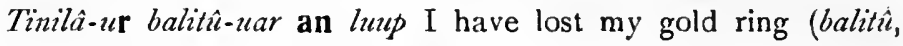
gold $+u+a r$; luup, ring).

The liberty thus existing in Isinai for a different grouping of the nouns that unite in designation of one object of thought, or the capacity of each to relieve another in the place of the chief representative of that object, is best seen where, with the number of attributives, there increases also the number of possible transpositions. Using again the previous sentence, "The two little American girls are dead», which in English would not admit of any change in the order of succession of the attributes this may adopt in Isinai, without any material change in significance, any of the following forms:

Uar duardarin americanan bava-in uunga Uar duardarin bava-in ungan americana Uar uungardarin duan americanan bava-i

Uar ungardarin americanan bava-in dua

Uar americanardarin duan bava-in uunga Uar bava-iardarin duan uungan americana ot natoira.

Other possible transpositions were indicated as unusual. The 
same liberty of position is shown in the following example belonging to a different type of construction. The sentence "These are the four black horses which I inherited» is, as far as the order of nouns is concerned, susceptible of any of these renderings :

Saratu ri opatar mangî̀-ngót kabayu an tinawir-u

Saratu ri opatar kabayın mangò-ngót an tinazvir-u

Saratu ri mangồ-ngótar opat an kabayu an tinawir-u.

In addition, the final attribute, connected in all three cases by an, and representing the relative clause "which I inherited" of the English sentence, may advance to the leading position:

Saratu ri tinawir-uar opat mangô-ngót kabayu, literally:

These p.o.1. the-inherited-objects-my four black horses. ${ }^{1}$ )

As indicated above, not all modes of collocation of the noun and accompanying adnouns that are theoretically possible, are actually in use. The language is in this respect apparently governed to some extent by usage, or is guided by considerations so difficult to penetrate, that even an intelligent Isinai like my teacher, possessing a certain schooling in English grammar, showed himself quite unable to assign any criterion for the arrangement of words, concerning which only his inborn feeling for the language told him whether it was right or wrong. We found, however, an instance of fixed position in the case of the predicate of the sentence established as a paradigm for the present inquiry; the words matdén mangkanta may not be inverted to *mangkantan matdé, but show this position exclusively in the si construction as mangkantat matdé or mangkanta si matde and then with the changed meaning pointed out in the beginning of this chapter. As the same fixed position obtains for expressions like:

malippatun manadal quick (literally "soft») learner

alegren mi-an jolly (Span. alegre) table-companion (literally, «fellow-eater»)

1) This latter construction, which is not only quite common in Isinai, but represents an elegant and classical trait of the language, may remind readers versed in German of the construction in a line from Goethes "Zauberlehrling : "Die ich rief, die Geister, werd ich nun nicht los!" an order of words which is as exceptional in German, as it is common in Isinai: Uar inayaihaar (The called-things-my) an banis (p.o.r. ghosts) ot uriâ (are objects-of-negation-my) domon (possible) pataiánon (object of banishing). 
mevvés mannihai skillful fisher

mevvés mamaril good rifleman

it appears that it is the presence of the nomen agentis, represented in all these combinations, that determines the immutability in the order of such words.

Still, from the liberty which has been shown to exist generally for the respective position of the words corresponding to our categories of substantive and adjective, from the ease with which the equivalents of the latter in Isinai are "substantivated" (addition of $a r$ ) in the face of the appellative proper, and from the submissiveness, so to say, of the latter to the role of a descriptive determinant of the former, I draw the conclusion that, behind the evident equivalency in functional value (Gebrauchswert) existing in Isinai between the members of these categories, there is present an equivalency in significant value (Bedeutungswert) which keeps the adnoun from taking, with respect to the noun, that subordinate position which the adjective of inflectional languages occupies ex officio. It has been said that names of properties generally appear in Isinai affixed with a particle - the most common one being ma - which adds to them a reference to something concrete. But even without such particle, words of this class of adjectives, the same as pronominal adjectives, and adjectives of quantity, seem to me to have in Isinai, a fuller, more complete, and more independent thought-content than the adjectives of inflectional languages possess by themselves. Words, for instance, like beu, tic, osá, would find their equivalents not in English "new, this, one, but in "newness, this thing, one thing." This view makes it, indeed intelligible that Isinai, lacking words naturally subordinate in significant value like our adjectives, finds it necessary to mark — where phonetically possible — the self-dependent adnoun by

n as associated with the antecedent, with which it then forms a sort of compound.

The fact that a composition has taken place does not appeal to us in all cases with equal conviction. It is most convincing where the component parts belong to a category which also in English furnishes material for compounds.

In expressions like: $\begin{array}{ll}\text { lansetan asero } & \text { steel knife (two Spanish loan words) } \\ \text { librun katát } & \text { leather book }\end{array}$ 
kuakun ayu wooden pipe

utun ba-iyur a mountain having the shape of the back of a louse

mahalilan Kantong Canton banana

ayun simbean twin tree (simbean married couple).

we are able to confront the existing composition with an equivalent combination of nouns from English or, more easily, from German, a language which excels in "Zusammensetzungen》(Cf. Stahlmesser, Lederbuch, Holzpfeife, Lausberg).

Note that some such compound nouns admit of transposition (compare katatar libru before quoted), while others are not thus changeable (aseron lanseta, for instance, is not usual). Note also the formation of compound nouns by simple juxtaposition in case of a consonantal ending of the first word. This occurs whenever the noun becomes definite by the addition of ar to a first word ending in a vowel; for example: lansetar asero, kuakuar ay'u. Other examples of this kind of composition are:

kiung auwoi rattan basket

$b \hat{a}-b \hat{a}$ yubot closing word

tuur batu stone pillar

In other cases of application of the same principle of Isinai syntax, viz, that of marking by $\mathbf{n}$, where phonetically possible, the intimate relation existing between the several expressions used in apposition, to designate one object of thought, our languages do not offer equally striking illustrations, though we must think here of that agreement in form wich is known to our grammar as concord.

In the following I give examples of the application of that principle, chosen with more freedom than the analysis of the single sentence thus far taken as a paradigm, permitted. They refer to categories of words not yet considered in that respect.

Personal pronouns with attribute:

Saon an Isinai tinatmô-u ri bin $\hat{a}-b \hat{a}$-nar I, being Isinai, have understood his words

Amoi-an mirngngét bohás Go and ask for rice (an $<{ }^{*} k a+\mathbf{n}$; mirngngé, hear, ask, beg, $<m i+$ dongngé)

Mahehéa-a an unga Thou art a diligent boy

Dâ-min maaiaiyuan tahu ot mantrabahot masa-it WVe miserable people work hard (Note that on separating suffix an from maaiaiyi an tahu (or maaiaiyún tahu) means "compassionate people») 
Immoiran nanpassial They went for a walk (literally: werewalkers-they-as promenaders)

Demonstrative prououns with attribute:

Sátien tahu ot pangamâ (or, slower, Sätie an taliu....) This man is my father by proxy (uncle, stepfather, adopted father, etc.)

Uátien unga ot nî-bus Manila (or: Uátie an unga...) This boy' has come from Manila

Sarion ayu of nara That timber is narra

Sárien unga ri nangazvitar sitien sulat. That boy (before mentioned) is the one that brought this letter

Uárien sussur ot dingng $\hat{i} i$ in $\hat{a}$ As for that tale I heard it from my mother

Awitom dion kiung! Bring that basket!

Piruóm dien $b \hat{a}-b \hat{a}$ ! Repeat those words!

For those of the preceding examples that begin with a demonstrative in emphatic form, as sátie, uátie, etc., there exists yet another construction which omits the connecting $\mathbf{n}$ (or an), and, in exchange, attaches ar to the following noun: Sátie tahuar, Uátie ungar, etc. It appears that the demonstrative in this construction points out the object with less force; thus sátien tahu is "This man here present», but sátie tahuar has the meaning of "These people around here», an idiomatic shaping of the sense which requires further study.

For an illustration of the use of numerical words in connection with attributes, I refer to $\S 22$ (toward the end).

The si construction.

$\S 65$. In $\S 28$ it was said that the particle an indicates a near, the particle si, a more remote, relation. This fact, though dwelt upon again in $\S 60$, has not yet found a fuller demonstration in regard to si. What was shown respecting si (\$37) was that it is primarily a particle of demonstration pointing vaguely into space. By this particularity it was presumed to have come to occupy the office of a particle of relation serving, in a certain class of sentences, called after it the si construction, to refer an antecedent predicate to indifinite objects of thought, in contradistinction to the particle ri which discharges a. similar office respecting definite objects. 
In connection herewith, an interesting transformation of the simple declarative sentence thus formed was pointed out in $\S 47$, consisting in the enlargement of that sentence by an anteponed dioi, "there is» for the purpose of giving the sentence a more narrative character. Thus the statement Cuarta si dinatóng-u became transformed into Diói si dinatíng-u si cuarta, in which the first si in introducing the indefinite dinatóng- $u$, establishes the connection between the two main parts of the sentence dioi and dinatóng-u; while the following si plays only the secondary rôle of joining the attributive cuarta to the antecedent dinatóng- $u$. In order to keep the si in the former capacity apart from si in the latter, they were, theoretically, distinguished as si predicative and si attributive.

The employment of this attributive si may now be examined more closely.

$\S 66$. Examples of the attributive use of si have not been lacking in the preceding part of this paper.

Already the discussion of the numerical noun gave occasion (§ 23) to point out the difference existing between osát and osán in the example Diói si osát and̀-ut mevvés and Dioi si oscin anò-ut mevvés. It was there said that the connection made between osá and the following noun and by $\mathbf{t}$ (si) was a less close one than by $\mathbf{n}$ : that the former preserved more clearly the independent numerical force of osí, while the latter made osa take the secondary sense of "a certain». The difference produced in the sense of these sentences by the change of the connective bears witness to the importance attaching, in certain cases, to the use of either the one or the other, and shown how vividly the distinct value of each must be felt by the language.

The ratio found for the use of these particles by thus comparing the meaning of the two sentences just quoted was confirmed in a later example ( $\$ 47$, toward the end) by a similar distinction between deét t $\alpha h u$, meaning "many people», and deén tahu, meaning "a crowd of people» (eine Menschenmenge), although the development of this phrase into a sentence by the addition of further attributives, with the help of either si or an, failed to show the observance of any fixed rule in their use; it revealed, on the contrary; an apparent unstableness which only my imperfect knowledge of the language kept me from 
setting down as a lack of grammatical consistency on the part of the speakers.

The first of these examples, Diooi si osát anà-ut mevvés, as well as the one last cited, Deét tahut neir nangamla si natói si gerar si milivit situ, clearly belong to the si construction. In the former, the independent numerical noun os $a$, introduced by predicative si, is enlarged by the two determinant nouns ani and mevvés wit the help of two attributive si in the form of $\mathbf{t}$. The latter is more developed in sense. Here the first member of the sentence, that is, the expression for the dominant idea opening the sentence, consists of a compound held together and demarcated more by the sense than by any grammatical form. It begins with a kernel dee't lahu, two nouns that are joined by si (in the form $\mathbf{t}$ ) and that, although not drawn together by this particle as closely as by $\mathbf{n}$, are presumably given the value of a standing plirase. This kernel is, in the first place, enlarged, with the help of the same connective si with which it is built up itself, through the phrase neir nangamta, which, to judge from our standpoint, appears grammatically as disconnected from the antecedent as if we were to begin a sentence with: «Many people, God may know who they were,...» After this attribute, which to us is, then, a kind of parenthesis, there follows a second group of words, again appositive to those going before and related to them again by the same particle si, viz. si nato $i$ si gerar, a group which we would arrange hypotactically, that is, by forming of it the relative clause wwho have died in the war». Ultimately, the sentence winds up with the phrase "si niluvi silum, which is added with the help of the same si that connects also all the preceding members and that characterizes also this final phrase as an attributive apposition.

This analysis of a longer period shows an essential characteristic of Isinai syntax, viz. the paratactical arrangement of successive groups of nominal forms, all of a certain assertive force, all held together by the repeated use of one and the same particle of relation, but lacking in their union that cohesion and finer organization which a similar sentence in one of our languages derives from the presence of the finite verb. In the absence of such a one there is, in this type of construction, no grammatical distinction between subject and predicatc, Both merge in the existing concatenation of ideas. The whole sentence presents itself, from the first word to the last, as an accumulation of attributives.

$\S 67$. For a more systematic observation of the function of si 
as an agent in the attributive enlargement of the simple declarative sentence, I go back to the examples used in the discussion of the si construction, and select here such as are built up with indefinite nouns, since, si being characteristic for these nouns, examples of this kind offer the best chance for observing the operation of this particle.

In $\S 42$, the following examples were given:

Cuarta si in-atór-u Money p.o.r. my-gift

Beoi si it-tía $\quad$ House p.o.r. my-dwelling-place

Láman si anô Venison p.o.r. my-food.

Enlarging the antecedent by an appropriate noun, I obtain these sentences:

Déen cuarta si in-atór-u Much money p.o.r. my-gift

Damdamán beoi si $i$ t-túa Old house p.o.r. my-dwelling-place Nalo-óyan láman si anô Soft-boiled venison p.o.r. my-food.

In these, the abstract nouns dee and damdamá, and the indefinite noun nalo-óya occupy the (emphasizing) first place and are connected with the following noun by $\mathbf{n}$. To find out if this connection (by $\mathbf{n}$ ) is the rule in the antecedent, I formed with my teacher's aid a considerable number of similar sentences, all of which gave the same result, with the single exception of phrases beginning with deé, a word which may take also si after it, although with a change of signification. For example, $d e \hat{e}+\mathbf{n}$ forms a sort of superlative (very much) as compared with the simple positive represented by deé $+\mathbf{t}$ (much, cf. $\S 47$ ). On the other hand, Urit-ti an cuarta, Duan peseta, and others could not possibly take the si connection.

Is the reason for the nearly exclusive use of $\mathbf{n}$ to be found here in the very nature of this class of sentences (cf. $\S 38$ ) which open abruptly with a single word, or else with a compound expression, but not with an expression divided in itself by si?

$\S 68$. Plain examples of the enlargement of the noun referred to (or introduced) by predicative si are as follows:
Diói si beoi si beu There is a new house

Diói si apui si amma-i There is a big fire.

The description thus initiated of the object referred to may be continued in the same manner; for instance, in the case of the house, thus:

Diói si beoi si beu, si amma-i, si malinis There is a new, large, clean house. 
The order of words here given may suffer different alterations according to the emphasis the speaker desires to lay upon one or the other noun, which noun is then put generally in the first place but may also occupy, as an important afterthought, the last.

\section{Diói si malinis si amma-it beoi}

Diói si anma-it beoi si malinis.

In these sentences the connection made by $\mathbf{t}$ marks a readier association of ideas, which thus results in lesser emphasis for the descriptive term so connected.

Another example of the same kind of enlargement was given by the transformation of the simple short statement

Cuarta si dinatóng-u, freely "I have found money" into:

\section{Diói si dinatóng-u si cuarta}

which conveys exactly the same intelligence, but is more narrative in form. Here the noun dinatong-u is enlarged by the apposition "si cuarta". This enlargement, now, may be continued by adding, for instance, the idea "covered with rust», Isinai napniit lati ("what is full of rust»), thus:

Diói si dinatóng-ut cuarta si napnut lati,

where the new apposition is again made with the help of si, although it is true that here again the language wavers between si and an inasmuch as the construction might also be:

Diói si dinatóng-ut cuarta an napnút lati.

If, on the other hand, the money were determined according to its intrinsic value, as in English by: "some gold coins", a similar determination would alway's be made with the help of n (or an) thus:

Diói si dinatóng-ut cuartan balitû.

To take yet another example. Under "The abstract noun» a short dialogue was given in which occurred the sentence:

"Diói si dimmatóng si tahu", freely "There has somebody arrived.» This is another illustration of a noun introduced by predicative si (si dimmatóng) and enlarged by attributive si (si tahu). If to this the idea "a stranger» were added, the sentence would run thus:

Diói si dimmatóng si tahu si beu, beu meaning "new, newness» and covering, as in English, the idea "new to a place." Or the order of words might be, accord- 
ing to the succession in which the ideas present themselves in the mind of the individual speaker, as more or less dominant ones, thus:

\section{Diói si tahut beu si dimmatóng,} or this:

\section{Diöi si beut tahut dimmatóng,}

but the connection between beu and tahu could not be changed from beut tahu to beun tahu without materially affecting the sense. The two ideas "new" and "man», allied into that close connection for which the particle $\mathbf{n}$ is characteristic, have been given a special meaning by the language which, in similarity to other Philippine languages, has coined the expression beun talu to denote the same as that which in English is expressed by "bachelor», (German "Junggesell») if applied to unmarried male persons actually young.

Note here that, owing to the existence of this compound noun, Isinai may say Diót si beun tahu eThere is a young unmarried man», but that in the previously used example eThere is a new housen, a construction *Dioi $i$ si beun beoi is inadmissible, while in the ot construction Sário ot beun beoi is the only correct form.

It may; then, be stated as a general rule that - excepting in cases not nearer to be determined by me, where the language appears indifferent as to the choice between si and an - nouns introduced by predicative si (t) are enlarged by nouns attached by the same particle (which, then, may be called attributive si), unless the determinant affects the very essence of the object designated by the preceding noun (cf. cuartan balitît), or constitutes with it a compound expression (cf. beun tahu), in which cases $\mathbf{n}$, or simple juxtaposition, is indispensable.

$\S 69$. Let us, at this point, cast a glance of comparison at the ri construction to see how attributive apposition is here generally effected. I take the case that the person who had made the statements above used for examples, viz.

Diói si dinatóng-u si cuarta si napnít lati

Diói si tahut beu si dimmatóng, is asked to show the objects mentioned.

He would, in following out the request, say now:

Etoi ri dinatóng-uar cuarta an napnit lati (etoi $=$ "here is, here are») 
Etoi ri tahuar an beun dimmatóng (but not: *an dimmatóng si $b e n$ )

that is, he would, after having given the leading noun the definite form, characterized by the suffix ar, connect now the following attributives, not by si, as in his first announcement, but by simple juxtaposition, or by $\mathbf{n}$ or an. Only lati remains as before connected by $\mathbf{t}$.

The following is another similar example. Somebody remarks that he has seen two American women:

Inilà (Seen-object-my) si duat bava-it americana (all nouns connected by $\mathbf{t}$ )

He then refers again to the same persons to say that they had been sitting on a stone:

Sárien duan bava-in americana of nammeongdat batuar (were sitters on stone $+a r$; alle nouns determining sáric connected by $\mathbf{n}$ )

These examples show that the particle si, which connects indefinite nouns under the si construction, cedes its place to $\mathbf{n}$, an, or simple juxtaposition, as soon as the construction changes to the one characterized by ri, that is, to the one dealing with definite objects of thought. Other examples showing the same enlargement of definite nouns and belonging to the ot construction are to be found in $\S 64$, and elsewhere in this paper.

Another result of the comparison of the si and ri construction in their enlarged forms is a confirmation of the theory propounded in $\$ 64$, regarding the self-dependency of the several concepts that find their expression in the adnouns. Considering the character of the particle si as sent forth in this paper under different aspects, it is indeed difficult not to perceive that words which already in their union by $\mathbf{n}$ appeared to possess each its independent thought-value, reveal such value still more clearly if encountered in the much looser si relation. A combination of words like tahuar an beun dimmatóng we can imitate by "the man who is newcomer", but the phrase tahut ben si dimmatóng or tahu si beu si dimmatóng contains the same thought material in an assemblage as disjointed as the ideas we invoke in the mind of a hearer by saying, "Imagine a man, tall, sturdy, broad shouldered, dark, etc., or even more so, since the particle si seems to place, a yet greater distance between the several epithets. 
A third observation to be made in the transformation of sentences above illustrated leads to a consideration of the particle si in a special character which was touched upon in $\S 60$. In the sentence

Diói si dinatóng-u si cuarta si napnít lati

alle nouns are linked together uniformly by si or t. As far as these signs, by themselves, go, they do not indicate any distinction to be made in the degree of interrelation of the several nouns. The ideas which these represent appear all uniformly associated. If the sense of the whole utterance had not told us before, it would be only in the ri construction:

Etoi ri dinatóng-uar cuarta an napnut lati

that we would become aware of a different value of that si which, in the form of $\mathbf{t}$, connects lati with its antecedent. This si introduces an attribute of an attribute, or, as an Isinai might say, it points out an idea too much apart, in proportion to the others, to permit of the same close connection which these experience in the ri construction, a form of sentence which, dealing with definite objects, proceeds with greater discrimination.

Just as before cases were found in which $\mathbf{n}$ was imperative, as a connective for compound nouns, so here a case appears where si (t) must necessarily be retained, and this case merits being considered more in detail.

$\S 70$. For the special value of si just found ("attributive si ${ }^{2}$ " as I shall call it), some examples have already occurred in the preceding part of this paper. I cite the following:

mit-tit danimar living in the water

mangkanta si matdé singing loudly

natói si gerar died in the war

nammeongdat batiar sitters on a (or: on the) stone.

In these examples an added $a r$ at the end of the second noun does not necessarily refer the idea expressed by such noun to certain particular objects, but helps to give substance to that idea, as previously explained. It thus adds to the force of attributive $\mathbf{s i}^{2}$ and makes the idea expressed in the phrase appear as something standing outside the general attributive structure of the sentence.

In the following I illustrate the employment of this particular si in a series of examples so arranged as to show clearly what the various relations covered by it would be in English syntax. 
Taking simple declarative sentences, I distinguish the two members of which they naturally consist by the figures I and II, and add thereto the attributive of the second degree as a third member, marked III. To symbolize the uniform manner in which this latter is pointed out in Isinai by the particle of relation si, I have again recourse to the index-hand previously employed in a similar manner.

I. Uar ungar-ot- The child (is)

II. mangkanta singing

III. si matdé ho loud loudly

or III. si bi-bihat bo morning in the morning

or III. si dalianar is the kitchen in the kitchen

or III. si gaiháyanar 5 joy-his + ar out of joy

or III. si livrinar 5 book-his + ar from his book

or III. si náut ho hymn a hymn (rectius: singer, respecting a hymn)

I. Sairien nait-ot- The said hymn (is)

II. dingngéna what-he-has-heard

III. si inanar 5 mother-his $+a r$

from his mother

I. Sárien livru-ot- The said book (is)

II. dinazuatna what-he-has-received

III. si ivanar lé-i h brother his $+a r^{1}$ ) from his brother

I. Sáricn livru-ot- The said book (is)

II. in-atórna what-he-has-given

III. si ivanar lé-i

I. Sinaliu- $\iota$ Bought-thing-my-

II. tien kabayu this horse

III. si amigo-ar ho friend $\mathrm{my}+a r$ for my friend or

I. Uar ungar-ot- The child (is)

II. ikantóna motive-of-singing-his

III. si balizváwai ino lullaby'

I. Kinompasána Struck-object-his

from my friend

II. $r i$ ungar p.o. r. child + ar

III. si auno $i$ a rattan

respecting $\mathrm{a}^{2}$ )

lullaby

with a rattan

1) As ivi denotes only the relationship without indication of sex, Isinai must add here lé-i male.

2) The child is sung to sleep by him with a lullaby. 
I. Inappiana Made-object-his

II. $r i$ beoinar p.o.r. house-his $+a r$

III. si batí : stone with stone

I. Natói Dead

II. ri amigoyuar p.o.r. friend-your $+a r$

III. si galotong ho smallpox from smallpox.

$\$ 71$. Not in all cases is si the particle marking that remoter attributive relation illustrated in the preceding examples.

Among the sentences given in $\$+3$ as belonging to the si construction were the following:

Tinto si inumô Claret p.o.r. drink-my

Ahái-hayâ si Mraria Object-of-affection-my p.o.r. Maria

A comparison of these two examples shows that si preceding names of persons, and representing a personal article (si Maria) is in that construction, not only in function, but also in sound, exactly like the ordinary particle of relation si (si inumô). This uniformity, which undoubtedly rests upon an etymological identity, ceases if the noun personal does not stand (as "Maria» does in the example just cited) in the place of that member of the sentence to which the dominant (Ahai-haya) is directly referred, but occupies, with respect to these two elements, a remoter, more independent position, in which it may be compared to the indirect object of our syntax. In such position, the noun personal takes, instead of $\mathbf{s i}$, the prepositive $\mathbf{i}$, apparently a more radical form of si.

The following examples show the personal article in this changed form.

I. Sárien lizru-ot- The said book (is)

II. in-atorna what-he-has-given

III. i Maria horia to Maria

I. Sinaliu-u Bought-thing-my

II. tien kabayu this horse

III. i Mariano h $\$$ Mariano for (or: from)

Mariano

I. Inilan Seen object .

II. $a$ I $\left.^{1}\right)$

III. i ama for father for (by) father.

This prepositive $\mathbf{i}$ occurs, in like function, also before those

1) Pronounced Inilanil, without break of the voice. 
forms of the personal pronoun which begin with $s a, s i$ da ( $r a$ ) di (ri). Here Isinai orthography (which, by the way, seems to be in an exceptionally unsettled condition) usually writes $\mathbf{i}$ in one word with the following pronoun, a practice which, in view of such forms as $r i$ isáonar "the mine» (das Meinige) appears quite reasonable. I use but two examples to illustrate all forms thus arising :

I. Sárien livru-ot- The said book (is)

II. in-atórna what-he-has-given

III. iscion ho I to me

I. Sinaliu-u Bought-thing-my

II. tien kabayu this horse

III. isi-a ho thou

for thee

III. isi(y)a ho he

for him

III. ir $\hat{a}-m i \hat{\hbar}$ we (exclusive)

for us (exclusive)

III. irita-u h we (inclusive)

for us (inclusive)

III. irita $\sqrt{5}$ we two

for us two

III. ir $\hat{x}-y u$ you

for you

III. irira 0 they

for them.

$\S 72$. In looking back, now, upon the various modes of employment of the particles $\mathbf{n}$ and si, I believe sufficient proof has been given of the truth of the statement made at the outset (\$ 28), viz, that $\mathbf{n}$ stands for a nearer, si, for a more remote, relation, and that the indication of these two degrees of relation forms a fundamental feature of Isinai syntax.

The series of examples produced for those particles form themselves, so to say, into two lines. At one end, these lines touch each other very nearly, and even overlap, so that they are not clearly distinguishable one from the other. These ends are the cases where the Isinai themselves waver, or are indifferent, as to the use of either the one or the other particle.

Since these particles are used here interchangeably, probably. no Isinai could give a decisive opinion upon the orthodox usage of his language in such cases, and we are reminded of the complaint which old Totanes, reputed master of Tagalog, made in a similar connection and which is quoted in the Introduction. From that common medium the two lines stretch away in quite opposite directions, so that their extremes are far apart. At one end are seen compound nouns formed with $\mathbf{n}$, at the other, prepositional phrases with si that is, with attributive $\mathbf{s i}^{2}$. 
Of the interesting phenomenon that the near relation finds an express inclication only after words with vocalic ending, but is otherwise left to be represented by mere juxtaposition, it is not for this paper to treat. Limited to an exposition of the facts of the single Isinai language, I find in the latter nothing to throw additional light upon that fact, which comes properly before a comparative study. Simply by way of information I will reproduce here in English translation a very interesting passage from Adriani ') concerning the particle $n$ :

"The particle $n$ is not uncommon in Indonesian languages. Tagalog, Bisaya, Dayak and Old Javanese use it to the same end as Sangir; Bali now only in determinate cases; where Sangir employs $\mathfrak{u}, n$ is absent in Tagalog, Dayak, and Bali. It has thus actually disappeared in Sangir in the same cases and has been substituted by $\mathfrak{u}$, which is properly a conjunction though with an undetermined conjunctive value. The reason for this is obvious, and has been stated already by Dr. Brandes in his dissertation, wherein he demonstrates by means of examules from Tagalog, that a genetival relation is properly to be expressed by a connective preposition $n$, and that this is absent in cases where, through the accumulation of consonants, its non-disappearance would create difficulty in pronunciation.»》

\section{The n si and $\mathbf{n} \mathbf{d i}$ constructions.}

$\$ 73$. Beside the three fundamental types of construction treated in the preceding part of this paper, there remains to be discussed ultimately a fourth relation which was already mentioned in $\$ 28$. This finds its expression in a combination of the $\mathbf{n}$ and the si (or the di) constructions, and the employment of these particles in pairs, as $\mathbf{n} \mathbf{s i}$ and $\mathbf{n} \mathbf{d i}$, may now serve us as a test for the correctness of what has been said previously regarding their typical character when used singly.

If the particle $\mathbf{n}$ stands for association (Zusammengehörigkeit) and is used to compound two or more nouns in description of the essence or nature of a single object (as, for example, in kuakun ayu, wooden pipe; German Holspfeife), and if the particle si (with its collateral di) points to something remote, and is used to establish a relation between two objects which are

1) Sangireesche Sprankkunst, Leiden (1893), p. 222. 
thought separately (for example, ayu si easar, tree in, or from, the forest, German Baum im Walde, or Baum vom Walde), it may, a priori, be expected that a simultaneous use of $\mathbf{n}$ and $\mathbf{s i}$ ( $\mathbf{n}$ and $\mathbf{d i}$ ) denotes a relation participating in some way of the nature of that characterized by either particle. And this is indeed the case.

The necessity for a similar combination arises, in the mind of the Isinai, when two ideas are to be indicated as slosely associated, and as constituting one whole; but when, at the same time; only one of the two ideas, which is thus a part of a whole, is to be made the subject of speech, so that the other has to recede to the position of a remoter determinant element.

Upon translating into English (or German) a phrase built according to this order of ideas, it may find in either of those languages its equivalent in a genitival construction, or in a compound noun. In any case, it shows itself as responding to a partitive relation, in a material or a metaphorical sense.

$\$ 74$. I compare this construction, in the first place, with an English compound noun, as its idiomatic use is thus better shown.

In the previously used example, utun ba-iyur, louse-shaped mountain (German Lausberg) the word ba-iyur, mountain, is an explanatory addition to the word $u t u$, louse. It is connected with it by the simple enclitic $\mathbf{n}$, and the sense of both words merges into one complex idea.

In another designation, similarly built with the noun utu, viz. utun si asu (asu, dog) the construction is in so far the same as here, too, utu is appended with $\mathbf{n}$, and this in order to express that close connection between the two animals, louse and dog, which in our languages has led to the formation of the equivalent compound nouns "dog tick», (German Itundclaus). In this case, however, asu not being (as above ba-iyur) descriptive of the essence of $u t u$, but only of its outward position, Isinai does not allow the two ideas to merge into one through the association indicated by $\mathbf{n}$, but modifies this association by the insertion of si before asu. By so doing, both concepts are kept apart and the wole phrase becomes epuivalent to: "louse of dog», a partitive relation.

It may be remarked here in passing that the Tagalog compound noun susung dalaga, cited in the Introduction, could as will be felt after what has just been said - not possibly be 
rendered in Isinai by *susun mariit, ') which would express a relation as in utun bai-yur $(\mathrm{A}=\mathrm{B})$, but must be given by susun si mariit ( $\mathrm{A}=$ part of $\mathrm{B}$ ).

Taking now the case where English too uses a genitival construction, I illustrate it by the well known example of "amor Dei». In Isinai "love, having God for its object» is aru si Diosar, love for God, a prepositional phrase built with the help of attributive $\mathbf{s i}^{2}$ as exemplified in $\$ 70$; "love, having God as subject» is arun di Diosar, God's love, a genitival construction both in Isinai and in English, which shows us, at the same time, that also in this construction definite nouns are referred to in Isinai by di (cf. $\$ 77$ ).

$\S 75$. The regular disappearance of $\mathbf{n}$ after consonants, already well known to us from previous experience, disturbs, of course, the transparency of the construction here introduced. In the few examples so far quoted the characteristic pair of particles ( $\mathbf{n}$ si or $\mathbf{n} \mathbf{d i}$ ) was fully represented. But in expressions as:

bubung si beoi house top, ridge of roof

sá-gur si muang karabau horn, horn of karabau

át-tai si bittuon excrement of star, i.e. shooting star

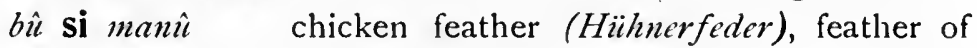
chicken

the particle si is left alone, $\mathbf{n}$ having disappeared in obedience to the phonetic rule just alluded to.

Still less perspicuous is this relation in the case of personal names which, used genitivally, lose the (personal) article si. In the sentence:

Kinorónandar iun Fesusar si suvit Crowned-object-their $+r$ (ri) head $+n$ Jesus + ar with thorn

the $\mathbf{n}$ after the vocalic ending of $i u$ (or: $i y u$ ), head, still indicates that relation; similarly in inan Lumazvigar, mother of Lumawig, matan Mariar eye of Mary: But in the sentence:

Ní-gou ri eeng Marianoar Burned p.o.r. clothes of Mariano $+a r_{\text {, even that }} \mathbf{n}$ has disappeared on account of the consonantal ending of eeng, clothes, and the combination of this word with Mariano would have the outward appearance of a compound noun (for example, like tuur batu, stone pillar) but for the suffix ar attached to Mariano. This ar, acting in regular co-

1) mariit, the Isinai equivalent of Tag. dalaga, = maiden. 
operation with the preceding $r i$ (compare $\$ 38$ ), differentiates this combination from the compound-noun just cited, since the latter would, if in definite form like the other expression, take that suffix after the first noun. Compare:

Inumbox di tuurar batu Fallen down p.o.r. pillar + ar stone.

The stone pillar has fallen down

$\S 76$. The rule for the position of suffix ar in case of genitival combinations was given in $\$ 14$. It may here be further illustrated by showing, in connection with what was said in the last paragraph, that the two particles ri and ar enclasp in such cases also a succession of two genitives:

Sário ri sî-bung di uzvan di amígo-ar This p.o.r. cap p.o.r. elder-brother $+n$ p.o.r. friend-my $+a r$ This is the cap of my friend's elder brother.

Uar panumen di ipus di ásuar ot amma-iar gailáyana The (containing particle $r i$ ) reason-of-wagging p.o.r. tail p.o.r. $\operatorname{dog}+a r$ is greatness $+a r$.joy-his. By wagging its tail the dog shows its great joy.

The fact that this disposition of the two particles ri $(u a r<u a+$ ri) and ar, one at the opening, the other at the end of the genitival combination, has the effect of binding the two or three nouns together, so that they are felt as a syntactical whole, may be gathered from the position of the word icir (left) as a determinant of matá (eye) in the following sentence:

Uar matán di and̀-uar içir ot diói sï atungna As-for-the eye

$+n$ p.o.r. child-my $+a r$ (juxtaposition) left p.o.r. extant

p.o.r. inflammation-its. The left eye of my child is inflamed.

$\$ 77$. In fuller illustration of the employment of the mixed type of construction, to which this chapter is dedicated, I give, in the following, some more examples showing it alternately characterized by si and by di.

First noun ending in a vowel:

Immoi si gawan si lavi $\mathrm{He}$ went in the middle of the night.

Immoi si gawan di laviar He went in the middle of last night.

Immoi si gawan si (or: di) lavion di huévesar $\mathrm{He}$ went in

the middle of the night of Thursday (Span. jueves)

Diói si tuvun si mahalila There are banana leaves

Anom dió tuvun di mahalilar Take away those banana leaves Nangan si bungan si kahél He has eaten (fruits of) oranges Uar bungan di kahélar ot neutu The (fruits of) oranges are ripe 
Diói si di-an si utong There are stains of iron

Uar di-an di átongar ot mandiritò The iron stains are red

Uar árunar ot amung arun si unga His love is like (the) love of a child

Uar arun di andi-nardari ot mampahailhaiya isia The love of his children is (a) cause of joy for him

First noun ending in a consonant:

Natói si sa-it si iyu (or: iuc) He died of headache

Mahanín matapálan di sa-it di iyuar The headache is easily. cured

Diói si dinatóng-u si bî si éau I have found a feather (or: feathers) of (a) hornbill (kalan)

Uar bù di eázvar ot manis-usilap The feathers of the hornbill are shining

Diói si damdamát pasax si tuur There is an (or plural) old post-nail

Uar pasax di tiurar ot damdama The post-nail is old.

$\$ 78$. Genitive of nouns preceded by a demonstrative pronoun

In a note to the section eDemonstrative pronouns with attribute», $\$ 64$, it has been remarked that demonstrative pronouns in emphatic form (sátic, uátie, etc.) were not always connected with the following noun by $\mathbf{n}$ (sátien talut), but that the noun was placed sometimes in mere juxtaposition, in which case it takes in exchange the definite form with ar (sátie tahuar). A modification of the sense was pointed out as attaching to this different construction in one instance.

The same alternative, now; I find in the formation of the genitive. For example, the sentence "The eyes of this man are blind $»$ is in Isinai either:

or: Uar matán di sátien tahu di sátie tahuar $\}$ ot mahuláu

Similarly, in the case of consonantal ending of the first noun, for "The clothes of this boy are dirty" either of the following forms may be used in Isinai:

$$
\begin{aligned}
& \text { Uar eeng di sáticn unga ? ot maavihan } \\
& \text { or: Uar ceng di sátie ungar }
\end{aligned}
$$

In both cases the sense is in no way affected by the changed phraseology.

Besides the two different forms here shown for each of these 
examples, yet others are possible. They are characterized by the use, in connection with the first noun, of the possessive pronoun anticipating the expression of the possessor, which expression then may follow in a fuller or a more concise form, thus :

\section{Uar matúnar di sútien tahu \\ Uar maténar tien tahu}

and :

\section{Uar cengnar di suiticn untga \\ Uar eengnar tien unga}

Also these alternative forms do not, as my teacher assured me, carry with them any modification of the sense.

\section{APPENDIX}

The Tale of the Turtle and Mr. Monkey.

$$
\text { Vidan }{ }^{1} \text { ) di Ba-ú-uar on si Aráu. }
$$

\section{Part I.}

Diói si osán ba-ú-u on aráu si sin-amigo, on uararátien sin-amigo ot immoiran nanpassiál si teantáhar.

5 Si sárien pampáspassiálda ya inilarát osán simpun mahalíla an mi-ánu-ánur on miléu-ui si áwu-áwung di danúmar.

10 Balapmós ta impangílayué ya inóiyun inéa on inawít dat teantáhar.

Datóng deat dí ya inatdín di aráwar si ba-ú-uar «Yä,

15 Amigo, pambewanta bayáu ta ayon-tan itanóm, ta ilan-
There were a turtle and a monkey who were united by friendship, and this pair of friends went to take a walk along the flat shore of a river.

While thus promenading they saw a trunk of a banana plant which floated on the water, following (the drift of) the waves.

Now, when they saw this they at once went to get it and. brought it to the shore.

On arriving there the monkey said to the turtle: "Look here, Friend, let us divide it and go to plant it; we shall

1) In Part I of the present tale only enclitic particles of relation are distinguished by different type. Accents have been used liberally. 
ta mu lumtà, ta lumtà ilá ya diói si ánon-ta.»

Balapmós ta ginottóng-dat

20 gáwanar, on uá isia, i Aráu, toi siar matdéar, ot pinílinar pungtúnar, toi anánea on siarir mahanúar lumtà, toi siarir matuvúanar, on

25 uá isia, i Ba-ú-u, toi siar makápuyar ot inatór di aráivar isiar púnanar toi sirir maavíhanar on maddahétar di abatáranar.

30 Balapmós ta asintónotnána on inawít-da si beoirardári on datóng deat beoirar ya binum-ás-dat tanóm.

Si sin-unún ehau limmá-us nanindatóng-dan sin-amigo

35 si osán lugár on impangilan lar ba-ú-uar i Aráu ya inatdí na:

"Hello, Amigo Aráu, kamosta-á on mevvés si bíç-

40 bihát isi-á! Kamosta bayáu ri intanóm-muar an nanbewanta?»

Inatdín di aráwar si ba-úuar: "Mevvésà-é. Sárie ilá

45 nanbewantar ya damamán echau mos natói. On kamosta bayáu ri isi-ár, Amigo ?» inatdín di aráwar si ba-úuar.

55 Inatdín di ba-ú-uar an nanabayat i Aráu, a Isáonar ilá an nanbéwanta ya nanbunga mos on deé mos si then see if it grows, and if it grows, then the two of us will have something to eat.

So they cut it in the middle, and as regards him, the mon$\mathrm{key}$, as he was the stronger, he chose the top part, thinking that this was what would grow most quickly, because the leaves were there, and, as for the turtle, she being the weaker, the monkey gave her the root part, because it was dirty and bad of appearance.

Now, after each had got his share, they brought it to their houses, and as soon as they. reached home they began with the planting.

Some time having passed, the two friends met again in a certain place, and when the turtle caught sight of Mr. Monkey, she said:

a Hello, Friend Monkey, how are you, and a good morning to you! How about that which you planted and we divided between us (the other day?)

Said the monkey to the turtle: *I am very well. As for that which we divided, why, it is dead a long time. But how is, I wonder, your own (share), Friend?" said the monkey to the turtle.

Said the turtle in answer to the monkey: "As for my part of what we divided, it is already. in fruit, and there is plenty of 
neutu uddú, mu sárilohóm

Besan impandongén lar aráwar ta deét neutu uddú ya inatdínan nanabáyat, "Aboleám lohóm, Amigo Ba-ú-u,

65 ta ánsanla saon manéwe isi-á.»

«Salamat, salamat isi-á mu mahò-gos-á ta ampailamu pambéwanta.»

70 Baliıpmós ta inawít di baú-uar si Aráu si beoinar on datóng deat di ya inawítnat loontánar.

Siriémos umas-asúp-dat pú-

75 nanar ya man-ílo-ílox tuát Aráu si ammá-iar gaiháyanan nanbatar si neutúar bungat diríng-at di túvuardári.

80 Siriémos an dimmatóng-dat púnanar ya impaéau Ba-ú-u si Aráu on si Ba-ú-u ilá ya nipaar si púnanar.

Datóng-ngé Aráu sirí uddún

85 di mahalílar ya binum-ás â-a-án si gostónar, on uá isia, i maahò-gósan Ba-ú-u, ot mî-dau i Aráu eámmos ya urián Aráu peleton toi

90 diói si a-ánar uddú.

Balapmós ta bungot lar baú-uar i Aráu ya immói nangeat deét suvít si teantáhar on datóng neat púnan di 95 mahalílar y’a binum-ás si ripe fruit on the top, but the only thing is that I cannot pick it.»

Now as soon as the monkey heard that there was ripe fruit on the top (of the plant), he said in answer: "Make yourself easy, Friend Turtle, I will undertake to pick it for you.»

"Thanks, thanks to you, if you will have pity on me, I don't mind sharing it with you.»

So the turtle took Mr. Monkey to her house and upon their arrival there, led him at once into the garden.

When they came near the plant, the monkey ran quickly (to it), overjoyed at the sight of the ripe fruit among the leaves.

Arrived at the plant, the turtle caused the monkey to climb up and she herself remained at the foot of the trunk.

Hardly had the monkey reached the top of the banana when he began munching to his heart's content, and as for poor Mrs. Turtle she was left to beg from the monkey who, however, did not listen to her, as he was busy with his feast at the top.

Now, the turtle, being very angry with the monkey, went and got a heap of thorns from the river-side, and, upon arriving again at the trunk of the banana, 
lurun si libolibor di mahalílar.

Pô-dax nean nanlurun ya immói nan-áp-áp si upà di 100 niuhar.

Balapmós ta sárien umpás mos si Aráu toi návus mos mangan ya uriánan domon toi areén di lurun ba-ú-uar.

$105 \mathrm{Si}$ sin-unún bâ-bâ ya nasuhatan si Aráu si ammá-i si in-opò-pásnar.

Inánap nar ba-ú-uar besan on dinatóng nat upà di

110 niuhar.

Impangilan lar aráwar isia ya inatdína, "Besan an tua, mu marían mambayar si ináp-appiámar isaon, mu

115 uriâ si-ân patayoón besan. Mampili-at baỹúwo-ar si-át lúsungar si ibbóng-uar si-át da-númar.»

Inatdín ba-ú-uar nanabayat

120 i Aráu, "Ahái-hayâ di bayúwonà-ar mu ibbóngà-ar si danúmar toi méngatà.»

"Haha! Mevvés toi imbahám!» Balapmós to ginú-

125 yurnan inawít si danúmar on datóng neat dí ya imbalívenat gawan di danúmar.

Besan impangivalíven lar 130 aráwar si ba-ú-uar ya man- at once set out planting them in the ground around it.

As soon as the planting of the thorns was finished she went and hid herself under a coconut-shell.

Now, when the monkey had finished eating and was about to descend, he could not do this on account of the multitude of thorns stuck in the ground by the turtle.

In short, the monkey got badly hurt in his descent.

He now searched for the turtle and found her under the coconut-shell.

As soon as the monkey saw her, he said: "Now, this is the truth, you will not pay for what you have done to me, if I do not kill you. Choose between my pounding you in the rice mortar and my throwing you into the water.»

Said the turtle in answer to Mr. Monkey: "I would sooner be made the object of pounding than be thrown into the water because I would get drowned."

"Haha! Good that you told me!» So he dragged her to the river and, once there, threw her into the middle of the water.

Now, hardly had the monkey thrown the turtle (into the 
iiat si Ba-ú-u on mantatawa i Aráu on inatdína isia: «Kuk! Beoi-uar latút aungá-ar!» water), when the latter began swimming about, laughing at Mr. Monkey and shouting: « Kuk! Why, this is the very home of my childhood!»

A key for the translation of Part I of the fable.

\section{Interlinear Notes.}

(Where a freer rendering of the sense of Isinai words was found necessary, the corresponding English words were put in quotation marks. Particles of relation discussed in the present paper were inserted untranslated into the English line with the object that the reader himself might give them their proper value. Complex word-forms were frequently broken up into two or more component parts in order to better show their structure.)

Bida $\mathrm{n}$ di ba-ú-uar on $\begin{aligned} & \text { si } \\ & \text { pers. }\end{aligned}$

Tale $n$ di turtle $+a r$ and art. Monkey.

Diói si osá $\mathrm{n}$ ba-ú-u on aráu si sin-amigo a mutual

Extant si (certain) $n$ turtle and monkey si friends on uararátie $n$ sin-amigo ot immoira $n$ nanpassiál si Perf. \& Plur. Perf. of and these $n$ friends ot of "one going» $n$ "prome- si nader $\gg$

teantáhar. Si sárie $\mathrm{n}$ pampáspassiál da ya inilará t flat shore the seen of river $+a r$. Si said $n$ "promenade, their $y a$ thing $+\quad t$ their

osá n simpún mahalila an mi-ánu-ánur on miléu-ui si a what is what is (certain) $n$ trunk banana an floating and following si

áwu-áwung di danúmar.

undulation $d i$ water $+a r$. 
Balapmós ta impangíla yué ya inói yu n Perf. of your Perf. of

"Now" then "time of seeing" $+\dot{e} y a$ "obj. of your $n$ going to fetch"

inéa (inéya) on inawít da $t$ teantáhar. Datóng

Perf. of Perf. of (Idea of)

"obj. of getting" and "obj. of their $t$ shore + ar "arrival" bringing»

dea t dí ya inatdí

n di aráwar

si contraction of Perf. of

$d a$ (their) +la $t$ di $y a$ cobj. of saying» $n$ di monkey $+a r$ si ba-ú-uar, «Yä, Amigo, pambewan ta bayáu ta ayon obj. of my and obj. of turtle- $a r$, «Say, Friend, dividing thy "may be» then going 10 ta $\mathrm{n}$ itanóm ta ilan ta mu lumtà, ta lumtà my and obj. of obj. of my and sprout- sproutthy $n$ planting then seeing thy if ing then ing

$\begin{array}{llllll}\text { ilá } & \text { ya } & \text { diói } & \text { si } & \begin{array}{l}\text { ánon } \\ \text { obj. of } \\ \text { eating }\end{array} & \begin{array}{l}\text { ta. } \\ \mathrm{my} \\ \text { and thy. }\end{array} \\ \begin{array}{l}\text { indeed } \\ \text { (or: if) }\end{array} & \text { extant } & \text { si } & & & \end{array}$

Balapmós ta ginottóng da $\mathrm{t}$ gáwanar on uá isia, Perf. of middle + "as obl. case "Now» then cobj. of their $t$ its $+a r$ and for» Pers.Pron. cutting *

3. Pers.

i Aráu, toi sia $r$ matdéar, ot pinílinar Pers. Pron. strong obj. selected + $i$ Monkey, because 3. Pers. $r(r i)$ one $+a r$, ot his $+r(r i)$ pungtúnar toi anánea on siarir mahanúar lumtà top part * "his think- "that is something what is its + ar because ing and just what, quick + ar sprouting

15 toi siarir natuvúanar, "that is Perf. of because just what" "place having on úa isia, "as obj. case leaves» + its $+a r$ and for» Pers. Pron. 3. Pers. 


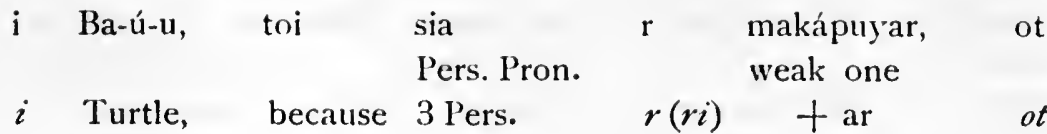
in-atór di aráwar isia $r$ púnanar toi sirí $r$ given monkey to root part

thing $d i+a r$ it $r(r i)$ its $+a r$ because there $r(r i)$

maavíhanar on maddahétar di abatáranar. what is what is aspect $t$

dirty $+a r$ and bad $+a r$ di its $+a r$

Balapmós ta asintónotnána on inawítda si beoirardári "after each brought

"Now" then had its share» and thing - si houses $f$ their their

20 on datóng dea $\mathrm{t}$ beoirardári ya binum-ás da $\mathrm{t}$ (idea of) ( $d a$ Perf. of

and "arrival» $+(a) t$ houses + their $y a$ «beginner they $t$ tanóm. Si sin-unú n ehau limmá-us nanindatóng da $n$ (idea of:) Perf. of Perf. of

planting Si «series» $n$ day "passing» "who are they $n$ meeting*

sin-amigo si osá $\mathrm{n}$ lugár on impangila $\mathrm{n}$ la $\mathrm{r}$ a (Span.) Perf. of emph.

friends si (certain) $n$ place and «time of $n$ part. $r(\boldsymbol{r} i)$ seeing»

ba-ú-uar i Aráu ya inatdí na, "Hello Amigo Aráu turtle Perf. of

$+a r \quad i$ Monkey ya cobj. of its "Hello Friend Monkey" saying»

kamosta a on mevvés si bíç-bihát isi-á! Kamosta bayáu (corr.

Span.) to sany how is thou and good si morning thee! How is how

$25 \mathrm{ri}$ intanóm muar planted thing

$r i+$ thy $+a r$

$\begin{array}{lll}\text { an } & \text { nanbewan } & \text { ta ?» } \\ \text { divided } & \text { our } \\ \text { an thing } & \text { (dual) }\end{array}$


Inatdí $n$ di aráwar si ba-ú-uar, "Mevvésà é Sárie ilá Said emph. "As for thing $n$ di monkey si turtle IVell part. that $+a r+a r+\mathrm{I}$ which

nanbéwan tar ya damdamá n ehau mos natói. On kamosta our

divided (dual)

thing $\quad+a r y a$ past $n$ day already dead. And how is bayáu ri isi-ár Amigo?» inatdín di aráwar di bau-ú-uar. "rather" the thine Friend

Inatdín di ba-ú-uar an nanabáyat i Aráu, «Isáonar ilá Perf. of The "as

an "one ans- $i$ Monkey mine for» wering »

30 an nanbéwanta ya nanbunga mos on deé mos si "shared between what has

$a n$ the two of us» $y a$ made fruit already and plenty already $s i$ neutu uddú mu sari lohóm toi uria $\mathrm{m}$ dómon what has "the thing is obj. of "possible ripened above but onlythat negation thing + my

sevéon.»

obj. of

reaping.

Besan impandongé $n$ la $r$ aráwar ta deé $t$ Perf. of emph. monkey

Now stime of $n$ part. $r(r i)+a r$ that plenty $t$ hearing»

neutu uddú ya inatdí na $\mathrm{n}$ nanabáyat, Aboleám ripe said poss. Perf. of "Never

things above $y a$ thing suffix $n$ aone replying» mind» -3. Pers.

35 lohóm, Amigo Ba-ú-u, ta ansan la saon emph. only, Friend Turtle, then responsible part. (quite) I 


$\begin{array}{ll}\text { manéve } & \text { isi-á. } \\ \text { one } & \text { for } \\ \text { reaping } & \text { thee }\end{array}$

«Salamat, salamat isi-á mu mahò-gos-á ta ampailámu Thanks, thanks you if pitiful + thou then «even if

$\begin{array}{ll}\text { pambéwan } & \text { ta.» } \\ \text { obj. of } & \text { our } \\ \text { dividing } & \text { (dual) }\end{array}$

Balapmós ta inawít di ba-ú-uar si Aráu Perf. of

"Now» then "obj. of di turtle si Monkey bringing*

40 si béoinar on datóng dea $t$ dí ya inawít house + (cf.same Perf. of si its tar and "arrival» above) $t$ di $y a$ "obj. of bringing 》

na $t$ loontánar. Sirié mos umas-asúp da $t$ púnanar The drawing "place of

its $t$ garden + its said already near they $t$ trunk far $+a r$.

"When»

ya man-ílo-ílox tuá $\mathrm{t}$ Aráu si ammá-iar gaiháyana $\mathbf{n}$ one walking true what is

ya quickly (truly) $t$ Monkey si great $+a r$ joy + its $n$

nanbatar si neutúar bunga $t$ diríng-at di túvuardári.

Perf. of ripened leaf + ardari

"oneseeing" si things fruits $t$ inter- $d i$ (foliage) $+a r \quad$ spaces

Siriémos an dimmatóng da $\mathrm{t}$ púnanar ya impaé(y)au.

Perf. of
"When" an "comer" they $t$ trunk tar $y a$ "what is

caused to

climb » 
45 Ba-ú-u si Aráu, on si Ba-ú-u ilá ya nipaar si Turtle si Monkey and si Turtle for» ya "one re- si maining»

púnanar. Datóng-ngé Aráu sirí uddú $\mathrm{n}$ di mahalilar place of Arrival banana trunk + ar hardly» Monkey there top $n d i+a r$

\begin{tabular}{|c|c|}
\hline ya & binum-ás \\
\hline$y a$ & $\begin{array}{l}\text { Perf. of } \\
\text { "beginner }\end{array}$ \\
\hline
\end{tabular}

si â-a-án si gostónar on uá isia, i maahò-gósan (Span,) «as it

si feasting si gusto, pleasure and to» (cas. $i$ pitiable $+n a+a r$ obl.)

Ba-ú-u ot mî-dau i Aráu eámmos ya urián Aráu one obj. of

Turtle ot begging $i$ Monkey "only» ya not being Monkey

50 peleton toi diói si a-ánar uddú. obj. of the eating

listening because khe is» "at» (or: his eating) above.

Balapmós ta bungot a la $r$ ba-ú-uar i Aráu (idea of:) (emph. turtle

"Now» then angry part.) $r(r)+a r \quad i$ Monkey "very"

$\begin{array}{lllll}\text { ya immói nangéa } & t \text { deé } t \text { suvít si teantáhar } \\ \text { Perf of } & \text { Perf. of } & & & \end{array}$

$y a$ "one going" "one fetching" $t$ plenty $t$ thorn $s i+a r$

on datóng nea (na la) $t$ púnan di mahalilar ya poss. suffix root banana

and arrival 3. p. +emph. part. $t$ part $+n d i+a r \quad y a$

binum-ás si lurun si libolíbor di mahalilar.

Perf. of planting banana

"one beginning» $s i$ of thorns si circumference $d i+\operatorname{ar}$ 
55 Pô-dax nea (na la) poss. suffix

$\begin{array}{lll}\substack{\text { nanlurun } \\ \text { Perf. of }} & \text { ya immói } \\ & \text { Perf. of }\end{array}$

"Finished» 3. Pers. +emph. $n$ "one planting $y a$ "one going part.

thorns»

\begin{tabular}{|c|c|c|c|}
\hline $\begin{array}{l}\text { nan-áp-áp } \\
\text { Perf. of }\end{array}$ & si & upà & $\mathrm{di}$ \\
\hline "one hiding" & si & shell & $d i$ \\
\hline
\end{tabular}

$\begin{array}{lllllll}\text { Balapmós ta sirie } \quad \mathrm{n} & \begin{array}{l}\text { umpás } \\ \text { one }\end{array} & \begin{array}{l}\text { mos } \\ \text { already }\end{array} & \text { si } & \begin{array}{l}\text { Aráu toi } \\ \text { Mon- }\end{array} \\ \text { "Now" } & \text { si key- } & \text { cause }\end{array}$

$\begin{array}{llllll}\begin{array}{l}\text { návus } \\ \text { Perf. of }\end{array} & \begin{array}{l}\text { nangan } \\ \text { Perf. of }\end{array} & \text { ya } & \begin{array}{l}\text { uriána } \\ \text { obj. of }\end{array} & \text { n } & \begin{array}{l}\text { dómon } \\ \text { obj. of }\end{array} \\ \text { "what is already } & \begin{array}{l}\text { "one eat- } \\ \text { ceasing» }\end{array} & \text { ing } & & \begin{array}{l}\text { not being }+ \text { Poss. Suffix 3.P. } \\ \text { possibility }\end{array} & \end{array}$

toi areé $\mathrm{n}$ di lurun di ba-ú-uar. Si sin-unún bâ-bâ, be- plenti- planted cause fulness $n$ di thorns $d i$ turtletar "In short».

60. ya nasuhátan si Aráu si ammá-i si in-opò-pas nar

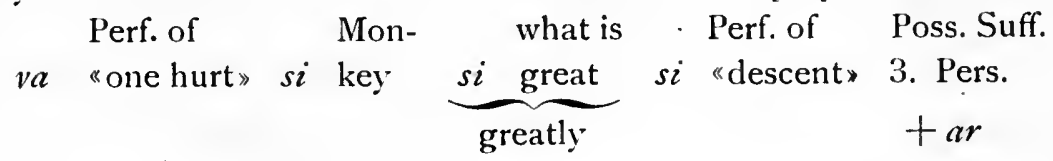

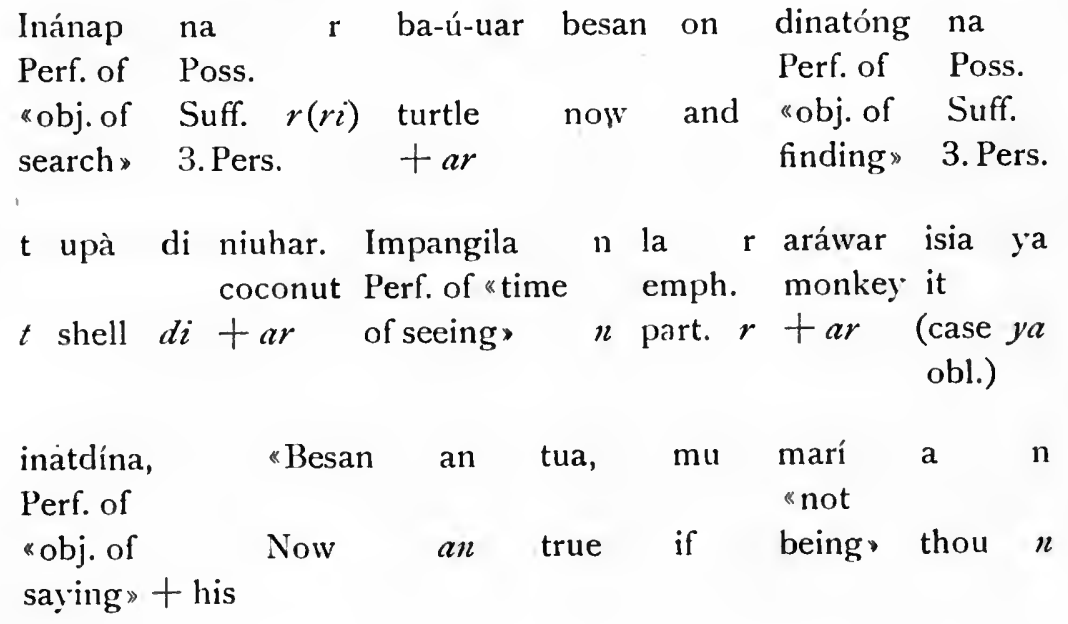




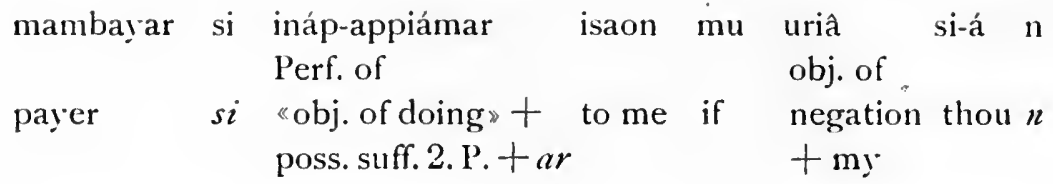

65 patayoón besan, Mampili a $t$ bayúwo-ar si-á $t$ lusungar obj. of one obj. of

killing now choosing thou $t$ pounding- thou $t$ mortar my $+a r+a r$

$\begin{array}{llllll}\text { si } & \begin{array}{l}\text { ibbóng } \\ \text { obj. of }\end{array} & \text { uar } & \text { si-á } & t & \text { danúmar.» } \\ \text { water } & & & \text { tar }\end{array}$

Inatdí $n$ di ba-ú-uar nanabáyat i Aráu: "AhaíPerf. of Perf. of hayâ

"obj. of $n$ di turtle $+a r$ "one answering" $i$ Monkey "Liking say'ing ,

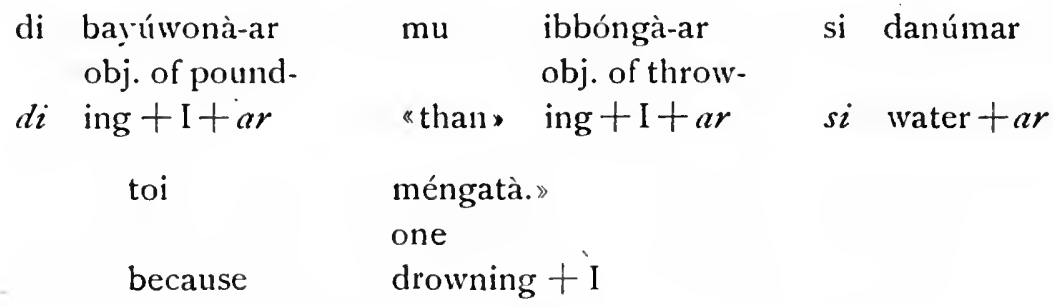

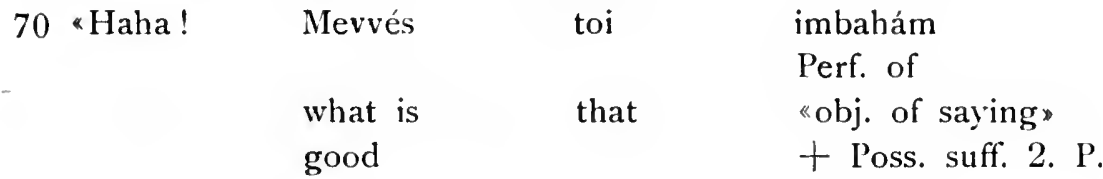

Balapmós to ginúyur ' na $n$ inawít si danúmar Perf. of Poss. Perf. of

"Now" then "obj. of suffix $n$ "obj. of si water tar dragging» 3 . Pers. bringing 》

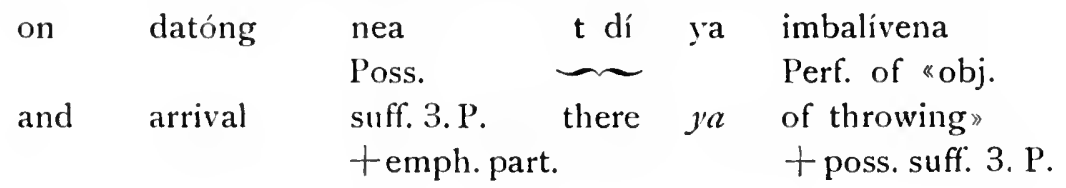

$\begin{array}{llll}\mathrm{t} & \text { gawa } & \mathrm{n} & \mathrm{di} \\ t & \text { middle } & n & d i\end{array}$




\begin{tabular}{|c|c|c|c|c|c|}
\hline water $+a r$ & Besan & $\begin{array}{l}\text { impangivalive } \\
\text { Perf. of "time } \\
\text { of throwing" }\end{array}$ & $n$ & $\begin{array}{l}\text { la r } \\
\text { emph. } \\
\text { part. } r\end{array}$ & $\begin{array}{l}\text { aráwar } \\
\text { monkey } \\
+a r\end{array}$ \\
\hline $\mathrm{si}$ & $\begin{array}{l}\text { ba-ı́-uar } \\
\text { turtle }\end{array}$ & $y \cdot a$ & & & \\
\hline si & $+a r$ & $y a$ & & & \\
\hline
\end{tabular}

man-iiat si Ba-ú-u, on mantatáwa i Aráu, on inatdí one swim- one laugh- Perf. of ming about si Turtle and ing $i$ Monkey and "obj. of saying"

na isia, «Kuk! Beoi uar la tú $t$ aungá-ar!» poss. it my emph infancy suff. (cas. House tar part. here $t m y+a r$

3. Pers. obl.)

\section{Explanatory Notes.}

Title. Bida from Spanish vida, life, biography. By "Vidas» or "Corridos" are designated a great number of cheap pamphlets written by Christian Filipinos under cxotic influence in description of the doings of imaginary princes, knights, and fair ladies of Spain, Portugal, Greece, etc. The application of this term to specimens of ancient Indonesian folklore, like the present, is a regrettable anachronism.

$b a-i \iota-u$ turtle, compare Tagalog bakoko, a certain kind of fish. Note the difference in the articles employed in: Tale of the Turtle (ar) and Mr. (si) Monkey. As the story-teller uses later both articles indiscriminately, attention is called to the capital letter used for the name following the personal article. Note also that the turtle is addressed by the monkey as a male person ("Amigo») in the Isinai text.

Line 1. dió $i$ extant, a particle of demonstrative character, similar in sense to "There is", but lacking any reference to time, a deficiency especially felt by us at the beginning of a story. (Compare English, "There was once upon a time», etc.). 
sin-amigo, united by friendship, (Span. amigo-friend) compare Tag. sandugò, united by (drinking one another's) blood.

Line 2. immói, the temporally undefined form (Indefinitum) is amói, used for Present or Future; nanpassiál (Span. pasear), Indef. mampassiál.

Line 4. simpun, united into one trunk or bunch; duan pun, two bunches.

Line 5. ázu-ázung di danumar: genitival relation!

Line 6. impangila yiue: the story-teller here engages the interest of his hearers by substituting for the proper possessive suffix of the 3. Pers. Pl. (ra, their) that of the 2. Pers Pl. ( $y u$, your); compare the use of euch in German: "Kaum schen sie den Stamm, so werden euch doch die beiden daran gehen und....»; the same in the case of inói yu. Inói (Indef. ayón) refers to "something gone for» or "fetched», with the idea of "bringing hither", distinguished from in-ói (Indef. $i$ - $o i$ meaning "something taken away, going hence»).

For $\dot{e}$ after impangila $y u$ compare note to line 51 .

Line 8. For dea, compare note to line 51.

inatdi: Indef. atdión.

Line 9. pambewan or pambewon ta; before other pronouns the form in on seems to be exclusively used: pambervo, my object of division, pamberwom, thy obj. of division, etc.

bayáu, a particle pleading or encouraging: "Let us dividen.

Line 10. lumtà : Perfect nilumtà.

Line 11. ilà: from its probable primary function of simply emphasizing the preceding expression, this particle acquires such different shades of meaning as «indeed" "if», "as regards». (Compare line 26)

anón. Perfect inán.

Line 12. ginóttong: Indef. got-tóngon.

Line 13. pinili: Indef. pilión.

Line 14. anánea $<$ anán (idea of pondering, weighing in mind, Tag. akala $)+n a+l a$. For contraction of $n a+l a$ to nea see note to line 51. The result of the reflection is introduced by on: "He thinks (or: He thought) that Maria is (was) dead» anúnea on natói si Maria. The 
expression anin with following possessive suffix is, as a rule, followed by an emphatic particle é or $(l) a$, thus: $\left.\begin{array}{l}\text { anci-é, my } \\ \text { anammé thy } \\ \text { anánea his }\end{array}\right\}$ pondering $\left.\begin{array}{l}\text { anán milá our } \\ \text { anán yué your } \\ \text { anán dea their }\end{array}\right\}$ pondering

Line 15. siarir: sia ri natuvianar would be "that is the leafy part of it»; by a reduplication of $r i$, sia-ri-r(i), the demonstration becomes more pointed: "that is just the .... Compare preceding "siarir mahanuar lumtà».

Line 17. in-atór: Indef. i-atór.

puna, the lower part of a tree, including roots (lamit)

Line 18. maavihan, what is dirty, compare mavic-à I nauseate, German es ekelt mich.

Line 19. asintónotnána: probably going back to tona as a radical part; tona has the meaning of "belonging" "corresponding to (somebody)»; tona in reduplication may very well take the form tonnotna to wich are added here the prefixes $(k) a$ and $\sin$, and the possessive suffix 3 . Pers. na.

Line 20. binum-ás: Indef. bum-ás; compare bo-ás idea of "finished»: bo-ás lar urainar after the rain.

Line 22. Impangila n la ri ba-it-uar: a genitival construction "time of seeing of the turtle." The particles $n$ and $r i$ characterizing the genitival construction are here separated by the emphatic particle la for wich see note to line 51 .

Line 23. Hello! one of a number of loan words introduced with the advent of Americans in the Philippines.

Line 24. kamosta corrupted from the Spanish "como esta (Vd)?». Line 27. natói, Indefinite matói who or what is going to die.

Line 29. nanabáyat, Indef. manabáyat.

Line 31. neutu or niutu, Indefinite meutu (miutu); compare Tag. malutu, boil.

dómon, also daumon is heard; Perfect dinaum; compare maraim powerful, mighty; domon is evidently to be explained as: radical daum(raim), idea of power, + suffix on (= Tag. $i n$ ) referring the idea of the radical to some object; dómo, dómom what I can, do, what thou, canst do; the same stem with infix um gives dumaium (also pronounced dumawím), one able. 
Sirien ilar dumazviumar mangéan si tien ayu ya atdâ si simpiun pesos To him who is able to climb this tree shall I give ten pesos.

Line 32. sevion, from seve, stalks, straw (of rice).

Line 33. impandongén la; for emphatic particle la compare note to line 51.

Line 34. aboléam $<{ }^{*}$ aboléan mu; apparently from radical bolé cost, price, although the derivation in sense is not equally clear. Mavvlé, precious, dear.

Line 35. ansan la: compare note to line 51.

Line 39. inawit di ba-i(-uar si Aráu, Object of conducting of the turtle (was) Mister Monkey, si beoinar, to her house.

Line 41. loónta, garden. Rocamora has: si Laontar Getsemani (p. 141.); the word appears to be a corruption of Span. la huerta, obsolete la hórta. The Spanish article la has been taken over, together with the following feminine noun, also in other Philippine loan words; compare Ilk. lacasa (la caxa), chest, box; lamesa (la mesa), noon, 12 o'clock (time for going to table).

Line 43. diring-at from ding-at, interspace, with pluralizing reduplication of first syllable.

Line 44. impaeau Ba-í-u si Aráu: the first two words represent a genitive construction "object caused to climb of (the) Turtle (was) Mr. Monkey.s The construction becomes somewhat more conspicuous by substituting the appellatives to the personal names: impaéan di ba-í-uar di arawar where at least one $(d i)$ of the two particles that characterize the genitival relation appears, before $b a-i t-u a r$, the other $(n)$ being made possible by the final diphthongal sound of impacau; but also $n$ appears, if we substitute impaéa by impaéa (vocalic final), meaning "what was caused fetched»: impacan di ba-il-uar di arazvar "object caused fetched of the turtle (was) the monkey" (that is, the turtle caused the monkey to be fetched). For the more remote relation indicated by si, compare with this last sentence the following: impaéan di ba-î-uar di mahalilar si arizuar "object caused fetched of the turtle (were) the bananas through the monkey.» That is, the 
turtle caused the bananas to be fetched by the monkey. Inclef. of impaciau is: pacazvón.

Line 46. datóng-ngé Ariu, commented upon in note to line 51. Line 49. urián Aríu peleton; peleton (Perfect pinclet) fluctuates in sense between object of listening, of needing, of. forcing; here the first of these meanings is expressed. Instead of uriain Ariu peleton, also urian peleton Ariu, or: uricin peleton di ariwar, might be said, but in any case a genitival construction is present "The turtle was not the object of the monkey's listening."

Line 51. bungot lar ba-u-uar $i$ Aráu, angry, emphatic particle + p.o.r. the turtle at Mr. Monkey. Here and in various other passages of the story a particle ${ }^{\circ} a$ occurs which, according to the existing context, lends itself to different interpretations. As its generic function seems to be that of laying a certain stress upon the expression preceding it, I have called it an emphatic particle. Seeing that it sometimes changes its form and, at others, is relieved by a particle $e$, it requires a more detailed explanation.

Instances of the occurrence of la are:

Line 22 impangilan lar ba-u-nar

Line 33 impandongén lar aráwar

In both of these cases $l a$ accentuates the preceding expressions of time (impangila, what was time of seeing, impandongé what was time of hearing) in a manner which may be considered equivalent to the use, in such cases, of an English preposition like "at or "upon» (at the time of seeing, upon hearing), or which, in freer, more verbal English phraseology, can be graduated, according to the context, by the choice of an appropriate adverbial connective, such as: when, as soon as, hardly, etc. Thus in the first of the two cases cited, we might translate: * when the turtle caught sight of the monkey», while in the second, the manifest greediness of the monkey suggests the rendering of la by the more vivacious "Hardly did the monkey hear of an abundance of ripe fruit." On the other hand, in the case of bungot lar ba-ituar $i$ Arau, it is not any time that is accentuated by la, but the degree 
of angry emotion of the turtle, so that here an appropriate rendering of the force of that particle would be: "very much" or "greatly», thus "Now, as the turtle was very much angry at the monkey." For a similar use of $l a$, to be covered again by English "very", though in an idiomatic employment, compare the concluding words of the first part of the tale: "Beoi uar la tit anngá-ar» This is the very home of my infancy.

As to the changing form of $l a$, it appears that after a preceding $a$, its first sound, $l$, merges with such $a$ into $e$. Without entering into an examination of this change as a phonetic phenomenon, I refer here only. to the same $\ell$ in Isinai, which in a considerable number of words shows itself, upon comparison with the same words in other Philippine dialects, as represented by $a l$ in these latter. I cite: $e a$, Phil. ala, idea of getting; eau, Phil. kalau, hornbill; ehau, Phil. arau, aldau, etc., sun, day; meong-kot, Tag.malungkot, sad; dea, Pang. dala, blood; many others will have been noted in the preceding part of this paper. I hold that it is this same $e$, to be resolved into $a+l$, which in the text repeatedly occurs in the words "datóng dea" and "datóng nea" (lines $8,20,40,53,72$ ) and in each case correctly corresponds with a theoretical form *datóng da la, or *datóng na la, forms of which my informant had to say, that they were in the nature of sbaby

- language». The explanation here given is confirmed by the fact that in each of the cases just cited there is applicable the same rendering by an adverbial conjunction of time which was above shown for la; thus, in some cases, "when they arrived" or, in others, suiting the, requirement of the context, "as soon as he arrived, " though in view of the nominal nature of the Isinai word-forms, a prepositional construction might be preferable: "upon their arrival," "at once. upon his arrival.» etc.

Besicles this $\epsilon$, now, whose origin as indicated can hardly be doubted, there occurs another $c$, equally emphatic and, since it alternates in a certain mode with the former, presumably related to it, but whose for- 
mation from $a+l$ is not equally clear. This $e$ will already have been noted in the table given in note to line 14 (compare andi-é, anammé, anan yuć). It occurs further in line 26: mevvésà-é, and in line 46: datóng-ngé Aráu, where it can be accounted for again by English "very": "I am very well" and "At the very arrival of the monkey:s Note that, like la (f. i. in: impangila n la ri ba-ik-uar), also this $c$ interpolates itself between the two members of a genitival construction: datóng-ngé Aráu. Note further that it tends to reinforce itself by attracting, in certain cases, a preceding consonant: anammé, datong-ngé. To judge from the table given in note to line 14 , it appears that this $e$ supplants $l a$ regularly after consonants (including the glottal check) and after the vowel $u$, an observation still more clearly to be made in the following list of the forms arising upon combination of dationg + poss. suffix + emph. part.

$\left.\begin{array}{lll}\text { datóng ué } & \text { mỳ } & \\ \text { datóng mué } & \text { thy } & \\ \text { datóng nea } & \text { his } & \\ \text { datóng milá } & \text { our } & \text { (exclusive) }\end{array}\right\}$ arrival

Whether this $e$ ultimately will be found to have sprung from la, or not, in force it is certainly equivalent to this latter particle. Line 54. lurun; with this word the Isinai indicate, according to my informant, a certain means of defense used for their dwellings, by the Ilongot (Isn. "Ivilau»), consisting in the surrounding of the houses with numbers of pointed sticks hidden by a covering af leaves.

Line 59. si sin-unin bâa $b \hat{a}$ "for a series of words», has the same meaning as English: "to make a long story short", "to be brief".

Line 60. in-opò-pas: Indefinite i-opò-pas; compare umpris, one descencling.

Line 61. incinap: Indef. anápon. Instrument of searching is i-anap, Perfect, in-anap. 
Line 63. "Bcsan an tua"; the words of the monkey following these, and as far as: "patayon besan", consisting of two sentences each of which begins with $m u$ and following negation, are probably a specimen of idiomatic Isinai phraseology, the sense of which does not easily. follow from the words themselves. I have attempted to render the double negation by something similar in the English text, without pretending to give therewith an exact counterpart of the Isinai form.

Line 72. imbalive: Indef. ivalive.

Line 74. Impangivalive $n$ la $r(i)$ ariwar si ba-u-uar: si has here the value of $s i^{2}$ as discussed in the preceding paper; the words impangivalive $n$ la $r(i)$ arawar form a genitival construction with $l a$ interpolated between the two characteristic particles $n$ and $r i$ (di). An approximate rendering of the construction of this phrase would be: "Just after the throwing-time of the monkey with regard to the turtle».

Part. II.

Uar aráwar ot masa-ít poddár nomnommar si impandongénar si sátien bâ-bâ.

Besan uar inappian di aráwar ot immói si beoi di ambuvussíar an impahogô-gos si ammá-i ta maraúm ilá ya dâ-dá-nat asása-ítanar on atdípaila i Ambuvússi i Aráu.

Besan datóng neat di mavvléar beoi Ambuvússi ya inatdína: "Mevvés si ehau, Apu Ambuvussi».
The monkey was greatly pained in his mind upon hearing these words.

Now what the monkey did was this: he went to the house of the ambuvussi ') to entreat him to help him, if possible, in his affliction, and so would the monkey help the ambuvussi.

Upon arriving at the respectable house of the ambuvussi, he said, "Good day, Master Ambuvussi.»

1) The animal here introduced under the name of "ambuvussi" is unknown to the fanna of the country of the Isinai. The latter know it, aecording to my informant, only as a legendary animal. Of a man who drinks excessively they are wont to say that he is an "ambuvussi". Compare the "dangkou" of the Tou-n Sea (Nortliern Celebes) in Kern's study mentioned in the Introduction. 
Inatdin di ambuvussíar an nanabayat: "Mevvés pai si ehau isi-á Araú; andie pelétomar? Besanat la lohóm si nangílà isi-á on inalíam sitú beoi uar?»

Inatdín di aráwar i Ambuvússi, «, Apu, toi uar sangkan-uar an immalíà sitú mavvléar it-tuam ot ta maraúm ilá ya milu-ui-á ai isaon ta turunaám ai dió danúmar si uang-uángar an nangibbongà si ba-ú-uar an namasait isaon ta uemu dómò ạn iveyus di inap-appiánar isaon.»

Besan inatdín di ambuvussíar i Aráu. "Annu? Andie sangkan muar an nangibbóng isiat dí ya anta beoinar diet aunganar; sirít nianà-anà é.»

«Besan eampai, Apu, toi impampili si bayúwo-ar si lusungar si ibbóng-uar si danúmar, on inatdína‘ Bayłúwonà-ar, uriánà lohóm ibbóng si danúmar toi méngatà'»

Besan inatdín di ambuvussíar i Aráu, "Annu? Andie kasalánanar an nangappiám si atdí?»

*Besan eampai, Apu, toi immóià si loontá-ar an manewet intanómuar an mahalila ya sirien dioià (dioyà) uddú mahalilar an mangeat neútuardárin bunga ya diói si dingngê si voses ${ }^{1}$ ) si punan
The ambuvussi replied, «Good day also to you, Monkey; what do you want? (Why is it that) only now do I see you and you come here to my house?.

Said the monkey to the ambuvussi, "O, Master, the reason of my coming here to your respectable dwelling is (to ask you) if possible, please to come whith me and kindly drink up the (broad, running) water which is where I threw the turtle who has offended me, so that I can revenge what she has done to me."

Now said the ambuvussi to the monkey: «What? For what reason did you throw her there, since you ought to know that that is the place of her infance; that just there she was born.»

"Well, Master, it is because I let her choose between being pounded by me in the mortar and my throwing her into the water, and she said: "Pound me, but do not throw me into, the water, because I shall get drowned.»"

Now said the ambuvussi to the monkey: "What? What was her fault that you acted like that?

«Because, Master, I went into my garden to reap the bananas which I had planted and when I was in the top of the banana plant, picking the ripe fruit, I heard a voice at the foot of

\footnotetext{
1) (From Span.) voz, voice.
} 
di inéauà-ar an mahalila. Sirien man-utdúngà ya inilà si Ba-ú-u an mî-clau si mahalila. Besan toi inuriâ inatclan o intâ-duhan si mahanú yaa uar inap-appiánar ot nilurúnanar libo-libor di inéauaar an mahalila. Besan sirien umpás-à mos ya nasuhátanà itoi-é besan mailar an suhat-u si batang-uar. Andóxollan sarit sangkanun immalit-tú isi-á an pahò-go-gós ta uemu dómò an iveyus di inap-appiánar isaon.

Besan immoiran duat uanguángar on datóng deat dí ya binum-ás si Ambuvússi si ihup si danúmar on sirien as-ásúp mos mâ-tian di danúmar on domon di aráwar on si Ambuvússi an amoi si it-tuan di baú-uar.

Besan ya immói si Ba-ú-u an timmáxtáx si amígonar Ahasit an impahò-go-gós ta maraúm ai ilá ya ipitonar putun di ambuvussíar ta uemu umulin miuà-uáx di danúmar an ininúmna.

Sirien dioira mos, da Aráu on si Ambuvússi, si gawan di uang-uángar an as-asúp da mos si it-tuan di ba-ú-uar ya uar inappi-án di ahasitar ot inípitnar putun di ambuvussíar. Uén! ni-uâ-uáx di danúmar si uanguángar. the plant, into which $I$, had climbed. When I looked in that direction, I saw the turtle, who was asking for bananas. Now, as I did not give or drop her some quickly enough, what must she do but plant thorns around the banana which I had climb. ed. So when I descended, I got hurt right here, the wounds being visible on my body. That is, therefore, the reason for which I have come here to you, imploring help so that I can take vengeance for what she has done to me.»

Now the two went to the river and, once there, the ambuvussi began to sup the water, so that, when it had nearly ebbed out, the monkey and the ambuvussi could go to the dwelling of the turtle.

Now the turtle went hurriedly to her friend the crab and begged her kindly to try and prick the belly of the ambuvussi, so that the water he had drunk would come pouring out again.

Already were the aforesaid two, the monkey and the ambuvussi, in the middle of the river, and already did they approach the dwelling of the turtle, when the crab did her work and pinched the belly of the ambuvussi. Sh-sh! came the water streaming back to the river. 


\section{5}

Besan uar aráwar on si Ambuvússi ya natóiran dua on uat Ba-ú-u ot ammá-ir gaiháyanar on misesalamat toi neír mos di aráwar an manguahuet.
So the monkey and the ambuvussi both perished, and as for the turtle, she rejoiced and gave thanks, for no longer was there the cruel oppressive monkey. 
|||||||||||||||||||||||||||| || 
